\section{Pacific Northwest}

National Laboratory

Operated by Battelle for the

U.S. Department of Energy

\title{
Assessment of Physical Properties of Transuranic Waste in Hanford Single- Shell Tanks
}

\author{
S.D. Rassat \\ L.A. Mahoney \\ B.E. Wells \\ D.P. Mendoza \\ D.D. Caldwell
}

March 2003

Prepared for the U.S. Department of Energy

under Contract DE-AC06-76RL01830

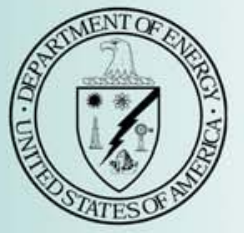




\title{
DISCLAIMER
}

This report was prepared as an account of work sponsored by an agency of the United States Government. Neither the United States Government nor any agency thereof, nor Battelle Memorial Institute nor any of their employees makes any warranty, express or implied, or assumes any legal liability or responsibility for the accuracy, completeness, or usefulness of any information, apparatus, product, or process disclosed or represents that its use would not infringe privately owned rights. Reference herein to any specific commercial product, process, or service by trade name, trademark, manufacturer, or otherwise does not necessarily constitute or imply its endorsement, recommendation, or favoring by the United States Government or any agency thereof, or Battelle Memorial Institute. The views and opinions of authors expressed herein do not necessarily state or reflect those of the United States Government or any agency thereof.

\section{PACIFIC NORTHWEST NATIONAL LABORATORY}

\author{
operated by
}

\section{BATTELLE}

for the

\section{UNITED STATES DEPARTMENT OF ENERGY}

\author{
under Contract DE-AC06-76RL01830
}

Printed in the United States of America

Available to DOE and DOE contractors from the Office of Scientific and Technical Information,

P.O. Box 62, Oak Ridge, TN 37831-0062;

ph: (865) 576-8401

fax: (865) 576-5728

email: reports@adonis.osti.gov

Available to the public from the National Technical Information Service, U.S. Department of Commerce, 5285 Port Royal Rd., Springfield, VA 22161

ph: (800) 553-6847

fax: (703) 605-6900

email: orders@ntis.fedworld.gov

online ordering: http://www.ntis.gov/ordering.htm

This document was printed on recycled paper. 
PNNL- 14221

\title{
Assessment of Physical Properties of Transuranic Waste in Hanford Single-Shell Tanks
}

\author{
SD Rassat \\ LA Mahoney \\ BE Wells \\ DP Mendoza \\ DD Caldwell
}

March 2003

\author{
Prepared for \\ the U.S. Department of Energy \\ under Contract DE-AC06-76RLO 1830 \\ Pacific Northwest National Laboratory \\ Richland, WA 99352
}




\section{Executive Summary}

CH2M HILL Hanford Group, Inc. (CH2M HILL) is identifying and developing supplemental process technologies to accelerate the tank waste cleanup mission at Hanford. One such technology targets the disposal of Hanford transuranic (TRU) process wastes stored in single-shell tanks (SSTs). Ten Hanford SSTs are candidates for designation as contact-handled TRU waste: the B-200 series tanks (B-201, B-202, B-203, and B-204), the T-200 series tanks (T-201, T-202, $\mathrm{T}-203$, and -T-204), plus $\mathrm{T}-110$ and $\mathrm{T}-111$. $^{\text {(a) }}$ The retrieval of these tanks is intended to be a "dry" process in which these wastes will be retrieved from the tanks as is or with a recycled liquid stream to help mobilize the waste in the tank and through transfer lines and vessels. Subsequently, the retrieved waste will be dewatered to remove excess liquid and transferred to waste packages in a form suitable for disposal at the Waste Isolation Pilot Plant (WIPP).

An understanding of waste physical properties is needed to support design and procurement of the SST TRU handling and packaging system and to produce suitable physical simulants to test such a process. Pacific Northwest National Laboratory (PNNL) has been tasked with developing these waste simulants. This report summarizes PNNL's assessment of available waste physical property information for the 10 candidate TRU SSTs. Data sources include the Hanford Tank Waste Information Network System (TWINS) database, technical reports, and visual observations from reviewing photographs and videotape recordings taken during the extrusion of various SST TRU waste core samples.

While the retrieval process is expected to alter certain waste physical properties such as shear strength, the effects of this process on waste properties cannot yet be quantified. Therefore, the scope of this report is to describe the properties of SST TRU wastes as they are known for unprocessed wastes or, in some cases, for diluted waste samples. The report focuses on the rheology, particle properties, settling characteristics, bulk density, and water content of the waste. Because some physical properties of the waste are related to the chemistry of the waste (e.g., particle hardness), a brief overview is provided of the process and chemistry resulting in the TRU waste. Other properties, including the potential for gas retention in the waste, are discussed briefly. Qualitative descriptions of how waste properties might be affected by retrieval and subsequent processing are also noted.

To provide a broad understanding of the waste rheology in all the TRU SSTs, photographs and videotapes of core extrusions were analyzed for seven of the ten tanks (B-203, B-204, the T-200 series, and T-110). Typically, waste ranged from very wet near the waste surface to a ductile, moderate-strength sludge below the surface, progressing to more brittle and stronger waste toward the bottom of the tank. Methodologies were developed to use extrusion length and

(a) Hanford waste tanks are designated with the prefix 241-. In this report, as in common usage, the prefix is omitted. 
slump measurements obtained from the videotapes to estimate the waste shear strength using previously reported extrusion data for ductile (bentonite clay/water) and brittle (kaolin clay/colloidal silica/water) simulants as reference. Applying these methods, the shear strength of the sludge in the seven tanks was estimated to range from $<30$ to $4000 \mathrm{~Pa}$. The bulk of the waste was categorized as ductile solid to moderately brittle with a shear strength range of 200 to $2000 \mathrm{~Pa}$. Observed waste rheology was similar across the set of TRU SSTs. The only notable difference was that the T-110 waste was somewhat more ductile up to higher shear strengths.

Limited amounts of rheology data have been previously reported for B-201, B-202, and T-111 waste samples, and these shear strength and viscosity data are discussed in this report. Measured shear strengths for six samples from B-201 and B-202 ranged from 200 to $1410 \mathrm{~Pa}$, consistent with the shear strengths estimated from core extrusions of other B- and T-200 series wastes. Similarly, the shear strength of undiluted T-111 samples was $500 \pm 230 \mathrm{~Pa}$. Viscosity results for B-201 and B-202 waste samples diluted 1:1 (volume basis) with water are reported in the form of yield power-law function parameters and shown graphically. At a $100 \mathrm{~s}^{-1}$ strain rate, the viscosity of the diluted waste ranged from 5 to $15 \mathrm{cP}$ for B-201 and from 2.1 to $4.5 \mathrm{cP}$ for B-202. Diluted T-111 samples also exhibited pseudoplastic behavior, but results were not correlated to yield power-law functions because the viscosity was near the system detection limit $(2 \mathrm{cP})$.

Particle size and solids settling data are of value for developing waste dewatering and handling processes. Particle size distribution results from earlier studies of B-201 and T-111 waste samples are summarized, and volume basis size distribution plots are shown for B-201. While the mean density particle size is consistently $<2 \mu \mathrm{m}$ for both tank wastes, the mean particle size in terms of volume fraction ranges from $\sim 7$ to $66 \mu \mathrm{m}$ for segments taken from two core samples of B-201 and from $\sim 8$ to $65 \mu \mathrm{m}$ for T-111 samples. There were no apparent trends in particle size distribution with vertical location in the tank.

Gravitational and centrifugal settling data for as-received (undiluted) and water-diluted (1:1 and 3:1 volume basis) samples of B-201, B-202, and T-111 wastes are presented. Essentially no settling occurred in the small undiluted samples at $1 \mathrm{G}$ (gravitational force on Earth), whereas centrifugation at more than $1000 \mathrm{G}$ produced 2 to $12 \mathrm{vol} \%$ free liquid in B-201 samples, 30 to $40 \mathrm{vol} \%$ free liquid in B-202 samples, and 28 to $34 \mathrm{vol} \%$ free liquid in T-111 samples. The rate of gravity settling in diluted samples decreased significantly after two days, but centrifugation clearly indicates that settling was not complete. For example, gravity settling for two days produced free liquid of 8 to $19 \mathrm{vol} \%$ in 1:1 (by volume) diluted B-201 samples, whereas centrifugal settling increased the free liquid to 42 to $58 \mathrm{vol} \%$.

The estimated shear strength of the wastes generally increased with depth in the tank, possibly because of waste self-compaction due to lithostatic loading. The water content (and bulk density) of the waste also appears to vary with location in the tank, with lower moisture content near the tank bottom. On the whole, the water content of waste sludge was found to 
range from 70 to $85 \mathrm{wt} \%$; the reported water content is somewhat higher in Tank T-111 (85 to $90 \mathrm{wt} \%)$ and lower in a few samples from T-201 ( $65 \mathrm{wt} \%)$. Most of the data for bulk solids samples, a matrix of waste solids and interstitial liquid, show bulk densities of 1.15 to $1.30 \mathrm{~g} / \mathrm{mL}$, and the density generally increases with decreasing water content. The shear strength estimates obtained from the extrusion methods were compared with the water content and bulk density of waste samples from the same core segments. The shear strength and, to a lesser extent, the density show some tendency to decrease with increasing water, but significant scatter exists in the data.

The physical properties of in situ and diluted SST TRU waste described in this report and summarized in the discussion above are tabulated in Table ES.1. In many cases, the expected range of properties is estimated from limited data. However, in those instances where data are available for many tanks and multiple locations within tanks, the data do not indicate major differences among individual tanks. Therefore, it appears reasonable to treat individual tank results as typical of Hanford SST TRU waste.

Table S.1. Expected Range of Physical Properties of In Situ and Diluted SST TRU Waste

\begin{tabular}{|c|c|c|}
\hline Property & Expected Range & Comments \\
\hline Shear strength & $\begin{array}{c}200 \text { to } 2,000 \mathrm{~Pa} \text { (majority of waste) } \\
0 \text { to } 4,000 \mathrm{~Pa} \text { (range, including liquid) }\end{array}$ & $\begin{array}{l}\text { Estimated from data obtained from core } \\
\text { extrusions (Sections } 3.1 \text { and } 3.2 \text { ) and } \\
\text { reported shear vane measurements } \\
\text { (Section 4.1). }\end{array}$ \\
\hline Viscosity & $\begin{array}{l}2 \text { to } 25 \mathrm{cP} \text { at } 10 \mathrm{~s}^{-1} \\
2 \text { to } 15 \mathrm{cP} \text { at } 100 \mathrm{~s}^{-1}\end{array}$ & $\begin{array}{l}\text { Results for } 1: 1 \text { dilution with water; higher } \\
\text { viscosities expected for waste diluted less } \\
\text { and at lower strain rates. Waste exhibited } \\
\text { pseudoplastic rheology. Section } 4.1 \text {. }\end{array}$ \\
\hline Waste settling & $\begin{array}{c}\sim 0 \mathrm{vol} \% \text { free liquid }(1 \mathrm{G}) \\
2 \text { to } 40 \mathrm{vol} \% \text { free liquid }(>1000 \mathrm{G}, 1 \mathrm{hr})\end{array}$ & $\begin{array}{l}\text { Undiluted waste, }>200 \text { Pa shear strength. } \\
\text { Weaker waste (liquid in the extreme) is } \\
\text { expected to produce more free liquid on } \\
\text { settling. Section } 4.2 \text {. }\end{array}$ \\
\hline Waste settling & $\begin{array}{c}5 \text { to } 25 \mathrm{vol} \% \text { free liquid }(1 \mathrm{G}, \sim 2 \text { days }) \\
40 \text { to } 60 \mathrm{vol} \% \text { free liquid }(>1000 \mathrm{G}, 1 \mathrm{hr})\end{array}$ & $\begin{array}{l}1: 1 \text { diluted waste, }>200 \mathrm{~Pa} \text { shear strength } \\
\text { prior to dilution. See comment above. } \\
\text { Section } 4.2 \text {. }\end{array}$ \\
\hline Waste settling & $\begin{array}{l}40 \text { to } 65 \text { vol\% free liquid }(1 \mathrm{G}, \sim 2 \text { days }) \\
70 \text { to } 85 \text { vol } \% \text { free liquid }(>1000 \mathrm{G}, 1 \mathrm{hr})\end{array}$ & $\begin{array}{l}3: 1 \text { diluted waste, }>200 \mathrm{~Pa} \text { shear strength } \\
\text { prior to dilution. See comment above. } \\
\text { Section } 4.2 \text {. }\end{array}$ \\
\hline $\begin{array}{l}\text { Particle size, } \\
\text { mean }\end{array}$ & $\begin{array}{l}7 \text { to } 70 \mu \mathrm{m} \text { (volume density) } \\
<2 \mu \mathrm{m} \text { (number density) }\end{array}$ & Section 4.3. \\
\hline Water content & $\begin{array}{c}70 \text { to } 85 \mathrm{wt} \% \text { (majority of waste) } \\
65 \text { to } 90 \mathrm{wt} \% \text { (range) }\end{array}$ & Section 5.1. \\
\hline Liquid Density & $\sim 1.05 \mathrm{~g} / \mathrm{mL}$ & Section 5.2 \\
\hline Bulk Density & $\begin{array}{c}1.15 \text { to } 1.3 \mathrm{~g} / \mathrm{mL} \text { (majority of waste) } \\
1.1 \text { to } 1.4 \mathrm{~g} / \mathrm{mL} \text { (range) }\end{array}$ & Section 5.2 \\
\hline
\end{tabular}




\section{Acknowledgments}

The authors would like to thank other individuals who contributed to this report. In particular, we thank Ray Akita of Fluor Hanford who graciously provided the photographs and videotapes of waste core extrusions, and student Craig Denney for his early review and cataloging of the videotape contents. Mike Johnson of CH2M HILL made us aware of some TRU waste data that we had not captured in our original search and also helped us clarify the details of the process history resulting in the TRU waste. Joel Tingey of PNNL provided particle size distribution figures from earlier work and helped clarify our understanding of some of the procedures used to analyze the waste. We thank Phil Gauglitz and Larry Bagaasen of PNNL for numerous technical discussions on various report topics. Additionally, they reviewed the report and provided insightful technical comments. We also thank Sheila Bennett for her valuable editorial support. 


\section{Contents}

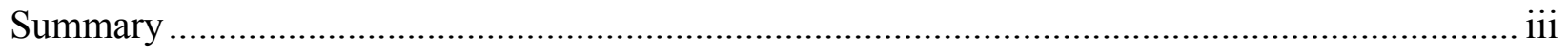

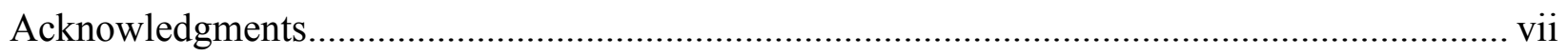

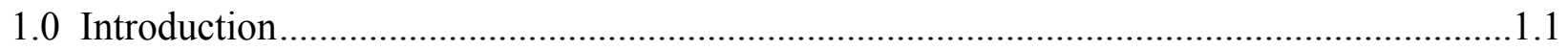

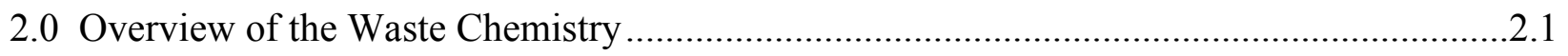

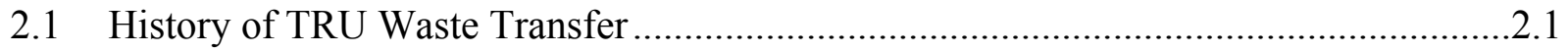

2.2 TRU Waste Composition ................................................................................2.2

3.0 Visual Observations and Shear Strength Estimates ........................................................

3.1 Visual Observations and Summary of Waste Shear Strength .........................................

3.2 Shear Strength Estimates from Extrusion Length and Slump.....................................

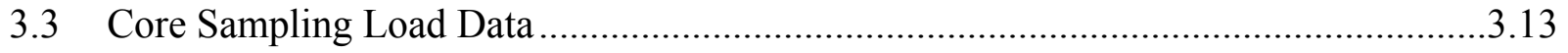

4.0 Waste Rheology, Solids-Settling, and Particle Characterization....................................4.1

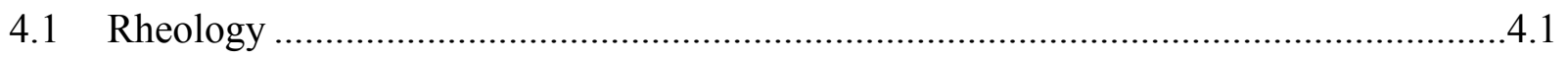

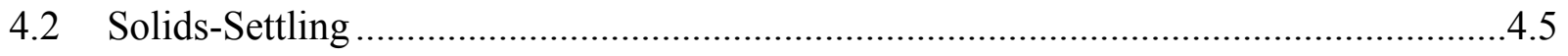

4.3 Particle Characterization ............................................................................ 4.8

5.0 Relationship of Water Content, Bulk Density, and Shear Strength .................................5.1

5.1 Water Content ..................................................................................................

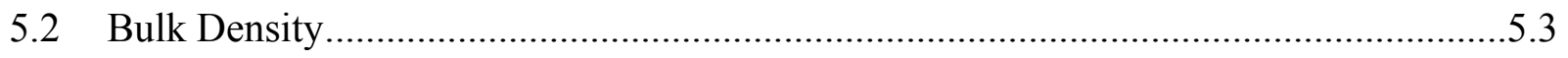

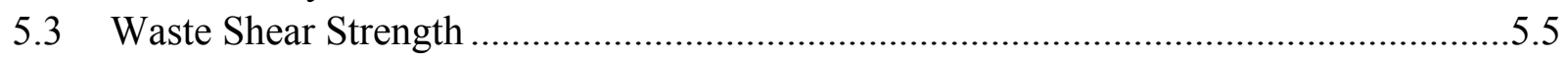

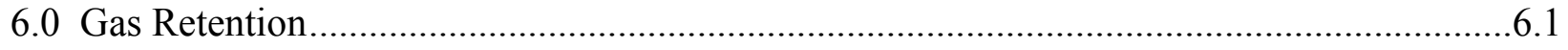

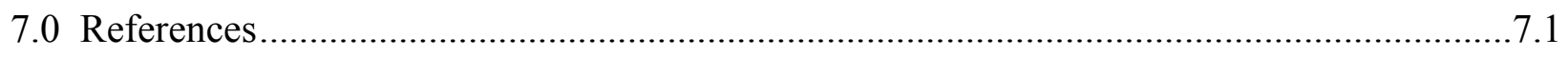

Appendix: Development of Extrusion Length and Slump Methodologies

to Estimate Yield Stress in Shear.................................................................. 1 


\section{Figures}

3.1 Photos of Core Extrusion Segments for Tank B-203, Core 122 ................................... 3.4

3.2 Photos of Core Extrusion Segments for B- and T-200 Series Tanks................................ 3.6

3.3 Shear Strength as a Function of Height in B-203, Core 115 .......................................... 3.9

3.4 Shear Strength as a Function of Height in B-204, Core 112 ....................................... 3.10

3.5 Shear Strength as a Function of Height in B-204, Core 114 ...................................... 3.10

3.6 Shear Strength as a Function of Height in T-110, Core 180......................................... 3.11

3.7 Shear Strength as a Function of Height in T-201, Core 192 ......................................... 3.11

3.8 Shear Strength as a Function of Height in T-202, Core 191 ........................................ 3.12

3.9 Shear Strength as a Function of Height in T-203, Core 190 ...................................... 3.12

3.10 Shear Strength as a Function of Height in T-204, Core 188 ........................................ 3.13

4.1 Viscosity as a Function of Strain Rate for 1:1 Diluted B-201 Samples............................ 4.4

4.2 Viscosity as a Function of Strain Rate for 1:1 Diluted B-202 Samples........................... 4.4

4.3 Particle Size Distribution in Core 27, Segment 1 of B-201 ............................................ 4.9

4.4 Particle Size Distribution in Core 27, Segment 2 of B-201 …....................................... 4.10

4.5 Particle Size Distribution in Core 27, Segment 3 of B-201 …....................................... 4.10

4.6 Particle Size Distribution in Core 27, Segment 4 of B-201 ........................................ 4.11

4.7 Particle Size Distribution in Core 27, Segment 5 of B-201 .......................................... 4.11

4.8 Particle Size Distribution in Core 27, Segment 6 of B-201 ........................................ 4.12

4.9 Particle Size Distribution in Core 27, Segment 7 of B-201 ......................................... 4.12

4.10 Particle Size Distribution in Core 27, Segment 8 of B-201 ........................................ 4.13

5.1 Waste Compaction, as Indicated by Variation in Water Content ................................... 5.2

5.2 Bulk Density Versus Water Content in the B-200 Series Tanks .................................... 5.3

5.3 Bulk Density Versus Water Content in the T-200 Series Tanks ...................................... 5.4

5.4 Bulk Density Versus Water Content in Tanks T-110 and T-111 ..................................... 5.4

5.5 Relation of Estimated Waste Shear Strength and Water Content................................... 5.5

5.6 Relation of Estimated Waste Shear Strength and Bulk Density .................................... 5.6 


\section{Tables}

S.1 Expected Range of Physical Properties of In Situ and Diluted SST TRU Waste................. v

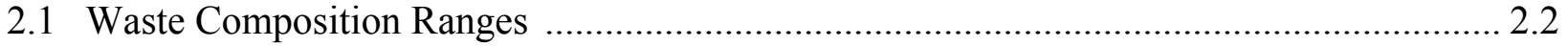

3.1 Shear Strength Estimates for B- and T-200 Series Tank Core Extrusion Segments .......... 3.3

4.1 Rheological Data for Waste Samples from Tank B-201, Core 26................................ 4.1

4.2 Rheological Data for Waste Samples from Tank B-202, Core 24 ................................. 4.2

4.3 Density and Settling Data for Waste Samples from Tank B-201, Core 26 ..................... 4.6

4.4 Density and Settling Data for Waste Samples from Tank B-202, Core 24 .................... 4.7

4.5 Density and Settling Data for Waste Samples from Tank T-111, Core 31 ..................... 4.7

4.6 Particle Size Distribution Data for Waste Samples from Tank B-201 ........................... 4.8

4.7 Particle Size Distribution Data for Waste Samples from Tank T-111 ............................. 4.9 


\subsection{Introduction}

CH2M HILL Hanford Group, Inc. (CH2M HILL) is in the process of identifying and developing supplemental process technologies to accelerate the tank waste cleanup mission. A range of technologies is being evaluated to allow disposal of Hanford waste types, including transuranic (TRU) process wastes. Gasper et al. (2002) identified 12 Hanford waste tanks that may meet the criteria for designation as TRU waste, including three double-shell tanks $\left(\mathrm{AW}-103, \mathrm{AW}-105\right.$, and SY-102) ${ }^{(\mathrm{a})}$ and nine single-shell tanks (SSTs): the B-200 series (B-201, B-202, B-203, and B-204), the T-200 series (T-201, T-202, T-203, and T-204), and Tank T-111. The SST T-110 has recently received attention as a candidate for designation as a TRU waste type. If not designated as TRU waste, it might be defined as low-level waste that could be handled and packaged with the same process used for other contact-handled TRU (CH-TRU) wastes from the SSTs.

Originally, a "dry" waste retrieval process was considered for these tanks - that is, no liquid was to be used to slurry, or soften, the waste for the process of retrieving and transferring the waste to a packaging system. In such a retrieval and transfer process, air (or other process gas) would be forced into the in-tank waste to decrease its effective density so that the "fluffed" waste could be vacuumed out of the tank, and the removed waste would accumulate in a hopper, with the bulk sludge (possibly still moist and having some entrained trapped gas) being transferred from the hopper into storage drums. The current retrieval plans call for a modified dry retrieval process in which a recycled liquid stream (minimal fresh water) flowing at $\sim 1.4$ to $5 \mathrm{gpm}$ is used to help mobilize the waste in the tank and through transfer lines and vessels. This retrieval approach requires that a significant portion of the liquid be removed from the mobilized waste sludge in a "dewatering" process such as gravity settling, centrifugation, or drying prior to transferring it to waste packages. Additionally, adsorbent may be added to the waste packages (e.g., drums) to prevent formation of a free liquid layer.

In support of CH2M HILL's effort to develop a TRU waste handling and packaging process, Pacific Northwest National Laboratory (PNNL) has been tasked with developing waste simulants. For the SST CH-TRU wastes, the suite of simulants is likely to include a nonradioactive chemical simulant of the waste liquid that will potentially be separated from the waste solids. This simulant would be used to evaluate packaging and sorbent material compatibility. Simulants that reproduce the important physical behavior of the waste, including mechanical, flow, and dewatering properties, are also needed to develop and evaluate the TRU waste handling and packaging process. To produce suitable physical simulants, PNNL is now evaluating TRU waste physical properties. This report summarizes PNNL's assessment of available physical property information for the 10 candidate TRU SSTs, including T-110.

(a) Hanford waste tanks are designated with the prefix 241-. In this report, as in common usage, the prefix is omitted. 
The information provided in this report will be supplemented in the near future with chemical and physical property data obtained from actual waste sample composites of Tanks B-203, T-203, T-204, and T-110. Experimental studies on these samples are ongoing at Hanford. It is expected that the tests will be completed and the results reported in fiscal year 2003.

The effects of the proposed CH-TRU retrieval and transfer systems on waste properties have not been quantified. Accordingly, the scope of this report is to describe the properties of TRU wastes as they are known for unprocessed wastes or, in some cases, for diluted waste samples. Qualitative descriptions of how waste properties might be affected by retrieval and transport are noted where appropriate.

This report focuses on the waste rheology, settling characteristics, particle properties, bulk density, and water content. Because some physical properties of the waste are related to the waste chemistry (e.g., particle hardness), a brief overview of the process and chemistry resulting in the TRU waste is provided in Section 2. Section 3 shows representative photographs of extruded SST TRU wastes, describes visual observations, and summarizes estimates of the waste shear strength derived from videotaped core extrusions. Other waste strength and viscosity measurements, gravity and centrifugal settling data, and particle properties, including size distribution, are discussed in Section 4. Section 5 summarizes the variation in water content and bulk density of the waste in the tanks and addresses the relationship of these properties and waste shear strength. Other properties, including the potential for gas retention in the waste, are discussed briefly in Section 6. Cited references are listed in Section 7, and the extrusion length and slump methodologies are detailed in the appendix. Data sources for this report include the Hanford Tank Waste Information Network System (TWINS) database, technical reports, and visual observations from the review of photographs and videotape recordings taken during the extrusion of various tank waste core samples. 


\subsection{Overview of the Waste Chemistry}

Although the physical simulants being developed are not expected to have the same chemical composition as the actual waste, this section of the report provides some background on the waste sources and composition for general information. Knowledge of the history and composition of the waste supplements the specific physical property data in the rest of this report.

\subsection{History of TRU Waste Transfer}

The wastes contained in the B-200 series, the T-200 series, T-110, and T-111 tanks originated primarily in the 224 Building waste stream, which was derived from the lanthanum fluoride decontamination step in the bismuth phosphate process (e.g., Gasper et al. 2002).

The tanks in the B-200 and T-200 series are considered to contain only 224 Building wastes (224 waste), based on waste transfer records. Tank B-201 received waste from the 224-B Concentration building from October 2, 1946 through October 1948, after which the tank was considered filled with solids and the 224-B Concentration building waste was diverted to Tank B-204, which was connected in a cascade with Tanks B-203 and B-202. Liquid was gravity discharged from the last tank in the cascade, B-202, to the 241-B-1 and 241-B-2 cribs. Solids contained in the 224-B Building waste were allowed to settle in Tanks B-204 through B-202. The cascade of Tanks B-204, B-203, and B-202 continued to receive 224-B Concentration building wastes until September 1952. The history of the filling of T-200 series tanks parallels that of the B-200 series tanks. Tank T-201 received waste from the 224-T Concentration building from November 4, 1946 through May 24, 1949, after which the tank was considered filled with solids and the 224-T Concentration building waste was routed to Tank T-204. Tank T-204 was connected in a cascade with Tanks T-203 and T-202. Liquid was gravity discharged from the last tank in the cascade, T-202, to the 241-T-1 and 241-T-2 cribs. Solids contained in the 224-T Building waste were allowed to settle in T-204 through T-202. ${ }^{\text {(a) }}$

Some 224 waste is also found in Tanks T-110 and T-111, along with "2C" waste, which is second-cycle decontamination waste from the bismuth phosphate process. Tanks T-110, T-111, and T-112 initially operated in a cascade, with waste received into the lead tank and allowed to overflow to the next tank in series. Tank T-110 received only 2C waste from January 1945 through May 1952. From May 1952 through December 1954, Tank T-110 received a mixture of $2 \mathrm{C}$ and 224 wastes. Waste was received into Tank T-110 and allowed to overflow into Tank T-111 until December 1954, when the primary waste stream was directed into T-111 and T-110 stopped receiving waste. Tank T-111 received only $2 \mathrm{C}$ waste that cascaded from Tank T-110 from January 1945 through May 1952. From May 1952 through October 1956, Tank T-111

(a) Johnson, ME. January 2003. Origin of Wastes in the B-200 and T-200 Series Single-Shell Tanks. RPP-13300, draft, CH2M HILL Hanford Group, Richland, WA. 
received a mixture of 2C and 224 wastes. From February 1960 through June 1967, dilute liquid equipment decontamination waste from T-plant was fed to Tank T-111. ${ }^{\text {(a) }}$

\subsection{TRU Waste Composition}

In the SST CH-TRU waste being considered for dry retrieval, bismuth (Bi) and sodium (Na) are the major metallic analytes, and nitrate $\left(\mathrm{NO}_{3}\right)$ is the major anion (Lumetta and Rapko 1994). Table 2.1 gives the bulk concentrations (including both solid and liquid phases) of the major constituents for nine of the 10 tanks; there is no bulk concentration data available for T-110. Water, which makes up most of the waste mass, is not included as a constituent in the table. The concentrations given in the table are based on core samples taken between 1991 and 1997. (Core sampling, in effect, forces a 1.125-in. inside-diameter pipe down through the waste and collects samples, each one a 19-in.-long segment, over the entire depth of the waste.)

Table 2.1. Waste Composition Ranges (major analytes)

\begin{tabular}{|c|c|c|c|c|c|}
\hline Tank & Bi (wt\%) & Na (wt\%) & $\mathrm{NO}_{3}(\mathrm{wt} \%)$ & \multicolumn{2}{|c|}{ "Others (wt\%) } \\
\hline B-201 & $8.7-12$ & $2.9-6.6$ & $4.8-5.5$ & $\begin{array}{l}\mathrm{Si}, 0.6-6.1 \\
\mathrm{Mn}, 1.5-3.2 \\
\mathrm{Fe}, 0.6-2.3 \\
\mathrm{Ca}, 0.5-2.3 \\
\mathrm{La}, 0.9-1.7\end{array}$ & 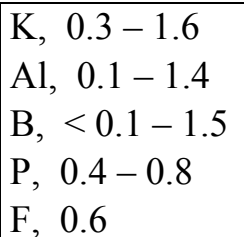 \\
\hline B-202 & $1.4-5.0$ & $3.4-6.5$ & $5.1-7.1$ & $\begin{array}{l}\mathrm{Fe}, 0.3-6.6 \\
\mathrm{La}, 0.7-2.6 \\
\mathrm{Mn}, 0.5-2.6 \\
\mathrm{Ca},<0.1-2.6 \\
\mathrm{~K}, 0.6-1.6\end{array}$ & $\begin{array}{l}\mathrm{A} 1,<0.1-1.4 \\
\mathrm{P}, 0.2-1.2 \\
\mathrm{~F}, 0.6 \\
\mathrm{Si}, 0.1-0.6 \\
\mathrm{~B},<0.1\end{array}$ \\
\hline B-203 & $1.4-5.6$ & $2.6-3.2$ & $3.0-5.6$ & $\begin{array}{l}\mathrm{Mn}, 0.5-2.4 \\
\mathrm{La}, 0.8-1.5 \\
\mathrm{Fe}, 0.2-0.8 \\
\mathrm{~F}, 0.6-0.7 \\
\mathrm{~K}, 0.4-0.5\end{array}$ & $\begin{array}{l}\mathrm{P}, 0.2 \\
\mathrm{Si},<0.1-0.1 \\
\mathrm{Ca},<0.1 \\
\mathrm{~A} 1,<0.1 \\
\mathrm{~B},<0.1\end{array}$ \\
\hline B-204 & $3.6-6.3$ & $2.3-2.9$ & $3.6-5.6$ & $\begin{array}{l}\text { Mn, } 0.9-1.8 \\
\mathrm{La}, 0.8-1.4 \\
\mathrm{Fe}, 0.2-1.1 \\
\mathrm{~F}, 0.5-0.7 \\
\mathrm{~K}, 0.5-0.7\end{array}$ & $\begin{array}{l}\mathrm{P}, 0.2-0.3 \\
\mathrm{Si},<0.1-0.2 \\
\mathrm{Ca},<0.1 \\
\mathrm{Al},<0.1 \\
\mathrm{~B},<0.1\end{array}$ \\
\hline
\end{tabular}

(a) Johnson, ME. January 2003. Origin and Classification of Wastes in Single-Shell Tanks 241-T-110 and 241-T111. RPP-13873, draft, CH2M HILL Hanford Group, Richland, WA. 
Table 2.1 (contd)

\begin{tabular}{|c|c|c|c|c|c|}
\hline Tank & Bi (wt\%) & $\mathrm{Na}(\mathrm{wt} \%)$ & $\mathrm{NO}_{3}(\mathrm{wt} \%)$ & \multicolumn{2}{|c|}{ Others (wt\%) } \\
\hline T-201 & $2.0-12$ & $2.3-3.2$ & $4.1-4.8$ & 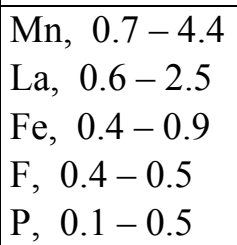 & $\begin{array}{ll}\mathrm{K}, & 0.1-0.5 \\
\mathrm{Si}, & 0.1-0.2 \\
\mathrm{Ca}, & 0.1 \\
\mathrm{Al}, & 0.1 \\
\mathrm{~B}, & <0.1\end{array}$ \\
\hline $\mathrm{T}-202^{(\mathrm{a})}$ & $2.8-4.4$ & $3.2-3.8$ & $5.7-6.6$ & $\begin{array}{l}\text { Fe, } 0.2-2.4 \\
\mathrm{Mn}, \quad 0.9-1.5 \\
\mathrm{La}, 0.9-1.3 \\
\mathrm{~K}, 0.6-0.8 \\
\mathrm{~F}, 0.6-0.7\end{array}$ & $\begin{array}{l}\mathrm{P}, 0.2-0.3 \\
\mathrm{Si}, 0.1-0.2 \\
\mathrm{Ca},<0.1 \\
\mathrm{~B},<0.1 \\
\mathrm{Al},<0.1\end{array}$ \\
\hline T-203 & $2.6-6.2$ & $3.2-4.5$ & $4.3-7.4$ & $\begin{array}{l}\text { Fe, } 0.2-2.2 \\
\mathrm{Mn}, 0.5-1.6 \\
\mathrm{La}, 0.7-1.4 \\
\mathrm{~K}, 0.7 \\
\mathrm{~F}, 0.5-0.7\end{array}$ & $\begin{array}{l}\mathrm{P}, \quad 0.2-<0.4 \\
\mathrm{Si},<0.1-0.2 \\
\mathrm{Al},<0.1-0.2 \\
\mathrm{Ca},<0.1 \\
\mathrm{~B},<0.1\end{array}$ \\
\hline $\mathrm{T}-204^{(\mathrm{a}, \mathrm{c})}$ & 5.2 & 3.2 & 5.5 & \begin{tabular}{|ll}
$\mathrm{Mn}$, & 1.4 \\
$\mathrm{La}$, & 1.2 \\
$\mathrm{~K}$, & 0.6 \\
$\mathrm{~F}$, & 0.6 \\
$\mathrm{Fe}$, & 0.4
\end{tabular} & 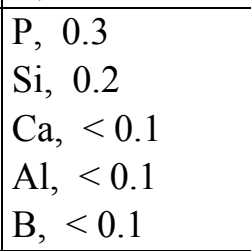 \\
\hline $\mathrm{T}-110$ & \multicolumn{5}{|c|}{ Only the liquid from this tank has been analyzed; there are no data for the bulk waste. } \\
\hline T-111 & $0.1-3.5$ & $2.2-4.1$ & $3.7-5.8$ & $\begin{array}{l}\mathrm{Mn}, 0.3-2.4 \\
\mathrm{Fe}, 1.2-2.0 \\
\mathrm{P}, 0.4-1.7 \\
\mathrm{Si}, 0.5-0.6 \\
\mathrm{La}, 0.3-0.5\end{array}$ & $\begin{array}{l}\mathrm{Ca}, 0.2-0.5 \\
\mathrm{~F}, 0.1-0.5 \\
\mathrm{~K}, 0.1-0.2 \\
\mathrm{~A} 1,0.1 \\
\mathrm{~B},<0.1\end{array}$ \\
\hline
\end{tabular}

(a) In this tank, acid dissolution was used to prepare all samples for analysis. This form of preparation could be seen to cause considerable underestimation of many constituents in this type of waste in other tanks where other preparation procedures were used and a comparison was possible. Thus, analyte concentrations that are low in this tank, compared with other tanks not noted in this way, may be artifacts.

(b) One half-segment of a core sample, 120:10-LH, contained 10 times as much $\mathrm{NO}_{3}, \mathrm{~F}$, and other anions as other segments and is ignored in this table as erroneous.

(c) In this tank analyses were made only on a composite of the entire core (a mixture of all the segments), not on individual segments. The average composition is available, but not a range. 


\subsection{Visual Observations and Shear Strength Estimates}

The shear strength for all but three of the 10 TRU SSTs was estimated from videotape recordings of core sample extrusions. In this section, representative photos of extruded waste and estimates of strength derived from measurements of waste extrusion length and slump are provided. A potential alternative data source for estimating waste strength, load data taken during core sampling of the waste, is also discussed briefly in this section.

The strength estimates described below are for minimally disturbed material representative of the in-tank (in situ) condition. The process of retrieving waste from the tanks, with or without the aid of a liquid diluent, will undoubtedly disturb and likely weaken the waste that is transported to and staged in a vessel (e.g., hopper) for subsequent dewatering and packaging. Onishi et al. (2003a), evaluating pump mobilization of Hanford double-shell tank waste, concluded that prior waste disturbance would reduce the waste yield strength and that the recovery of strength is time-dependent. The effects on waste properties of the disturbance resulting from TRU SST waste retrieval are also likely time-dependent and difficult to quantify.

Although we do not know the strength and other rheological properties of the retrieved and processed TRU waste, it is reasonable to use physical property information from relatively undisturbed waste to help bound the range of expected behavior. It is also possible that the disturbed waste will substantially regain its original strength depending on how it is handled. For example, a centrifugal dewatering process could result in compacted waste similar in strength to that present in the waste tanks.

\subsection{Visual Observations and Summary of Waste Shear Strength}

Videotapes or photographs of core extrusions are available for the SST TRU wastes except for Tanks B-201, B-202, and T-111, which predate the use of photography during waste extrusions. ${ }^{(a)}$ The similarities in process history surrounding the filling of these tanks suggests they have properties similar to their sister tanks (e.g., the B-200 and T-200 series tanks for B-201 and B-202, and T-110 for T-111). Visually, significant similarity exists among all the B-200 and $\mathrm{T}-200$ series videos and photographs. This is not to say that they are homogeneous; rather, they fit substantially within a range of characteristics that may be found in any individual tank. The visually similar properties among the B-200 and T-200 series tank photos include color (dark brown to black), apparent moisture content (high sheen to dull), extrusion shape and fracturing (ranging from ductile to nearly brittle), and apparent strength. The T-110 waste is mustard yellow and is generally more ductile than the other observed waste samples. However, the range of apparent strength is bracketed by that estimated for the B-200 and T-200 series samples.

(a) Personal communication on December 2, 2002 from Ray Akita, Fluor Hanford, who also provided copies of the videotapes and photos. 
Figure 3.1 shows photos representative of extruded core segments (nominally $19 \mathrm{in}$. length and 1.125 in. diameter) for core $122^{(a)}$ from Tank B-203. Starting from the top of the figure, which corresponds to higher in the waste tank, extrusion segments \#3 through \#14 are shown. These photos were taken in Hanford hot cells in late December 1995 and early January 1996. Segment \#3 has a pool of dark liquid ${ }^{(b)}$ extruded ahead of weak, wet sludge. (The waste in segments $\# 1$ and $\# 2$, above \#3, consisted almost entirely of liquid that is hard to see in the extrusion footage.) Segments \#6 and \#7 are relatively ductile, but segment \#6 appears somewhat stronger and shows a series of fractures. The observations for segments \#6 and \#7 suggest that waste lower (deeper) in the tank (\#7) can be weaker than that layered above it. In our assessment of the visual evidence, this is not routine but also not uncommon. The lower B-203 waste segments (>\#8) in Figure 3.1 appear even stronger, drier, and more brittle than those layered above.

Note also that the waste characteristics can vary within segments. For example, the lower portion of B-203 segment \#8, shown on the left side of Figure 3.1, is fractured and somewhat brittle, whereas the upper portion of the segment (right side of the photo near the piston) is ductile and weaker, like the bottom of segment $\# 7$ above it. This is likely due to vertical heterogeneity within the tank waste, but it could result in part from changes in the waste samples after core sampling and prior to extrusion. Core extrusions such as that depicted in Figure 3.1 provide a vertical picture of waste variation within a tank. Waste properties can also vary axially within tank waste. ${ }^{(\mathrm{c})}$

Figure 3.2 shows captured video images from in-process extrusions for segments from the B-200 and T-200 series tanks. The Figure 3.2 photos are ordered vertically from weakest (upper) to strongest (lower) and bound the range of behavior observed in Tank B-203 segments in Figure 3.1. For example, the upper photo in Figure 3.2 for Tank T-204 core 188 segment \#3 shows weak, wet sludge as it is extruded, exhibiting visual characteristics similar to those observed in B-203 segment \#3. The lower photo in Figure 3.2 for Tank T-201 core 192 segment \#7 depicts relatively brittle and long subsegments characteristic of stronger waste fractions in the TRU SSTs.

The middle photos in Figure 3.2 were taken from the extrusion of Tank B-204 core 114 and are representative of the bulk of waste observed in the TRU SST videotapes and photos. Segment \#4 (upper-middle photo) is continuous and relatively ductile, having a characteristic sigmoid extrusion shape. Segment \#10 (lower-middle photo) is moderate strength, and it fractures, creating short to medium-length subsegments.

(a) The core number is sequential for cores taken from all Hanford waste tanks; it is not the number of cores taken from an individual tank.

(b) The Hanford TWINS database on December 12, 2002 indicated that four of the 10 SST TRU tanks (B-203, B-204, T-201, and T-110) have small amounts of residual supernatant liquid at the surface.

(c) For example, PA Meyer and WL Kuhn assess the potential redistribution of solids in a Hanford saltcake waste tank in letter report TWS02.074, entitled Modeling Solids Redistribution in Tank S-112, dated September 2002. 
With other properties such as waste density and particle structure equal, an increasing length of extruded segments at failure (e.g., fracture for more brittle materials) is an indicator of increasing waste strength (Section 3.2 and the appendix). Many of the waste segments observed in the TRU SSTs had fractured subsegments ranging in length to the extremes depicted in the lower two photos of Figure 3.2.

Using the videotapes, we systematically assessed the shear strengths of the TRU sludge segments shown in Figure 3.2 from the measured extrusion length and slump discussed in Section 3.2. The method is an extension of the visually based core-extrusion shear strength estimation technique described by Gauglitz and Aikin (1997). They videotaped extrusions of bentonite clay/water and kaolin clay/colloidal silica $\left(\right.$ Ludox ${ }^{\circledR}$ )/water simulants of known and varying shear strengths and used the photographic results as a guide to estimating the shear strength of wastes exhibiting similar characteristics. Comparing their results with available tank waste strength data, they concluded that estimates of shear strength from horizontal extrusions were likely accurate within a factor of 2 .

In Section 3.2 and the appendix to this report, we describe the horizontal extrusion length methodology that was applied here. The accuracy of the technique is not known, but a basis is given for placing bounds on the shear strength estimates that are approximately $\pm 25 \%$ of the central value. Table 3.1 summarizes the estimated ranges of shear strength resulting from the application of the extrusion length and slump techniques to the extrusion segments shown in Figure 3.2 and other comparable extruded waste segments. In the table we attempt to categorize visual observations of the SST TRU wastes and their typical range of estimated shear strengths. However, the visual descriptors do not correspond universally to the strength range indicated in Table 3.1. For example, ductile materials were observed in some cases (e.g., Tank T-110) with strengths greater than 200-700 Pa.

Table 3.1. Shear Strength Estimates for B- and T-200 Series Tank Core Extrusion Segments Shown in Figure 3.2

\begin{tabular}{||l|c|c||}
\hline \multicolumn{1}{|c|}{$\begin{array}{c}\text { Typical Visual } \\
\text { Descriptors }\end{array}$} & $\begin{array}{c}\text { Figure 3.2 Waste } \\
\text { Examples } \\
\text { Tank-Core:Segment \# }\end{array}$ & $\begin{array}{c}\text { Estimated Shear } \\
\text { Strength Range } \\
\text { (Pa) }\end{array}$ \\
\hline $\begin{array}{l}\text { Weak; wet; slumping } \\
\begin{array}{l}\text { Moderate strength; ductile; } \\
\text { continuous sigmoidal } \\
\text { extrusion }\end{array}\end{array}$ & B-204-188:3 & $30-114: 4$ \\
\hline $\begin{array}{l}\text { Moderate strength; more } \\
\text { brittle; less ductile; fractured } \\
\text { subsegments of short to } \\
\text { medium length }\end{array}$ & B-204-114:10 & $700-700$ \\
\hline $\begin{array}{l}\text { Strong; brittle; longer } \\
\text { fractured subsegments }\end{array}$ & T-201-192:7 & $2000-4000$ \\
\hline
\end{tabular}


Segment \#3 (toward top of waste)

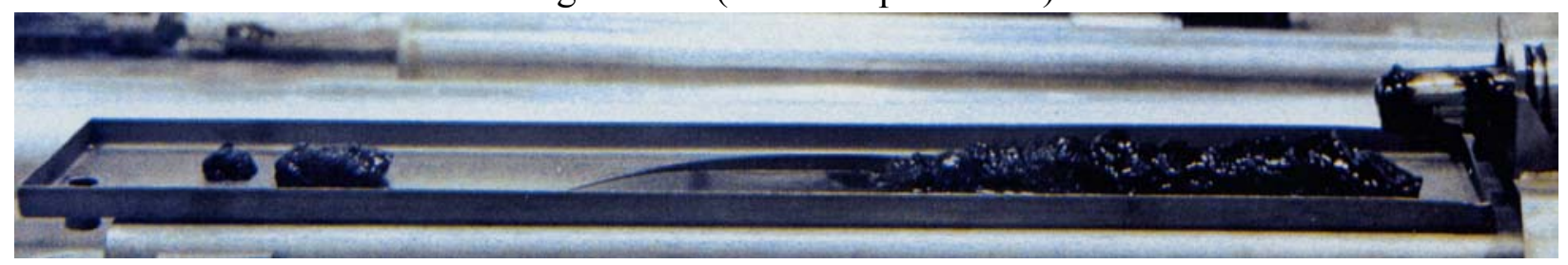

Segment \#4

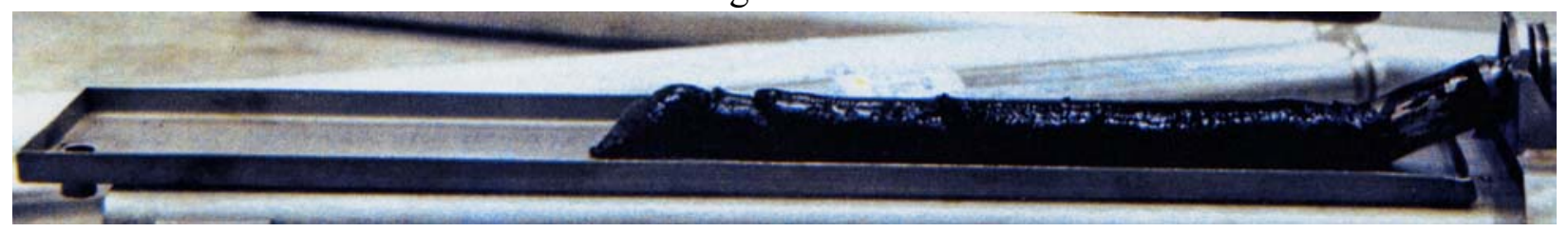

Segment \#5

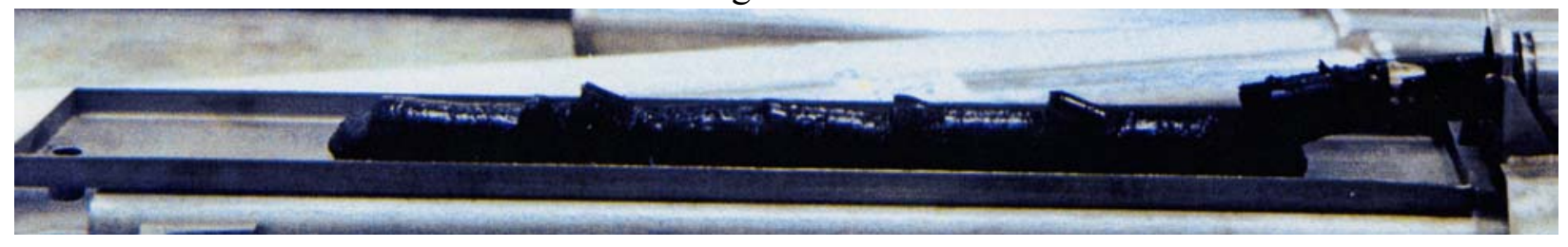

Segment \#6

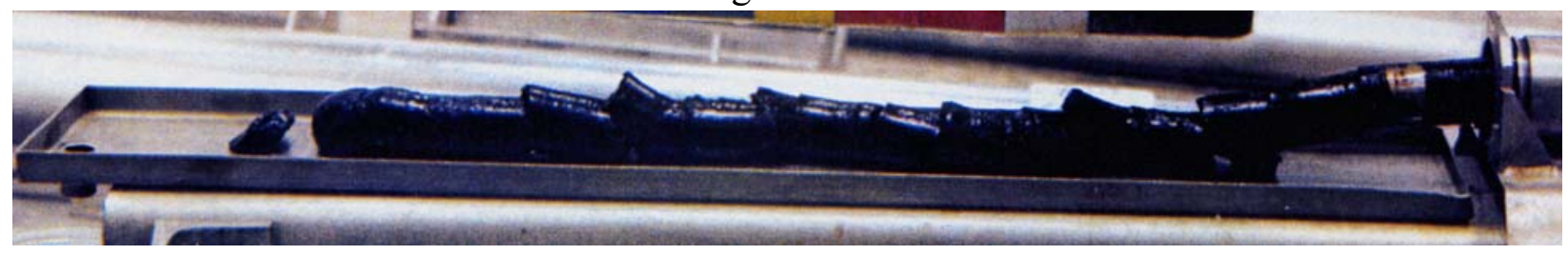

Segment \#7

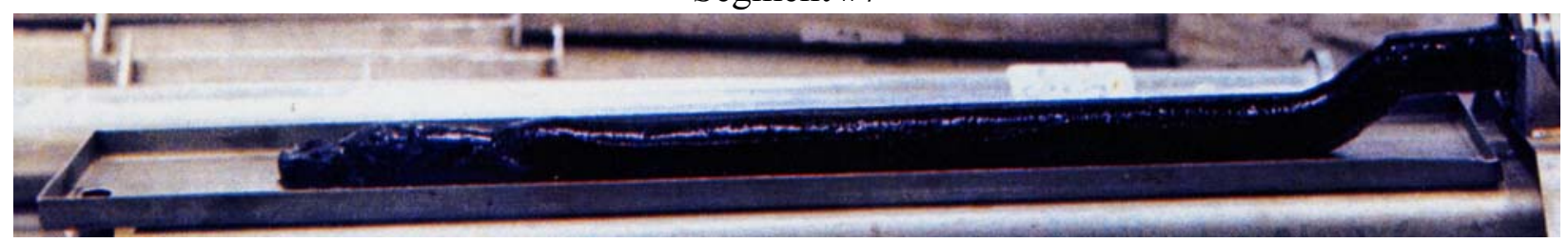

Segment \#8

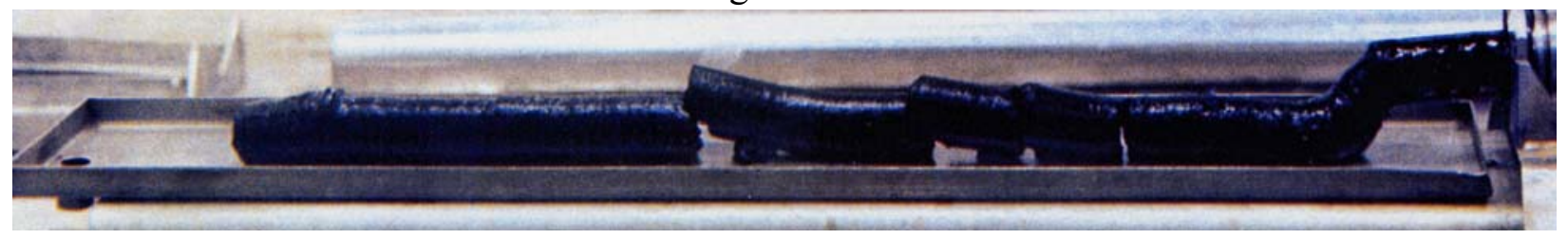

Figure 3.1. Photos of Core Extrusion Segments for Tank B-203, Core 122 from near the top of the waste (segment \#3) to the bottom of the tank (segment \#14) 
Segment \#9

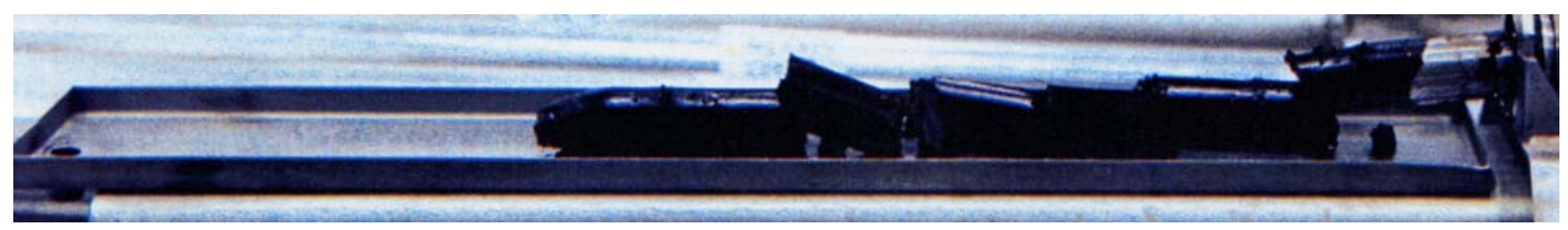

Segment \#10

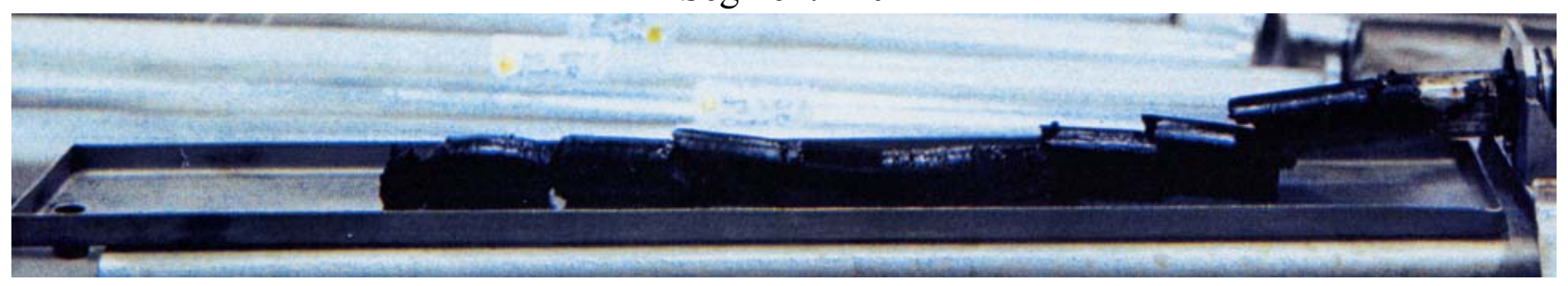

Segment \#11

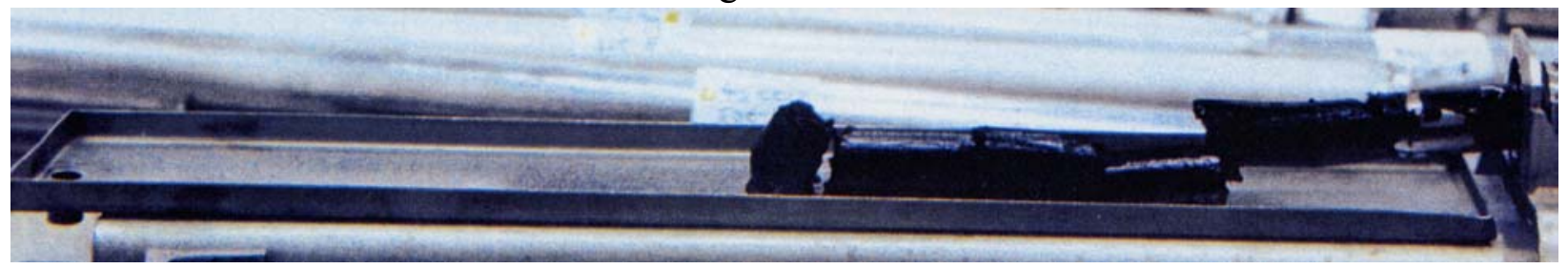

Segment \#12

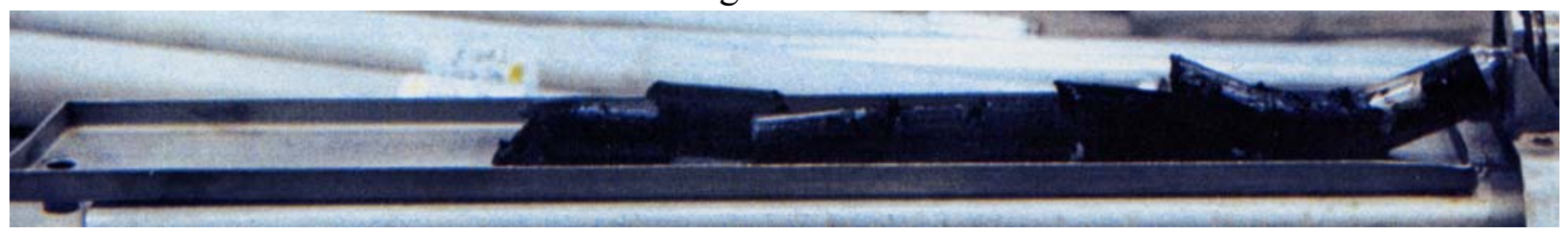

Segment \#13

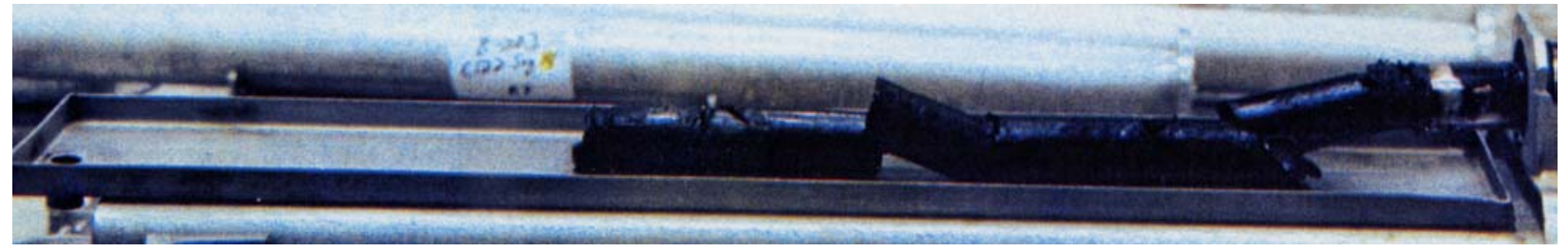

Segment \#14 (lower in tank)

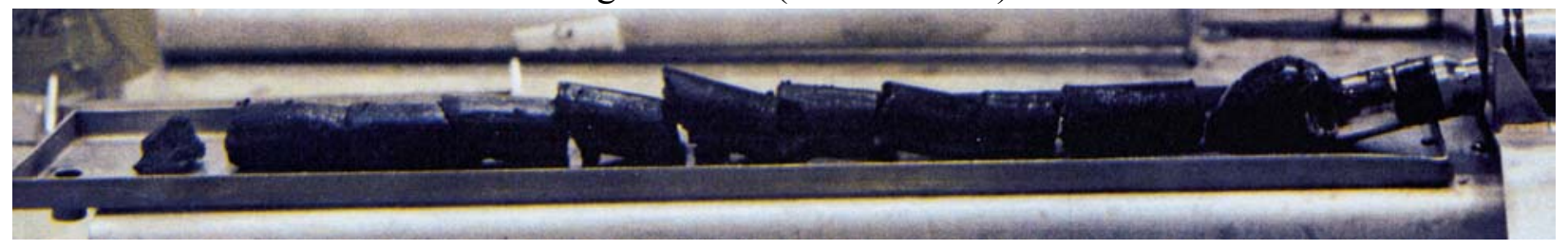

Figure 3.1 (contd) 


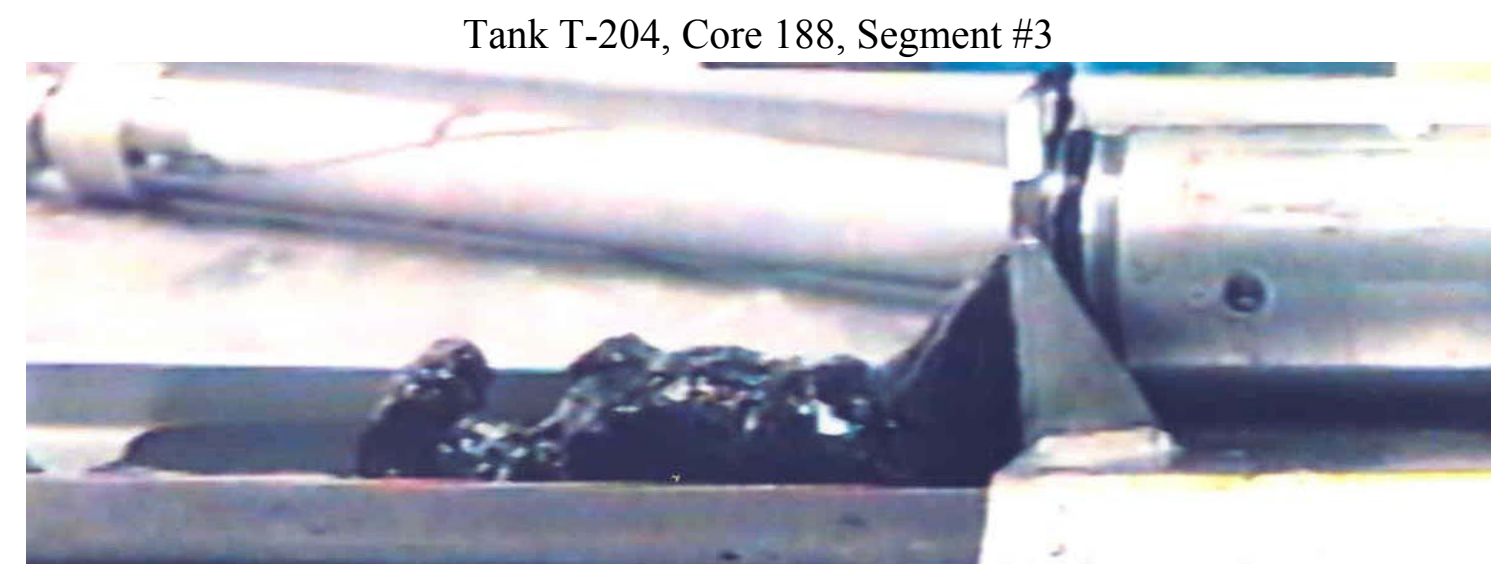

B-204, Core 114, Segment \#4

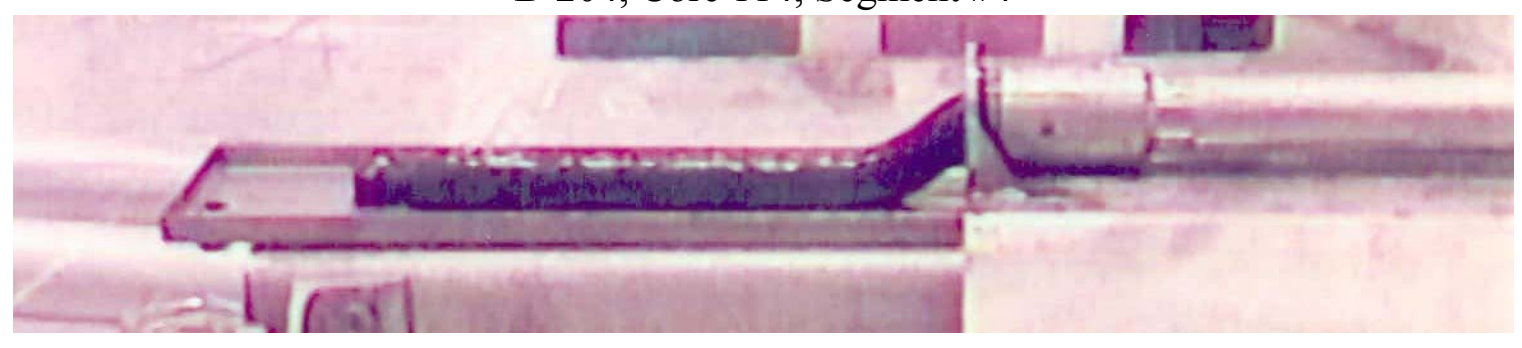

B-204, Core 114, Segment \#10

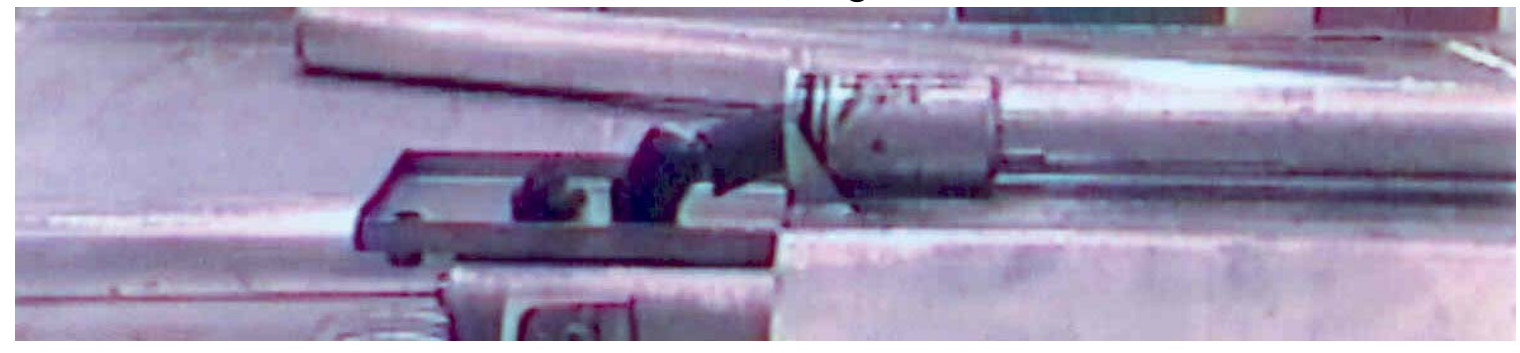

T-201, Core 192, Segment \#7

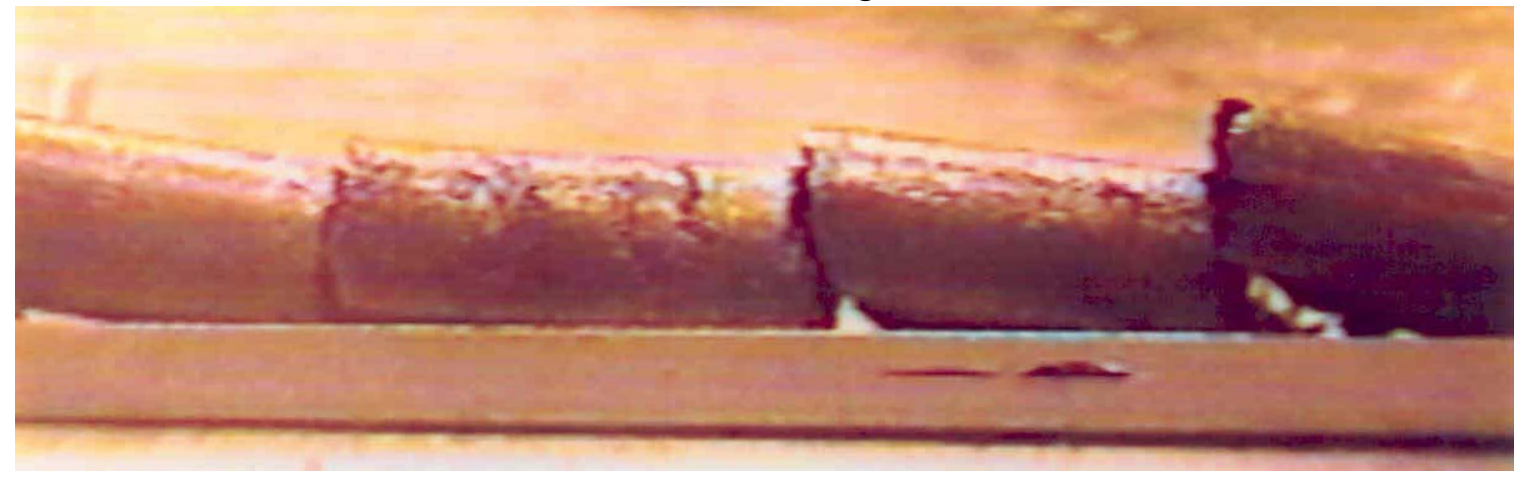

Figure 3.2. Photos of Core Extrusion Segments for B- and T-200 Series Tanks from Weakest (upper photo) to Strongest (lower photo). 
Of the $>50$ waste segments observed for 10 core extrusions from the seven TRU SSTs with photos available, the majority of waste fits in the strength range categorized by Tank B-204 core 114 segments \#4 and 10 in Figure 3.2 (200-2000 Pa). For example, the bulk of the waste in Tank B-203 core 112 below segment \#4 (Figure 3.1) appears to fit this categorization. ${ }^{\text {(a) }}$ However, relatively weak wastes (30-100 Pa), like the sludge portion of segment \#3 (B-203, Figure 3.1 and T-204, Figure 3.2), and relatively strong wastes (2000-4000 Pa), like segment \#7 (T-201, Figure 3.2), also represent an appreciable fraction of the waste in the tanks. A few segments from all the SST photos reviewed indicate that some waste, typically nearer the bottom of the tank, may be even stronger (4000-6000 Pa estimated) than that depicted by the lower photo of Figure 3.2. The estimated waste strength as a function of location in the SST TRU waste tanks is examined in greater detail in Section 3.2.

Sludge strength variations in these tanks may be related to differences in moisture content, possibly resulting from settling and compaction. Water fractions and bulk density as a function of vertical location within the tanks are presented in Sections 5.1 and 5.2, and the relationship of estimated waste strength to these properties is explored further in Section 5.3.

\subsection{Shear Strength Estimates from Extrusion Length and Slump}

As presented in Section 3.1, a methodology developed by Gauglitz and Aikin (1997) allows one to estimate the rheological properties of waste sediment (solid, liquid, and gas matrix) based on a visual comparison of horizontal extrusion behavior for simulants with known yield stress in shear (or "shear strength," as it is commonly called in Hanford literature) to that of Hanford waste. Here, a related core extrusion shear strength estimation technique based strictly on extrusion length was developed from the simulant extrusion results presented in Gauglitz and Aikin. This extrusion length methodology, as well as the "slump" method, are developed and evaluated in the appendix and summarized below. The shear strength results from the application of these methodologies to the TRU SSTs are also presented.

Gauglitz and Aikin (1997) horizontally extruded bentonite/water and kaolin/Ludox/water simulants of known shear strength and reported the length at which the extrusion exhibited "failure." With these data we have the ability to correlate the shear strength of the material directly with the functional form of maximum tensile stress in a round cantilever beam:

$$
\tau_{\mathrm{y}}=\mathrm{K} \frac{\rho g \mathrm{~L}^{2}}{\mathrm{~d}}
$$

\footnotetext{
(a) The categorization of the B-203 core 112 waste is based on the photographs in Figure 3.1 and not on an assessment of initial extrusion lengths from videotape as was completed for the waste segments shown in Figure 3.2. A videotape of the B-203 core 112 extrusion was not available; the strength estimates derived from other B-203 core extrusion videos are presented in Section 3.2.
} 
where $\mathrm{L}$ and $\mathrm{d}$ are the beam failure length and diameter, respectively, $\rho$ is the material density, and $\mathrm{g}$ is the acceleration of gravity. The proportionality coefficient $\mathrm{K}$ of Eq. (3.1) provides a means to compute the shear strength of a material given its density and the plastic failure length of a horizontal extrusion. Plastic failure occurs in the relatively ductile bentonite simulant as necking, while the brittle kaolin/Ludox simulant fractures.

As discussed in the appendix, the proportionality coefficient is likely a function of the material microstructure. The shear strength of a material with a microstructure similar to that of the bentonite simulant is expected to be 0.89 times $\rho g L^{2} / \mathrm{d}$. For materials with a microstructure similar to that of the kaolin/Ludox simulant, the shear strength is estimated to be 1.45 times $\rho g L^{2} / \mathrm{d}$. As reported in Gauglitz and Aikin, the two simulants were chosen to reflect the wide variety of mechanical behaviors typical of wastes from the Hanford tanks. If we assume that the simulants "bound" the mechanical behavior of Hanford waste, we can expect that the shear strength of the waste will be between 0.89 and 1.45 times $\rho \mathrm{gL}^{2} / \mathrm{d}$. These proportionality coefficients are subsequently referred to as the "extrusion length bounds." By back-applying these results, indiscriminate of material type, to the simulant extrusion experiments, we determined that the best fit to the data is achieved with a proportionality coefficient of 1.15 . This proportionality coefficient is referred to as the "extrusion length best fit."

In the event that the extruded material is so weak that it "pours" out of the sampler instead of extending out, the yield stress in shear of the material may be determined by the "slump" method, or the amount of deformation the material undergoes (Pashias et al. 1996). This methodology is detailed in the appendix.

The extrusion length and slump methodologies were applied to TRU waste Tanks B-203, B-204, T-110, and the T-200 series tanks. Horizontal core extrusion videos for these tanks were evaluated for failure length determined by the point at which failure was judged to occur. Slump measurements were also recorded where applicable.

Data taken from the upper half of a core segment are ascribed to a level in the tank corresponding to 0.75 of the segment length plus the lowest tank elevation of the segment. Similarly, data taken from the lower half of a core segment are assigned the segment elevation plus 0.25 of the segment length. Multiple measurements were available for individual segment halves in some instances, and each measurement is reported for that elevation. Waste density values, which are discussed further in Section 5.2, were taken from TWINS. ${ }^{(a)}$

The shear strength estimates for core 115 from B-203 are presented in Figure 3.3. Shear strengths ranging from less than $100 \mathrm{~Pa}$ near the top of the sediment to approximately 2,000 $\mathrm{Pa}$ were estimated with the extrusion length and slump techniques. An upper-bound shear strength estimate of $\sim 2,500 \mathrm{~Pa}$ was determined for one B-203 core segment. These values appear

(a) Tank Waste Information System database. http://twins.pnl.gov/twins3/twins.htm. 
reasonable compared with other available shear strength data for Hanford wastes (Gauglitz and Aikin 1997; Hedengren et al. 2000; TWINS). As expected due to lithostatic loading, the shear strength in B-203 tends to increase with depth, although some exceptions are noted.

Shear strength estimates for Tanks B-204 (cores 112 and 114), T-110 (core 180), T-201 (core 192), T-202 (core 191), T-203 (core 190), and T-204 (core 188) are shown in Figures 3.4 through 3.10, respectively. Results again range from less than $100 \mathrm{~Pa}$ to approximately $2,000 \mathrm{~Pa}$ for the bulk of the waste, and the shear strength increases with depth. As shown in Figure 3.7, the shear strengths of two segments of T-201 were estimated to exceed 2,000 Pa. One of these, photographed in the lower portion of Figure 3.2, had an upper-bound shear strength of $\sim 3,500 \mathrm{~Pa}$.

In B-204, an appreciable amount of data exists for two cores. Reasonable agreement in shear strength for the cores (approximately $3 / 4$ out from tank center toward the tank wall, $180^{\circ}$ opposed), which represent unique radial locations in the tank, is shown in Figures 3.4 and 3.5.

Because of the numerous variables involved, it is not yet possible to use the core extrusion methodology to estimate strength values with a high degree of certainty. For example, the stronger waste segments of Figures 3.1 and 3.2 appear less ductile than the bentonite clay simulants and less brittle than the kaolin/Ludox simulants used as guides. Applying the extrusion technique to other simulants that more closely match the behavior of actual waste over the entire shear strength range could improve strength evaluations using the technique described here.

- Extrusion Length Upper Bound $\square$ Extrusion Length Lower Bound $\times$ Extrusion Length Best Fit $\quad \Delta$ Slump

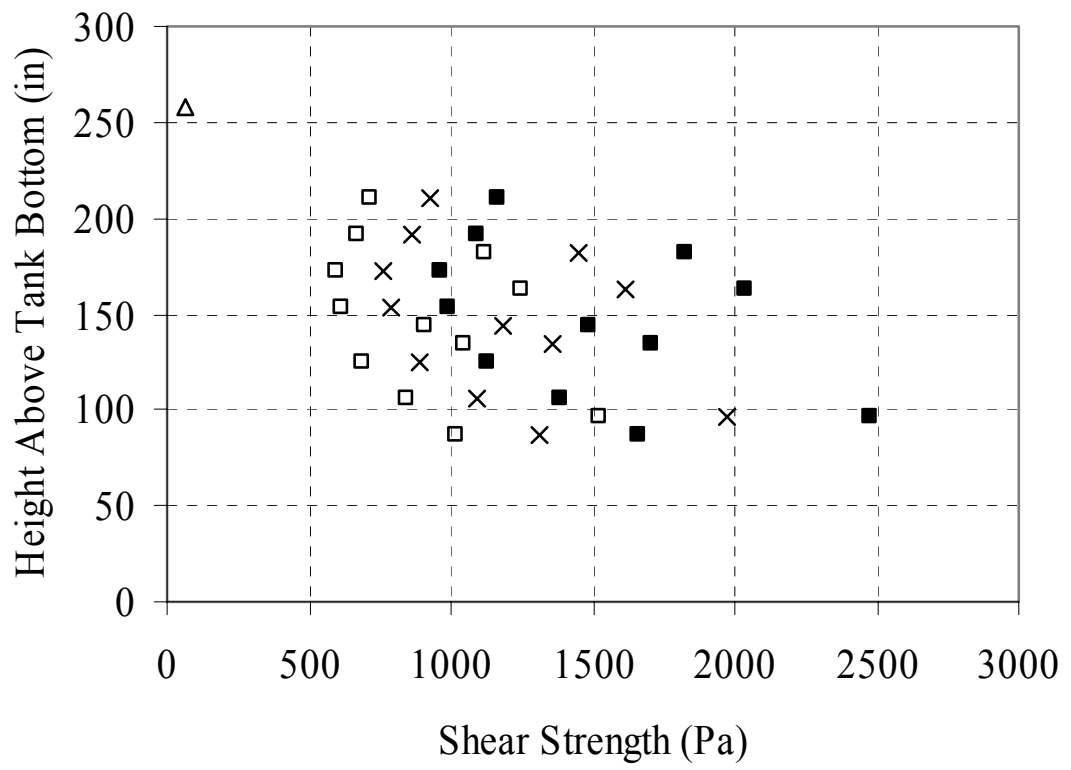

Figure 3.3. Shear Strength as a Function of Height in B-203, Core 115 


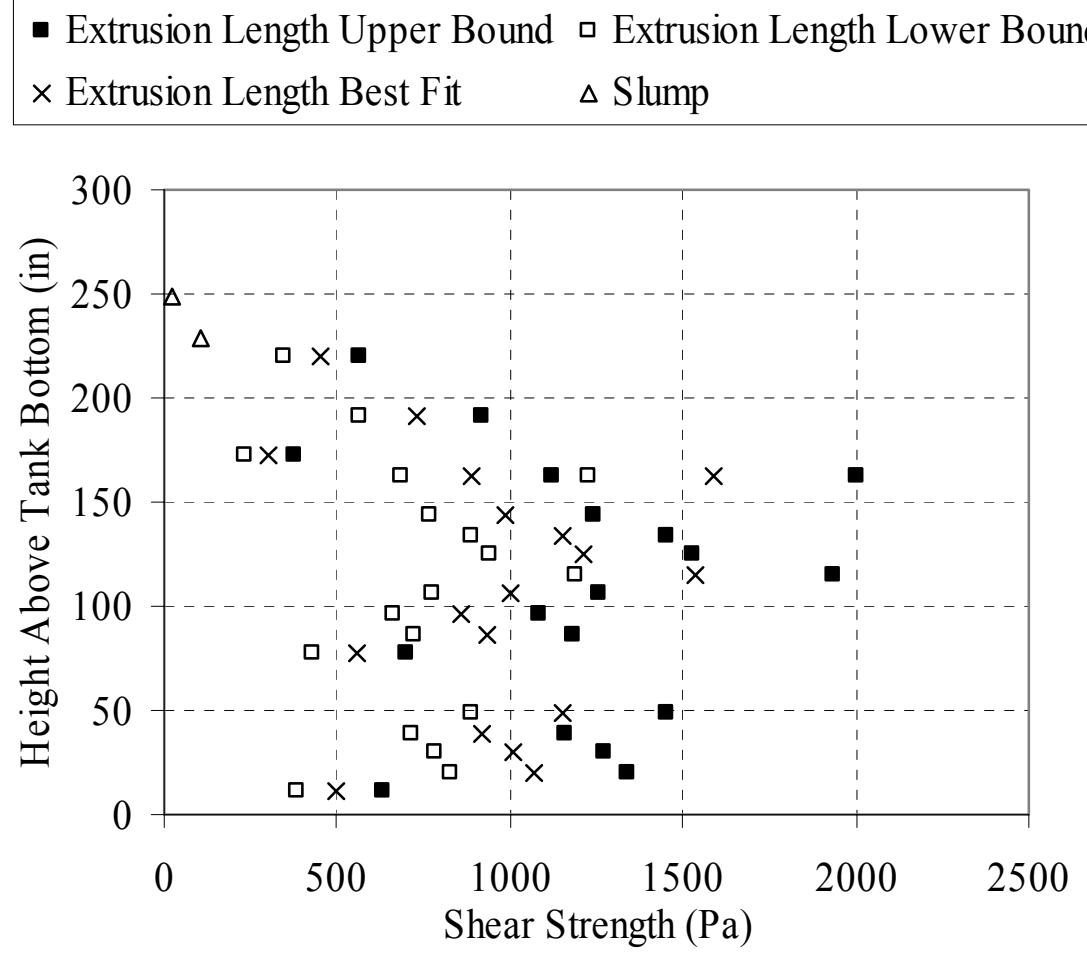

Figure 3.4. Shear Strength as a Function of Height in B-204, Core 112

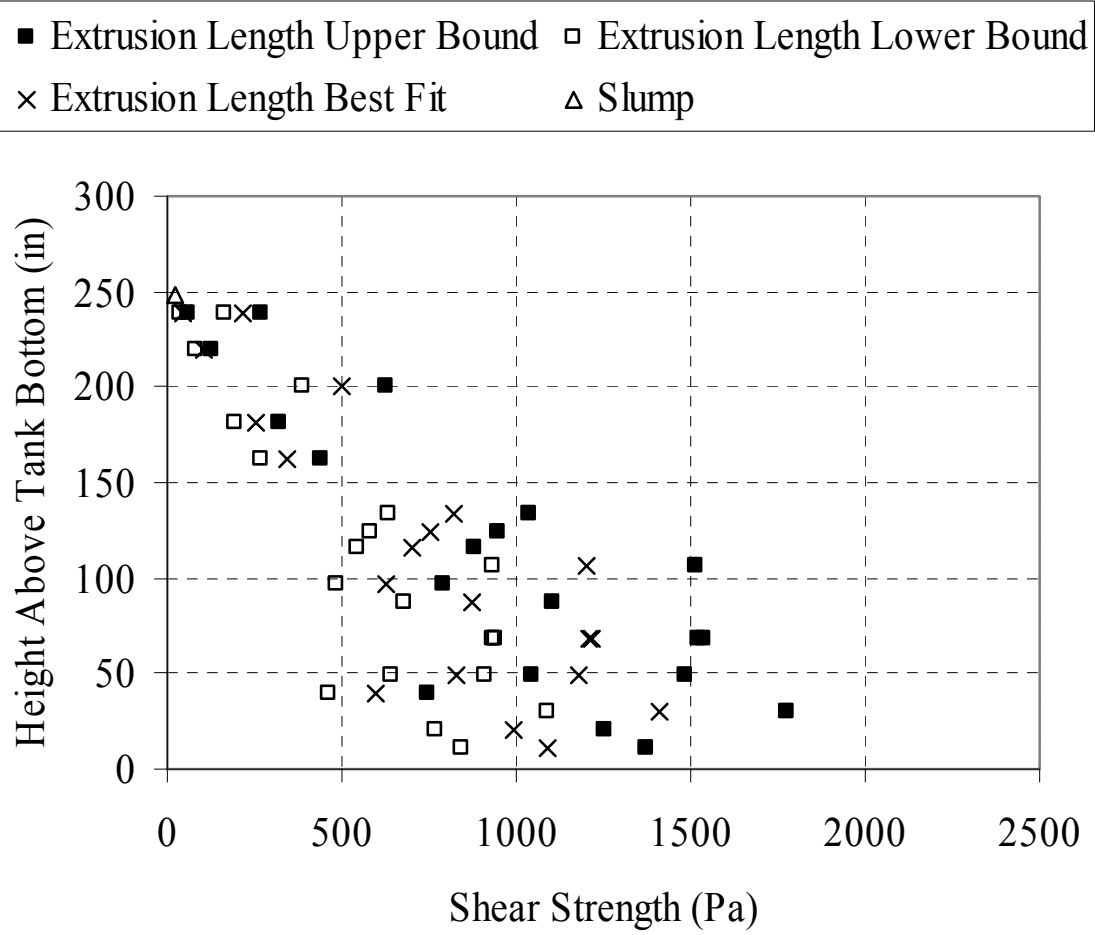

Figure 3.5. Shear Strength as a Function of Height in B-204, Core 114 
- Extrusion Length Upper Bound $\square$ Extrusion Length Lower Bound $\times$ Extrusion Length Best Fit

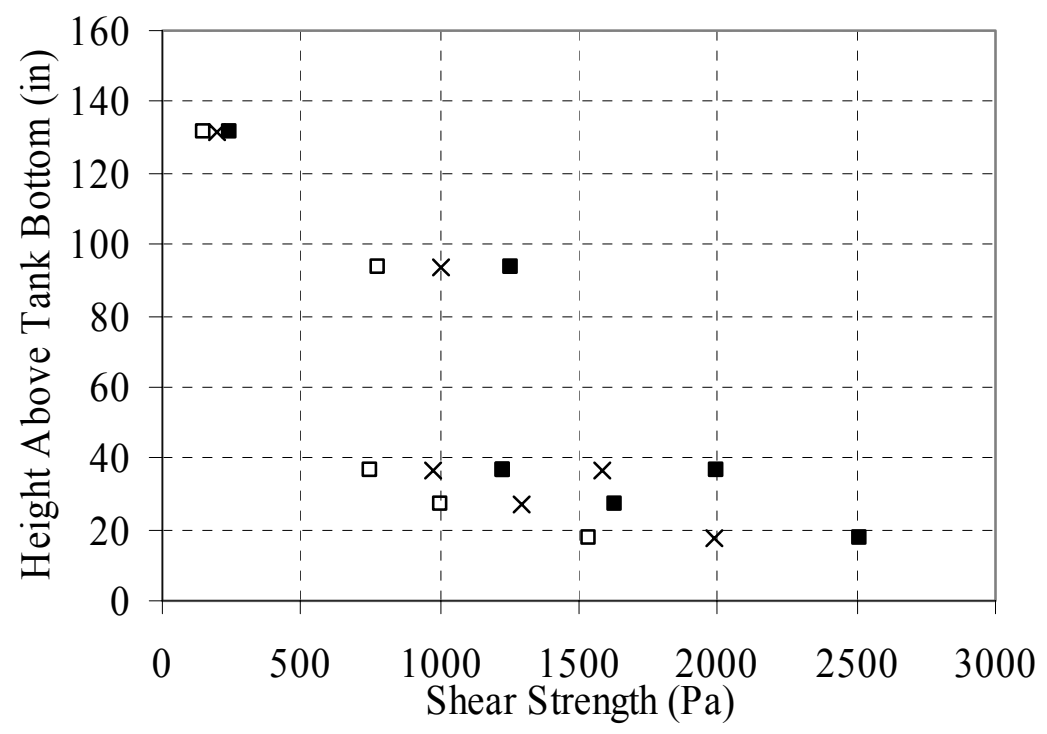

Figure 3.6. Shear Strength as a Function of Height in T-110, Core 180

- Extrusion Length Upper Bound $\square$ Extrusion Length Lower Bound $\times$ Extrusion Length Best Fit

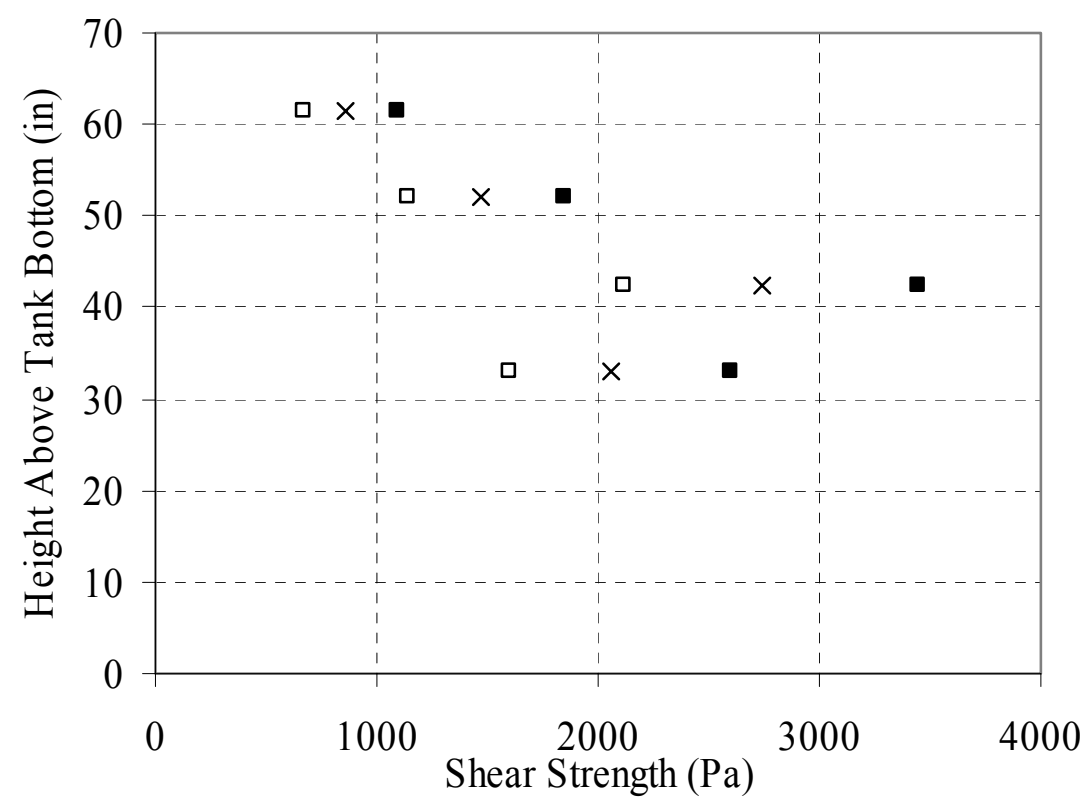

Figure 3.7. Shear Strength as a Function of Height in T-201, Core 192 
- Extrusion Length Upper Bound a Extrusion Length Lower Bound $\times$ Extrusion Length Best Fit $\quad \Delta$ Slump

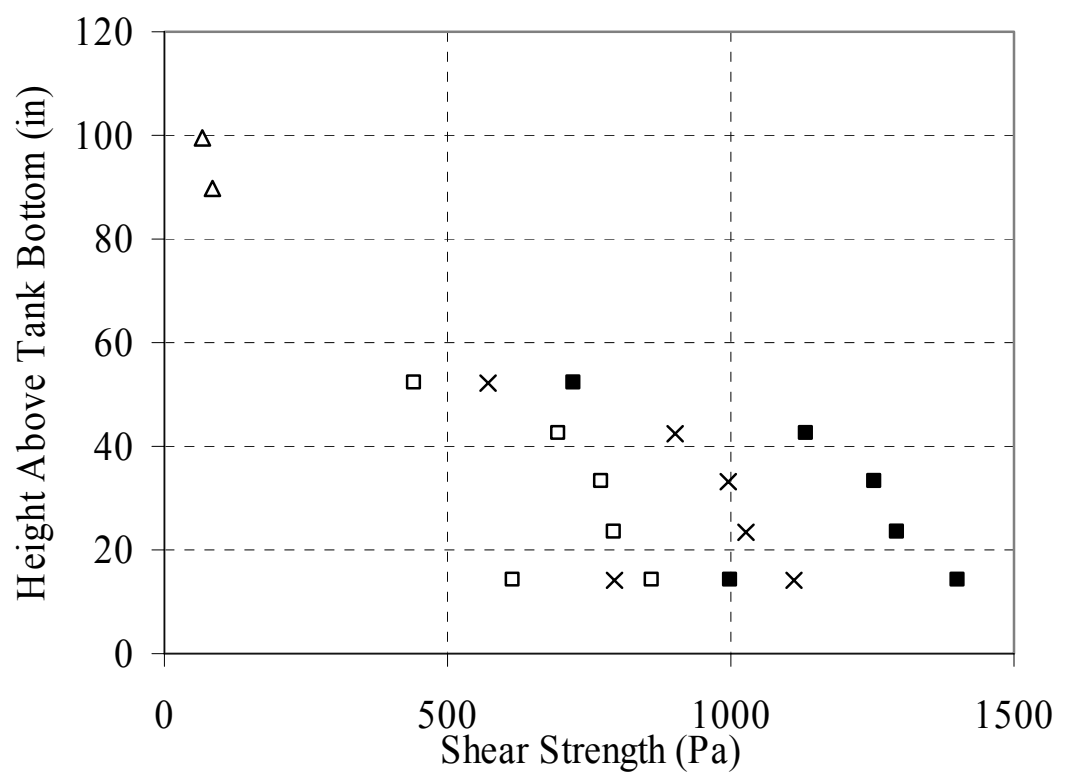

Figure 3.8. Shear Strength as a Function of Height in T-202, Core 191

- Extrusion Length Upper Bound a Extrusion Length Lower Bound $\times$ Extrusion Length Best Fit $\quad \Delta$ Slump

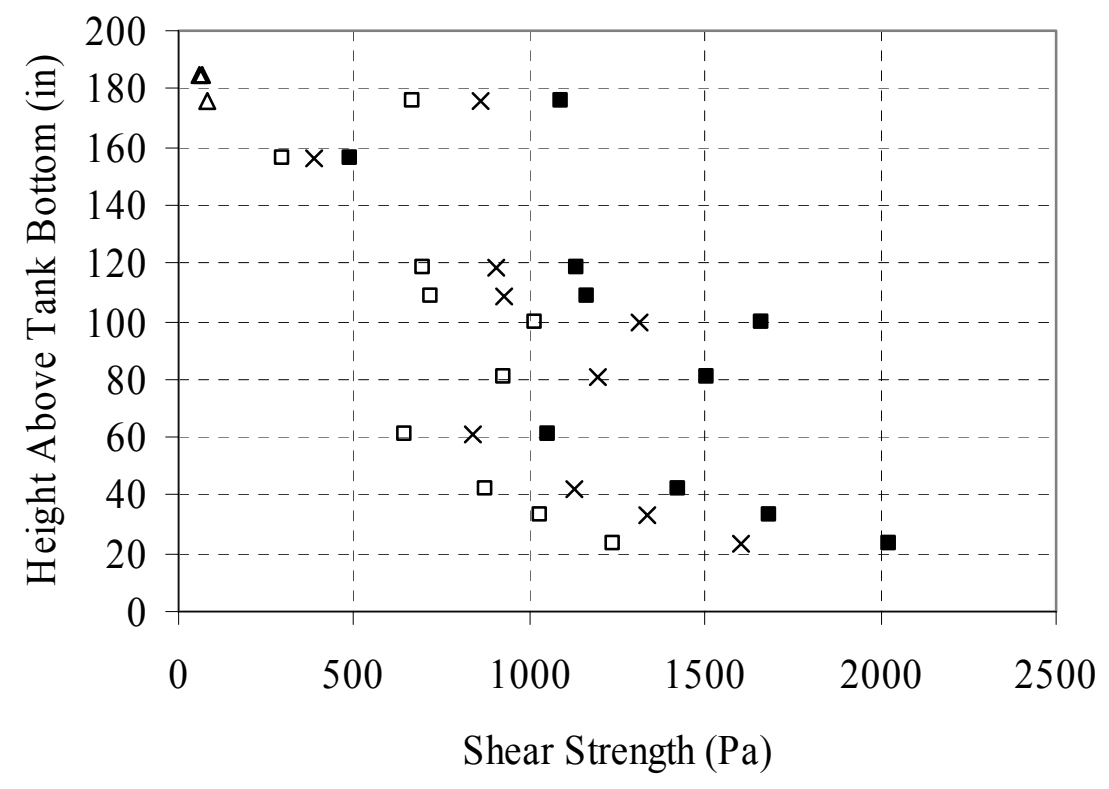

Figure 3.9. Shear Strength as a Function of Height in T-203, Core 190 


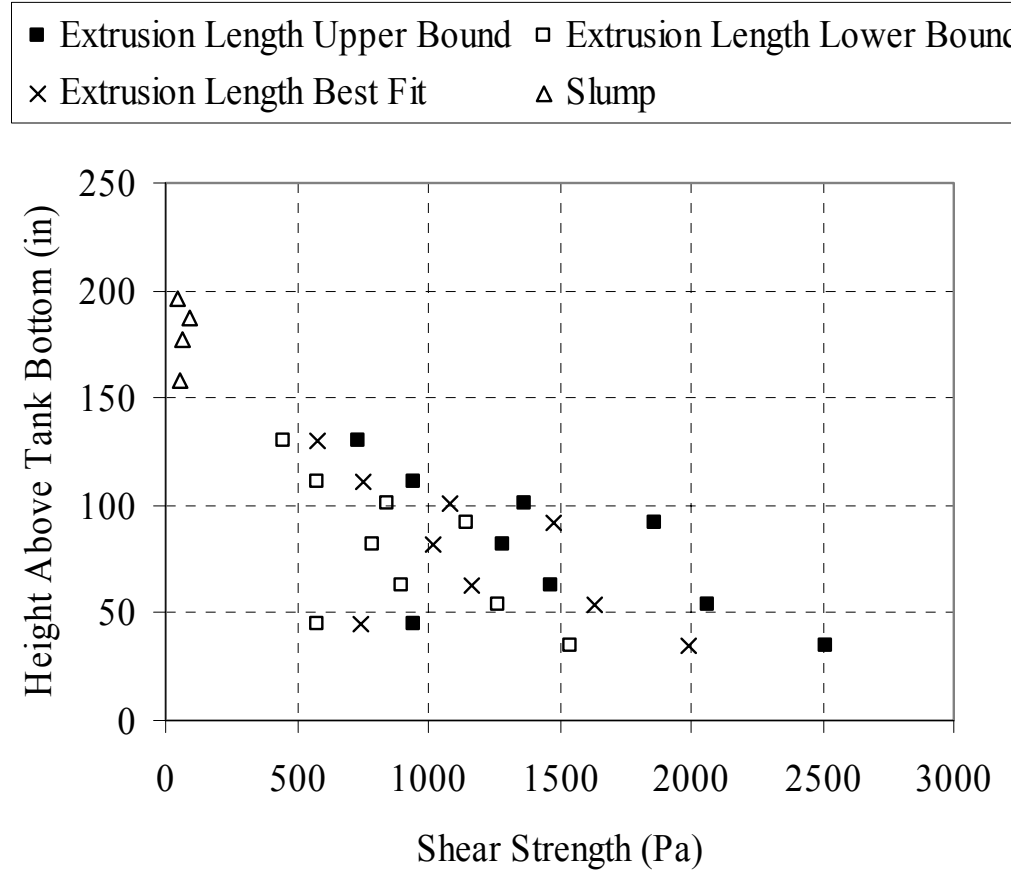

Figure 3.10. Shear Strength as a Function of Height in T-204, Core 188

\subsection{Core Sampling Load Data}

To obtain core samples, a sampler is pushed or rotated into the waste. The push is provided by the mass of the sampling apparatus and hydraulics on the sampler truck. It was hypothesized that this downward force could be evaluated to determine the shear strength of the waste. Rassat et al. (2000) used a similar methodology to evaluate the yield strength of the SY-101 crust layer from load data of a mechanical mitigation arm and water lance.

Investigation of the load data for the core sampling apparatus was not encouraging. Comments on the data ranged from "...down forces are independent of material properties..."(a) to “...don't use (load values) quantitatively...data is affected by internal friction of the sampling apparatus...."(b) The load data gathered from TWINS for DST and TRU tank wastes illustrate these comments. No load data trends with depth were apparent. The load data for supernatant liquid samples are counter-intuitive; higher loads are observed in the liquid than in the sediment below. Further, using just the sampler mass and the methodology in Rassat et al. (2000), the waste yield strength required to support the mass of the sampler is one to two orders of magnitude $(\sim 30,000$ to $60,000 \mathrm{~Pa})$ greater than other measured strengths. Based on these expectations and observations, the load data from the core sampling apparatus were not evaluated to estimate waste strength.

(a) Personal Communication from AM Templeton (CH2M HILL) to BE Wells (PNNL) on January 14, 2003.

(b) Personal Communication from J Douglas (CH2M HILL) to BE Wells on January 14, 2003. 


\subsection{Waste Rheology, Solids-Settling, and Particle Characterization}

This section summarizes the limited amount of reported strength, viscosity, particlecharacterization, and solids-settling data available for the 10 SST TRU wastes. The shear strength measurements tabulated in this section were made with viscometers, in contrast to those determined by the core extrusion observation method discussed in Section 3. The results given by the two methods are compared in this section to the limited extent possible.

\subsection{Rheology}

This section contains the rheological measurements that have been made on diluted waste samples from three of the TRU tanks, B-201, B-202, and T-111. Shear strength, but not viscosity, has also been measured for undiluted, unhomogenized samples. The diluted samples consistently showed pseudoplastic rheological behavior in which viscosity decreases as shear rate increases.

Tables 4.1 and 4.2 summarize rheology data for waste samples from Tanks B-201 and B-202 that were reported by Shaver (1993a, b). Several shear strength results measured with a viscometer and shear vane are included in the tables. The ranges of shear strengths were 1220 to $1410 \mathrm{~Pa}$ for three segments of B-201 waste and 200 to $750 \mathrm{~Pa}$ for six segments of B-202 waste.

Table 4.1. Rheological Data for Waste Samples from Tank B-201, Core $26^{(\mathrm{a})}$

\begin{tabular}{|c|c|c|c|}
\hline Properties & $\begin{array}{c}\text { Segment } 2 \\
\text { (top of waste) }\end{array}$ & $\begin{array}{c}\text { Segment } 5 \\
\text { (mid-depth) }\end{array}$ & $\begin{array}{c}\text { Segment 8 } \\
\text { (bottommost) }\end{array}$ \\
\hline \multicolumn{4}{|l|}{ As-received properties } \\
\hline $\begin{array}{l}\text { Shear strength }(\mathrm{Pa}) \text { (Haake RV100 viscometer, } \\
\text { M5 head and custom shear vane, } 0.3 \mathrm{rpm})\end{array}$ & 1410 & 1310 & 1220 \\
\hline \multicolumn{4}{|l|}{ At 1:1 by vol dilution, $30^{\circ} \mathrm{C}$} \\
\hline $\begin{array}{l}\text { Power-law consistency factor }\left(\mathrm{Pa}-\mathrm{s}^{\mathrm{n}}\right) \text { (Haake } \\
\text { RV100 viscometer, } 0 \text { to } 500 \mathrm{~s}^{-1} \text { shear rate range) }\end{array}$ & 0.011 & 0.016 & 0.047 \\
\hline Power-law flow behavior index, $\mathrm{n}$ & 0.86 & 0.92 & 0.80 \\
\hline Power-law yield stress $(\mathrm{Pa})$ & 1.7 & 5.6 & 8.1 \\
\hline Apparent viscosity (cP) at $10 \mathrm{~s}^{-1}$ shear rate & 180 & 570 & 840 \\
\hline True viscosity $(\mathrm{cP})$ at $10 \mathrm{~s}^{-1}$ shear rate & 6.8 & 12 & 24 \\
\hline Apparent viscosity $(\mathrm{cP})$ at $100 \mathrm{~s}^{-1}$ shear rate & 23 & 67 & 100 \\
\hline True viscosity $(\mathrm{cP})$ at $100 \mathrm{~s}^{-1}$ shear rate & 5.0 & 10 & 15 \\
\hline
\end{tabular}


Table 4.2. Rheological Data for Waste Samples from Tank B-202, Core 24

\begin{tabular}{|c|c|c|c|}
\hline Properties & Segment 2 & Segment 4 & Segment 6 \\
\hline \multicolumn{4}{|l|}{ As-received properties } \\
\hline $\begin{array}{l}\text { Shear strength (Pa) (Haake RV100 viscometer, } \\
\text { M5 head and custom shear vane, } 0.3 \mathrm{rpm})\end{array}$ & $200^{(\mathrm{a})}$ & $750^{(a)}$ & $670^{(\mathrm{a})}$ \\
\hline \multicolumn{4}{|l|}{ At $1: 1$ by vol dilution, $30^{\circ} \mathrm{C}$} \\
\hline $\begin{array}{l}\text { Power-law consistency factor }\left(\mathrm{Pa}-\mathrm{s}^{\mathrm{n}}\right) \text { (Haake } \\
\text { RV100 viscometer, } 0 \text { to } 500 \mathrm{~s}^{-1} \text { shear rate range) }\end{array}$ & 0.0024 & 0.0047 & 0.018 \\
\hline Power-law flow behavior index, $\mathrm{n}$ & 0.98 & 0.94 & 0.76 \\
\hline Power-law yield stress $(\mathrm{Pa})$ & 0.9 & 1.0 & 1.1 \\
\hline Apparent viscosity $(\mathrm{cP})$ at $10 \mathrm{~s}^{-1}$ shear rate & 92 & 100 & 120 \\
\hline True viscosity $(\mathrm{cP})$ at $10 \mathrm{~s}^{-1}$ shear rate & 2.2 & 3.8 & 7.9 \\
\hline Apparent viscosity $(\mathrm{cP})$ at $100 \mathrm{~s}^{-1}$ shear rate & 11 & 14 & 17 \\
\hline True viscosity $(\mathrm{cP})$ at $100 \mathrm{~s}^{-1}$ shear rate & 2.1 & 3.4 & 4.5 \\
\hline
\end{tabular}

These results are consistent with the range of strengths estimated from the core observations for several segments of B-203 and B-204 waste (Section 3.2), although segment 2 of B-201 core 26 is stronger than most of the near-top segments whose strengths are given in Section 3.

Rheology experiments were carried out on Tank T-111 waste including samples from segments 2 and 8 of core 31 (McKinley et al. 1992). Tests were also done on segment 4, but the sample had dried out prior to testing, and the results were not considered representative. Applying the same test methods used on the B-201 and B-202 samples, the shear strength of the undiluted T-111 samples was $500 \pm 230 \mathrm{~Pa}$.

A limited amount of rheological testing was performed on waste from Tanks B-201 and B-202 that had been diluted 1:1 (volume basis) with water. The rheological parameters were obtained by curve-fitting data for shear stress versus strain rate to a yield power law function. The form of the yield power-law function is

$$
\tau=\tau_{y}+K \gamma^{n}
$$

where

$$
\begin{aligned}
\tau & =\text { shear stress in fluid }(\mathrm{Pa}) \\
\tau_{\mathrm{y}} & =\text { yield stress }(\mathrm{Pa}) \\
\mathrm{K} & =\text { consistency factor }\left(\mathrm{Pa} \mathrm{s}^{\mathrm{n}}\right) \\
\mathrm{n} & =\text { flow behavior index } \\
\gamma & =\text { shear rate }\left(\mathrm{s}^{-1}\right) .
\end{aligned}
$$


The "apparent" viscosity values in Tables 4.1 and 4.2 were calculated as $\tau / \gamma$ and are most accurate for high shear rates. The "true" viscosity values were calculated as the derivative of $\tau$ with respect to $\gamma$. For pipe flow, the shear rate at the wall is roughly equal to $8 \mathrm{~V} / \mathrm{D}$, in which $\mathrm{V}$ is the average flow velocity and $D$ the pipe diameter (Wasp et al. 1977); this relation can be used to estimate the shear rate so that the viscosity at that condition can be calculated.

In Tank B 201, whose rheological data are summarized in Table 4.1, the viscosity and the power law yield stress of the diluted waste increases from top to bottom (Shaver 1993a). At a strain rate of $100 \mathrm{~s}^{-1}$, the true viscosity of the diluted waste ranges from $\sim 0.0050$ to $0.015 \mathrm{~Pa}$-s (5 to $15 \mathrm{cP}$ ). Table 4.2 presents similar data for waste samples from Tank B-202 (Shaver 1993b). The diluted samples from B-202 are somewhat lower in power law yield stress and viscosity [ 0.0021 to $0.0045 \mathrm{~Pa}$-s $(2.1$ to $4.5 \mathrm{cP})$ at $\left.100 \mathrm{~s}^{-1}\right]$ than those from B-201. In B-202, as in B-201, the viscosity increases from the top to the bottom of the waste.

The true viscosity of the diluted waste in B-201 and B-202, as computed from the derivatives of their respective power law functions from Tables 4.1 and 4.2, is presented in Figures 4.1 and 4.2 , respectively. Note that data obtained from the typically used viscometers may be questionable for strain rates of less than $50 \mathrm{~s}^{-1}$ (e.g., Herting 1999). At a constant strain rate, viscosity increases with waste depth (Figures 4.1 and 4.2).

The increase in viscosity with depth is expected if we attribute decreased water content in the waste with depth, as is shown in Section 5.1, to increased undissolved solids content. For a given waste, we expect a sample with a higher undissolved solids content to also have a higher undissolved solids content after dilution than a sample having a lower initial undissolved solids content and diluted equivalently. Typically, at a fixed strain rate, the viscosity of a mixture will increase with increasing undissolved solids volume fraction. This may be seen in Einstein-type correlations, which relate slurry viscosity to the undissolved solids volume fraction and base liquid viscosity (Wasp et al. 1977). The effect of temperature on slurry viscosity is not addressed in the current discussion.

To relate the diluted waste sample viscosity results to in situ waste conditions from the viewpoint of increased undissolved solid volume fraction, examination of data for other Hanford wastes is insightful. Data from DST saltcake waste suggests that, at very low strain rates $\left(<1 \mathrm{~s}^{-1}\right.$, data from the ball rheometer) (Stewart et al. 1996b), halving the undissolved solid volume fraction (by dilution, for example) could reduce the slurry viscosity by as much as four orders of magnitude (Onishi et al. 2003a, b). The effect of the altered base liquid viscosity by dilution is negligible. At a strain rate of approximately $100 \mathrm{~s}^{-1}$, the effect of the halved solids volume fraction is reduced to approximately one to two orders of magnitude (Onishi et al. 2002, 2003a, b), and at $1,000 \mathrm{~s}^{-1}$, the effect is reduced to less than $0.025 \mathrm{~Pa}-\mathrm{s}(25 \mathrm{cP})$. Qualitatively, therefore, the argument may be made that the viscosity values of Figures 4.1 and 4.2 are likely lower than the waste at in situ conditions for a given strain rate. 


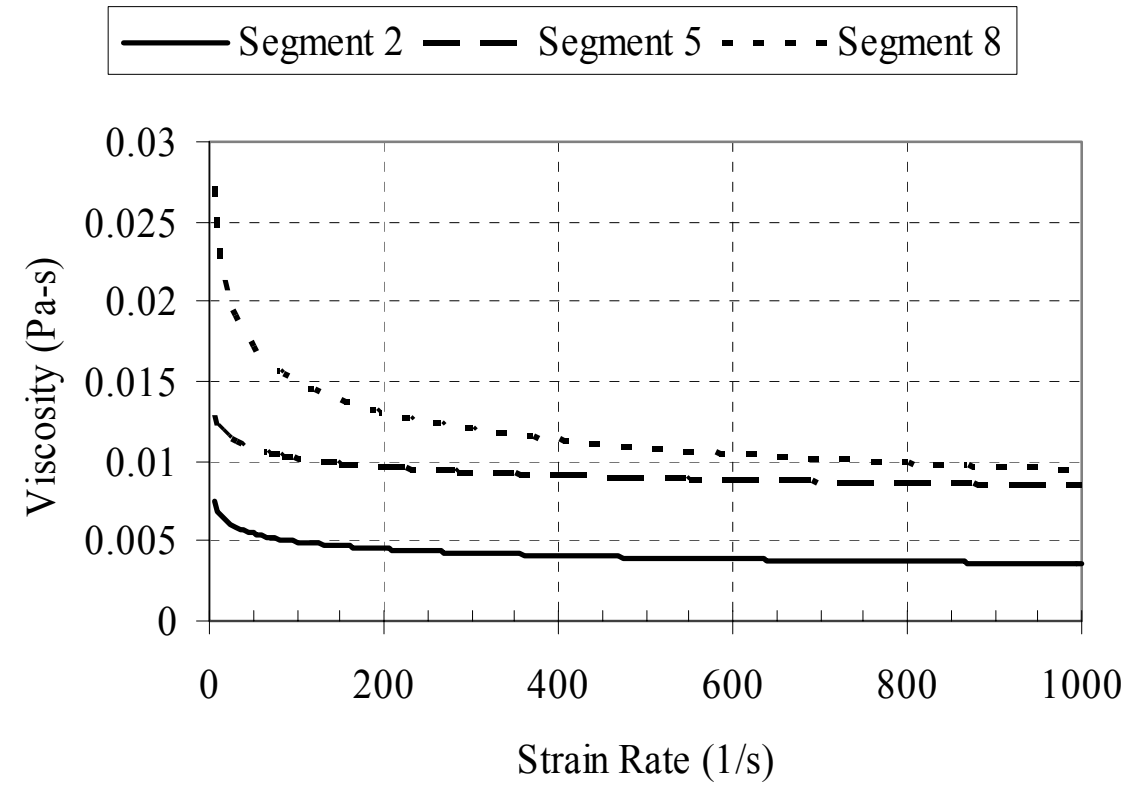

Figure 4.1. Viscosity as a Function of Strain Rate for 1:1 Diluted B-201 Samples (core 26, parameters from Table 4.1)

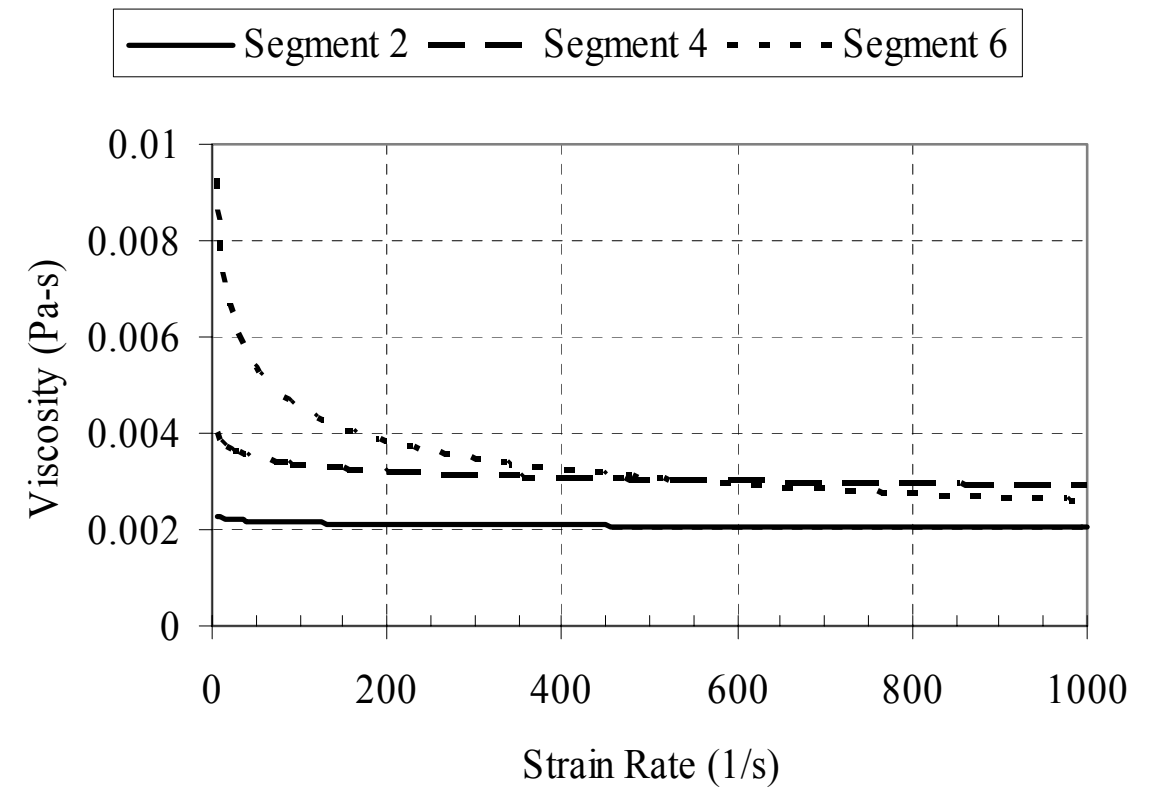

Figure 4.2. Viscosity as a Function of Strain Rate for 1:1 Diluted B-202 Samples (core 24, parameters from Table 4.2) 
The viscosity of diluted and undiluted samples of T-111 was also investigated (McKinley et al. 1992). Rheograms (shear stress versus strain rate) showed that the undiluted T-111 samples behaved like greases and lubricants: the viscometer cone tended to slip over the sample, with the slippage increasing with shear rate. As a result, the rheological behavior of these samples could not be described in power-law form. The viscosity of the T-111 samples was also measured for 1:1 and 3:1 sample dilutions with water. The diluted samples evidenced pseudoplastic behavior. Because the viscosities were near the detection limit of the system $(2 \mathrm{cP})$, the data could not be correlated and power-law constants are not available.

\subsection{Solids-Settling}

Design issues related to the development of a TRU waste dewatering process can be partially addressed by solids-settling data for the wastes. This section discusses the available settling data. Simple solids-settling tests were conducted for undiluted and diluted samples from B-201, B-202, and T-111 (Shaver 1993a, b; McKinley 1992). The results of the tests are summarized in Tables 4.3, 4.4, and 4.5. The tests showed that at $1 \mathrm{G}$ (gravitational force on Earth), under the small hydrostatic head available in a centrifuge tube, essentially no settling occurred in the undiluted samples. Centrifugation of the undiluted samples at more than $1000 \mathrm{G}$ produced 2 to $12 \mathrm{vol} \%$ free liquid in B-201 samples and 30 to $40 \mathrm{vol} \%$ free liquid in B-202 samples. This may represent an upper bound for the amount of waste settling and dewatering that could be produced by vibration or other disturbances.

Both as-received and water-diluted samples showed potential for settling under their own weight and for centrifugal dewatering. The data in Shaver (1993a, b) and McKinley et al. (1992) suggest that the rate of gravitational settling for both waste types decreased significantly after two days, but centrifugation clearly indicates that settling was not complete. In two days, gravity settling produced free liquid of 8 to 19 vol\% in 1:1 (by volume) diluted B-201 samples, whereas centrifugal settling increased the free liquid to 42 to $58 \mathrm{vol} \%$. Likewise, the free liquid in 3:1 diluted B-201 samples was 43 to 63 vol\% after $30 \mathrm{hr}$ at $1 \mathrm{G}$ and 76 to $84 \mathrm{vol} \%$ when centrifuged. Dissolution of salt solids may contribute to the reduced total mass of solids in diluted samples.

Studies of other TRU wastes that have high metals content, though considerably different in composition than those shown in Table 2.1, have suggested that the volume of long-settled sludge would be half that of sludge settled for only a few days (Swanson 1991). The applicability of these studies to the particular TRU wastes under consideration in this report is unknown, but this observation seems roughly consistent with the decrease in volume between $>1$-day gravity settled solids volumes and the centrifuged solids volumes shown in Table 4.3 for 1:1 and 3:1 diluted B-201 samples. 
Table 4.3. Density and Settling Data for Waste Samples from Tank B-201, Core $26^{(\mathrm{a})}$

\begin{tabular}{|c|c|c|c|}
\hline Properties & $\begin{array}{c}\text { Segment } 2 \\
\text { (top of waste) }\end{array}$ & $\begin{array}{c}\text { Segment } 5 \\
\text { (mid-depth) }\end{array}$ & $\begin{array}{c}\text { Segment } 8 \\
\text { (bottommost) }\end{array}$ \\
\hline \multicolumn{4}{|l|}{ As-received properties } \\
\hline $\begin{array}{l}\text { Centrifuged bulk solids density }(\mathrm{g} / \mathrm{cc}) \\
\text { (centrifuged for } 1 \mathrm{hr} \text { at }>1000 \mathrm{G} \text { ) }\end{array}$ & 1.66 & 1.52 & 1.37 \\
\hline Centrifuged liquid density (g/cc) & 1.19 & 1.19 & 1.05 \\
\hline $\begin{array}{l}\text { Settled solids (vol\%) } \\
\text { (settling at } 1 \mathrm{G} \text { in centrifuge tube) }\end{array}$ & 100 & 100 & 100 \\
\hline Centrifuged solids (vol\%) & 98 & 98 & 88 \\
\hline Centrifuged solids (wt\%) & 98 & 98 & 90 \\
\hline \multicolumn{4}{|l|}{ At 1:1 dilution by volume, $30^{\circ} \mathrm{C}$} \\
\hline Pre-centrifugation bulk density (g/cc) & 1.33 & 1.17 & 1.13 \\
\hline $\begin{array}{l}\text { Centrifuged bulk solids density }(\mathrm{g} / \mathrm{cc} \text { ) } \\
\text { (centrifuged for } 1 \mathrm{hr} \text { at }>1000 \mathrm{G}\end{array}$ & 1.59 & 1.40 & 1.33 \\
\hline Centrifuged liquid density (g/cc) & 1.01 & 1.00 & 0.99 \\
\hline $\begin{array}{l}\text { Settled solids (vol\%) } \\
\text { (after } 8 \mathrm{hr} \text { at } 1 \mathrm{G} \text { in centrifuge tube) }\end{array}$ & 90 & 88 & 94 \\
\hline $\begin{array}{l}\text { Settled solids (vol\%) } \\
\text { (after } 48 \mathrm{hr} \text { at } 1 \mathrm{G} \text { in centrifuge tube) }\end{array}$ & 83 & 81 & 92 \\
\hline Centrifuged solids (vol\%) & 58 & 43 & 42 \\
\hline Centrifuged solids (wt\%) & 69 & 52 & 49 \\
\hline \multicolumn{4}{|l|}{ At 3:1 dilution by volume, $30^{\circ} \mathrm{C}$} \\
\hline Pre-centrifugation bulk density (g/cc) & 1.10 & 1.05 & 1.05 \\
\hline $\begin{array}{l}\text { Centrifuged bulk solids density }(\mathrm{g} / \mathrm{cc} \text { ) } \\
\text { (centrifuged for } 1 \mathrm{hr} \text { at }>1000 \mathrm{G} \text { ) }\end{array}$ & 1.48 & 1.36 & 1.24 \\
\hline Centrifuged liquid density (g/cc) & 0.99 & 1.00 & 0.99 \\
\hline $\begin{array}{l}\text { Settled solids (vol\%) } \\
\text { (after } 8 \mathrm{hr} \text { at } 1 \mathrm{G} \text { in centrifuge tube) }\end{array}$ & 48 & 40 & 60 \\
\hline $\begin{array}{l}\text { Settled solids (vol\%) } \\
\text { (after } 30 \mathrm{hr} \text { at } 1 \mathrm{G} \text { in centrifuge tube) }\end{array}$ & 42 & 37 & 57 \\
\hline Centrifuged solids (vol\%) & 24 & 16 & 21 \\
\hline Centrifuged solids (wt\%) & 32 & 21 & 25 \\
\hline
\end{tabular}


Table 4.4. Density and Settling Data for Waste Samples from Tank B-202, Core $24^{(\mathrm{a})}$

\begin{tabular}{|c|c|c|c|}
\hline & Segment 2 & Segment 4 & Segment 6 \\
\hline \multicolumn{4}{|l|}{ As-received properties } \\
\hline Pre-centrifugation bulk density $(\mathrm{g} / \mathrm{cc})$ & 1.23 & 1.20 & 1.21 \\
\hline $\begin{array}{l}\text { Centrifuged bulk solids density }(\mathrm{g} / \mathrm{cc} \text { ) } \\
\text { (centrifuged for } 1 \mathrm{hr} \text { at }>1000 \mathrm{G} \text { ) }\end{array}$ & 1.32 & 1.29 & 1.29 \\
\hline Centrifuged liquid density $(\mathrm{g} / \mathrm{cc})$ & 1.06 & 1.05 & 1.03 \\
\hline $\begin{array}{l}\text { Settled solids (vol\%) } \\
\text { (settling at } 1 \mathrm{G} \text { in centrifuge tube) }\end{array}$ & 100 & 100 & 100 \\
\hline Dissolved \& undissolved solids (vol\%) & 36 & 28 & 27 \\
\hline Undissolved solids (wt\%) & 33 & 24 & 24 \\
\hline Centrifuged solids (vol\%) & 67 & 61 & 69 \\
\hline Centrifuged solids (wt\%) & 72 & 65 & 73 \\
\hline \multicolumn{4}{|l|}{ At 1:1 dilution by volume, $30^{\circ} \mathrm{C}$} \\
\hline $\begin{array}{l}\text { Settled solids (vol\%) } \\
\text { (after } 8 \mathrm{hr} \text { at } 1 \mathrm{G} \text { in centrifuge tube) }\end{array}$ & 84 & 87 & 92 \\
\hline $\begin{array}{l}\text { Settled solids (vol\%) } \\
\text { (after } 55 \mathrm{hr} \text { at } 1 \mathrm{G} \text { in centrifuge tube) }\end{array}$ & 77 & 80 & 87 \\
\hline \multicolumn{4}{|l|}{ At 3:1 dilution by volume, $30^{\circ} \mathrm{C}$} \\
\hline $\begin{array}{l}\text { Settled solids (vol\%) } \\
\text { (after } 8 \mathrm{hr} \text { at } 1 \mathrm{G} \text { in centrifuge tube) }\end{array}$ & 43 & 45 & 54 \\
\hline $\begin{array}{l}\text { Settled solids (vol\%) } \\
\text { (after } 55 \mathrm{hr} \text { at } 1 \mathrm{G} \text { in centrifuge tube) }\end{array}$ & 39 & 40 & 49 \\
\hline
\end{tabular}

Table 4.5. Density and Settling Data for Waste Samples from Tank T-111, Core $31^{(a)}$

\begin{tabular}{|c|c|c|}
\hline As-received properties & Segment 2 & Segment 8 \\
\hline Pre-centrifugation bulk density (g/cc) & 1.19 & 1.28 \\
\hline $\begin{array}{l}\text { Centrifuged bulk solids density }(\mathrm{g} / \mathrm{cc} \text { ) } \\
\text { (centrifuged for } 1 \mathrm{hr} \text { at }>1000 \mathrm{G} \text { ) }\end{array}$ & 1.22 & 1.34 \\
\hline Centrifuged liquid density $(\mathrm{g} / \mathrm{cc})$ & 1.07 & 1.10 \\
\hline $\begin{array}{l}\text { Settled solids (vol\%) } \\
\text { (settling at } 1 \mathrm{G} \text { in centrifuge tube) }\end{array}$ & 100 & 100 \\
\hline Dissolved \& undissolved solids ( $\mathrm{wt} \%$ ) & 22.4 & 29.3 \\
\hline Undissolved solids (wt\%) & 19.0 & 25.4 \\
\hline Centrifuged solids (vol\%) & 65.8 & 71.9 \\
\hline Centrifuged solids (wt\%) & 67.3 & 75.9 \\
\hline \multicolumn{3}{|l|}{ At 1:1 dilution by volume, $30^{\circ} \mathrm{C}$} \\
\hline $\begin{array}{l}\text { Settled solids (vol\%) } \\
\text { (after } 8 \mathrm{hr} \text { at } 1 \mathrm{G} \text { in centrifuge tube) }\end{array}$ & 92 & 96 \\
\hline $\begin{array}{l}\text { Settled solids (vol\%) } \\
\text { (after } 60 \mathrm{hr} \text { at } 1 \mathrm{G} \text { in centrifuge tube) }\end{array}$ & 87 & 80 \\
\hline \multicolumn{3}{|l|}{ At 3:1 dilution by volume, $30^{\circ} \mathrm{C}$} \\
\hline $\begin{array}{l}\text { Settled solids (vol\%) } \\
\text { (after } 8 \mathrm{hr} \text { at } 1 \mathrm{G} \text { in centrifuge tube) }\end{array}$ & 65 & 58 \\
\hline $\begin{array}{l}\text { Settled solids (vol\%) } \\
\text { (after } 52 \mathrm{hr} \text { at } 1 \mathrm{G} \text { in centrifuge tube) }\end{array}$ & 52 & 40 \\
\hline
\end{tabular}




\subsection{Particle Characterization}

Particle size in the waste and the abrasiveness of the particles may have significance in the development of TRU waste handling and packaging equipment and the physical simulants needed to test the process. The available data on particle properties of the SST TRU wastes from Tanks B-201, B-202, and T-111 are presented in this section.

The particle size distribution in the waste from B-201 was measured in glycerol dispersions made from unhomogenized subsamples of each segment using a laser-scan transit-time technique. The instrument was a Brinkman Model 2010 particle size analyzer (Shaver 1993a). A summary of particle size distribution ${ }^{(a)}$ is given in Table 4.6. Particle size distributions were measured by similar methods in T-111 core 31 , and the results are summarized in Table 4.7.

Figures 4.3 through $4.10^{(\text {b) }}$ show the particle size distributions in each segment of core 27 in volume percent. The segments are given in order of decreasing elevation; segment $1(27: 1)$ is

Table 4.6. Particle Size Distribution Data for Waste Samples from Tank B-201

\begin{tabular}{|c|c|c|c|c|}
\hline \multirow[t]{2}{*}{ Core:Segment } & \multicolumn{2}{|c|}{$\begin{array}{l}\text { Particle Size } \\
\text { Distribution, } \\
\text { by Volume }\end{array}$} & \multicolumn{2}{|c|}{$\begin{array}{l}\text { Particle Size } \\
\text { Distribution, } \\
\text { by Number }\end{array}$} \\
\hline & $\begin{array}{c}\text { Mean } \\
(\mu \mathrm{m})\end{array}$ & $\begin{array}{c}\text { Median } \\
(\mu \mathrm{m})\end{array}$ & $\begin{array}{c}\text { Mean } \\
(\mu \mathrm{m})\end{array}$ & $\begin{array}{c}\text { Median } \\
(\mu \mathrm{m})\end{array}$ \\
\hline $26: 1$ & 31.3 & 13.8 & 1.22 & 0.90 \\
\hline $26: 2$ & 22.4 & 13.8 & 1.32 & 0.93 \\
\hline $26: 3$ & 29.2 & 27.9 & 1.21 & 0.91 \\
\hline $26: 4$ & 10.7 & 5.28 & 0.99 & 0.82 \\
\hline $26: 5$ & 28.4 & 26.3 & 1.26 & 0.92 \\
\hline $26: 6$ & 38.7 & 43.1 & 1.14 & 0.88 \\
\hline $26: 7$ & 20.4 & 12.2 & 1.23 & 0.93 \\
\hline $26: 8$ & 6.83 & 4.83 & 0.98 & 0.81 \\
\hline $27: 1$ & 26.4 & 20.0 & 1.13 & 0.88 \\
\hline $27: 2$ & 65.5 & 46.6 & 1.31 & 0.91 \\
\hline $27: 3$ & 30.5 & 21.6 & 1.48 & 0.92 \\
\hline $27: 4$ & 18.0 & 12.1 & 1.07 & 0.84 \\
\hline $27: 5$ & 9.42 & 6.46 & 1.16 & 0.87 \\
\hline $27: 6$ & 41.8 & 37.5 & 1.56 & 1.03 \\
\hline $27: 7$ & 18.6 & 17.4 & 1.24 & 0.93 \\
\hline $27: 8$ & 23.2 & 17.6 & 1.10 & 0.86 \\
\hline
\end{tabular}

(a) Tank Waste Information Network System (TWINS), http://twins.pnl.gov:8001/data/data.asp.

(b) McKinley SG, LR Greenwood, EW Hoppe, RT Steele, JM Tingey, and MW Urie. May 7, 1993. Core 27 Data Report, Tank B-201 Rev. 0, Pacific Northwest Laboratory, Richland, WA. 
Table 4.7. Particle Size Distribution Data for Waste Samples from Tank T-111

\begin{tabular}{|c|c|c|c|c||}
\hline \multirow{2}{*}{ Core:Segment } & \multicolumn{2}{|c|}{$\begin{array}{c}\text { Particle Size Distribution, } \\
\text { by Volume }\end{array}$} & $\begin{array}{c}\text { Particle Size Distribution, } \\
\text { by Number }^{(\text {a) }}\end{array}$ \\
\cline { 2 - 5 } & $\begin{array}{c}\text { Mean } \pm \\
\text { Std. Dev. } \\
(\mu \mathbf{m})\end{array}$ & $\begin{array}{c}\text { Median } \\
(\mu \mathbf{m})\end{array}$ & $\begin{array}{c}\text { Mean } \pm \\
\text { Std. Dev. } \\
(\mu \mathbf{m})\end{array}$ & $\begin{array}{c}\text { Median } \\
(\mu \mathrm{m})\end{array}$ \\
\hline $31: 1$ & $28.6 \pm 35.9$ & 5.8 & $1.23 \pm 0.89$ & 0.94 \\
\hline $31: 2$ & $14.9 \pm 20.8$ & 4.8 & $1.13 \pm 0.80$ & 0.88 \\
\hline $31: 3$ & $65.0 \pm 46.2$ & 58.7 & $1.17 \pm 1.00$ & 0.91 \\
\hline $31: 4$ & $24.9 \pm 34.2$ & 5.6 & $0.93 \pm 0.60$ & 0.80 \\
\hline $31: 5$ & $37.9 \pm 47.9$ & 12.3 & $0.95 \pm 0.63$ & 0.81 \\
\hline $31: 7$ & $8.0 \pm 11.9$ & 4.0 & $0.97 \pm 0.60$ & 0.83 \\
\hline $31: 8$ & $24.7 \pm 28.2$ & 10.0 & $1.02 \pm 0.85$ & 0.82 \\
\hline $31: 9$ & $59.7 \pm 49.0$ & 59.0 & $1.02 \pm 0.83$ & 0.83 \\
\hline (a) Field (1997), Tables B2-8 and B2-9. & \multicolumn{4}{|l}{} \\
\hline
\end{tabular}

the top segment and segment 8 (27:8) the bottom. Tank waste segments are 19 inches apart. The reason for the irregular particle size variation from segment to segment is unknown. Particle size distributions for T-111 waste samples, though not identical, exhibit a range of behavior similar to that of B-201 in Figures 4.3 to 4.10.

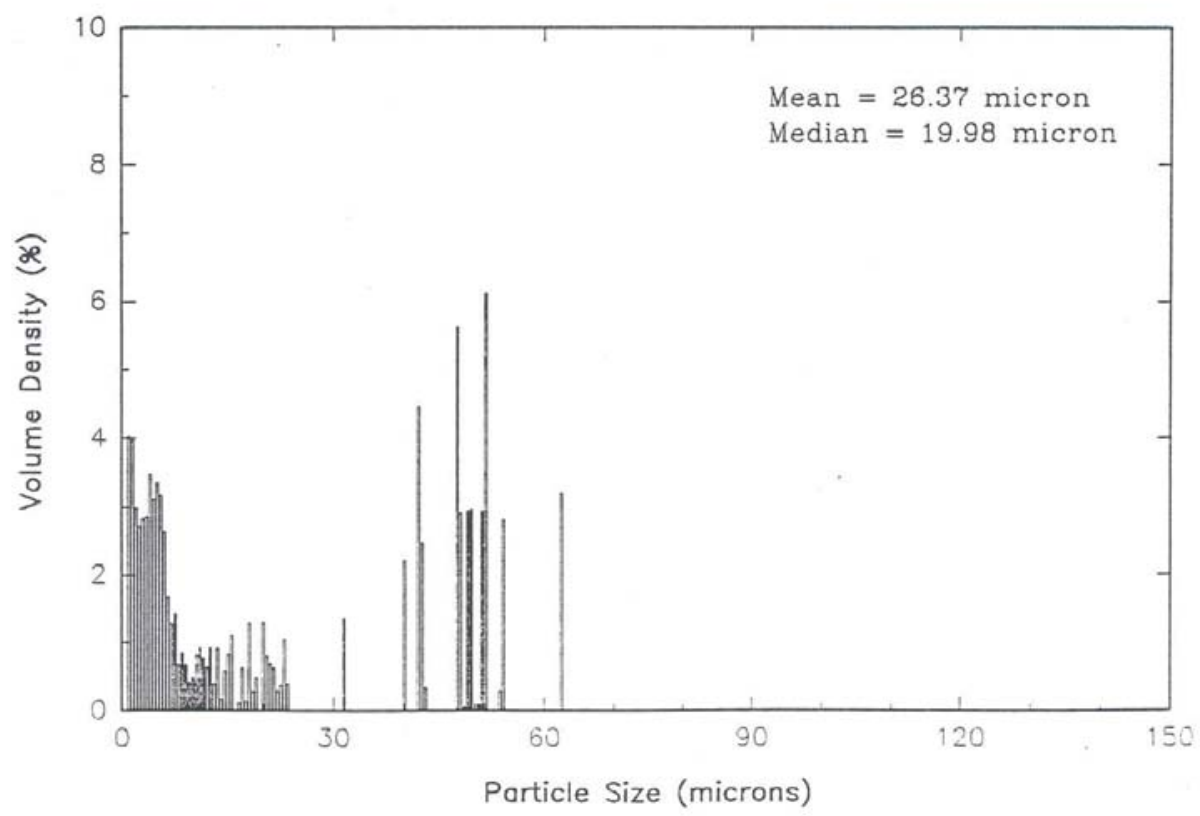

Figure 4.3. Particle Size Distribution in Core 27, Segment 1 of B-201 


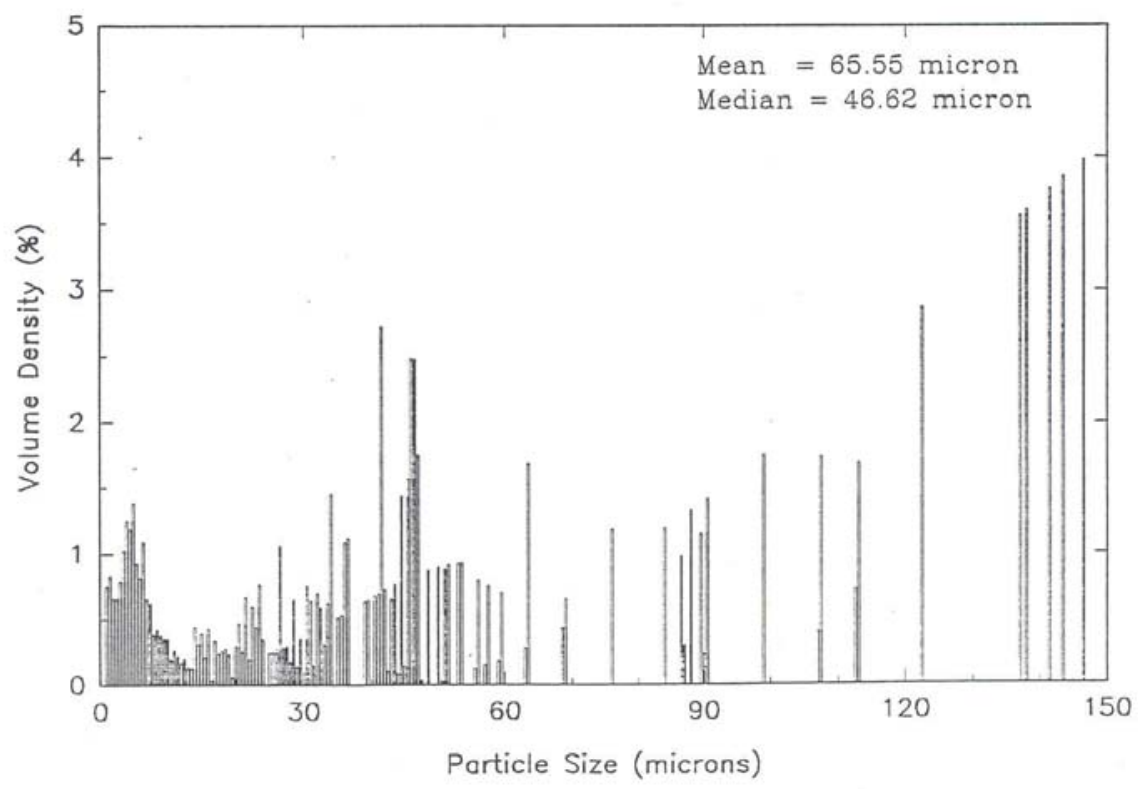

Figure 4.4. Particle Size Distribution in Core 27, Segment 2 of B-201

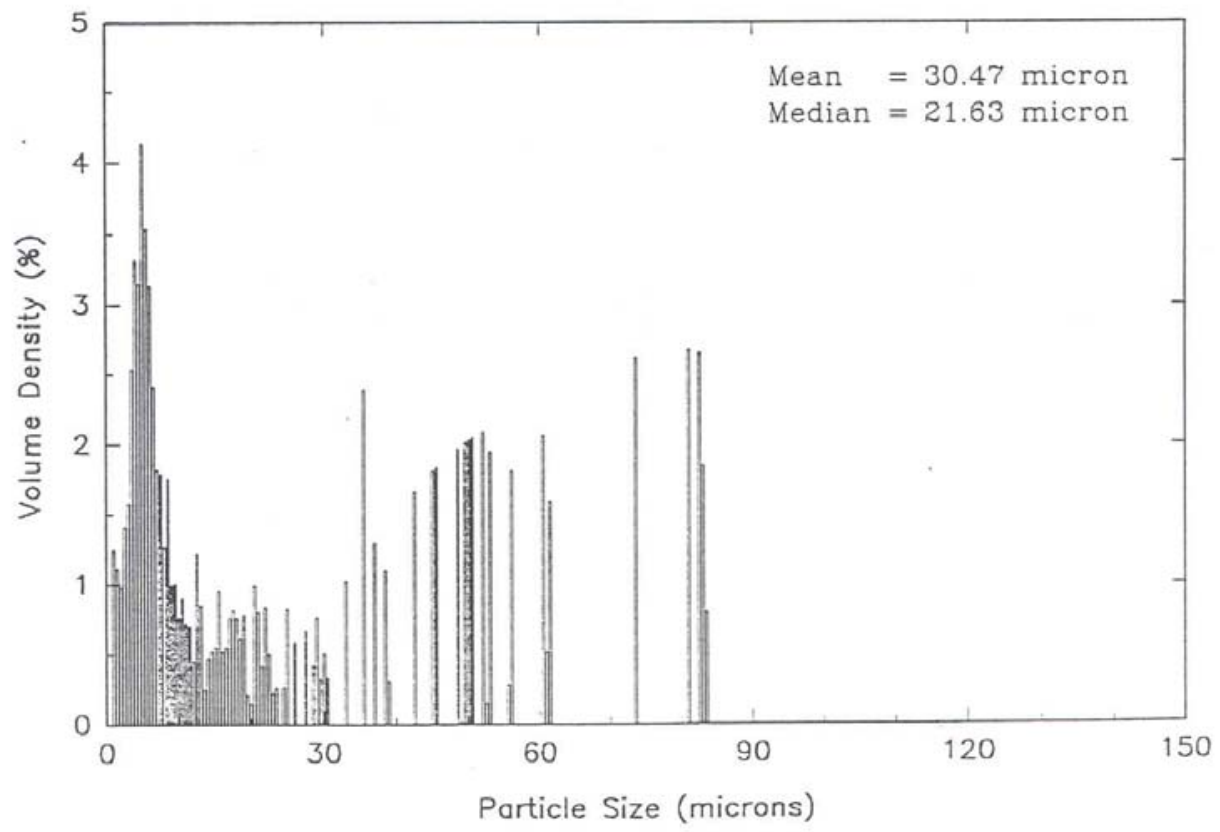

Figure 4.5. Particle Size Distribution in Core 27, Segment 3 of B-201 


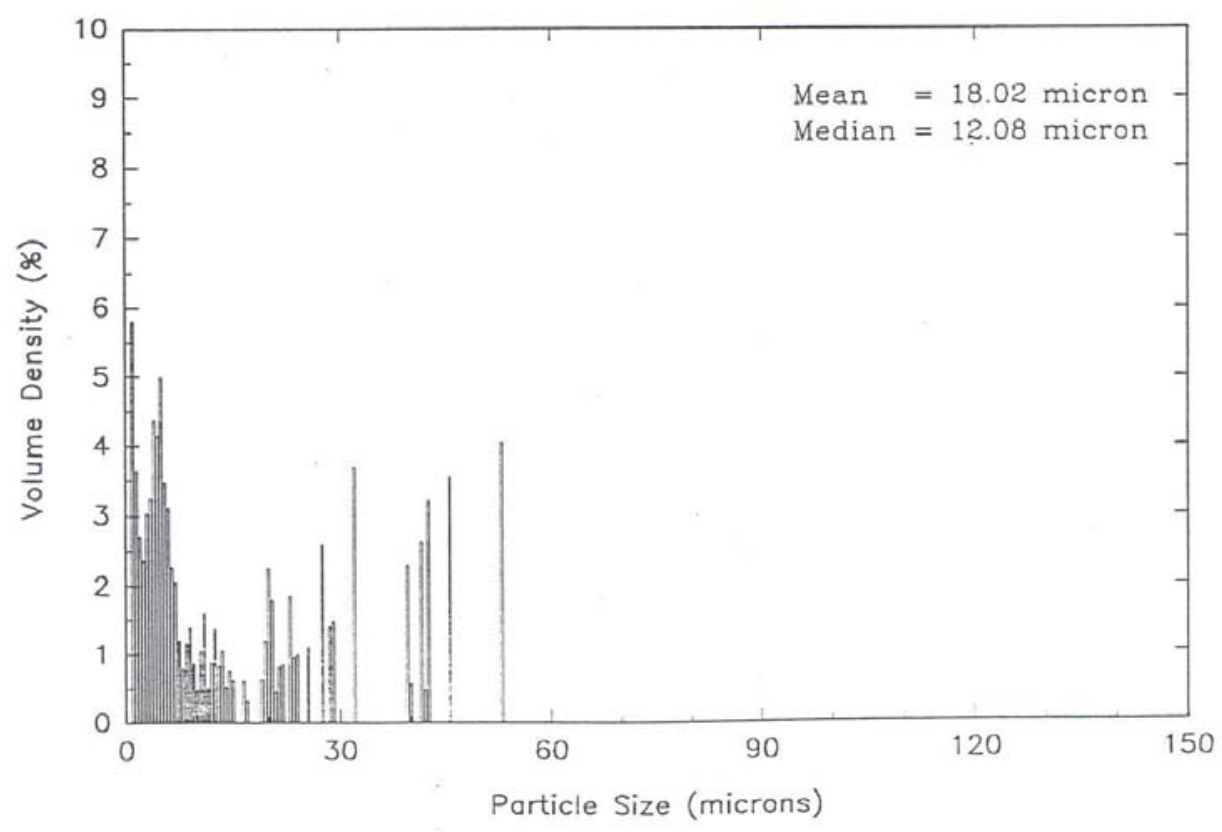

Figure 4.6. Particle Size Distribution in Core 27, Segment 4 of B-201

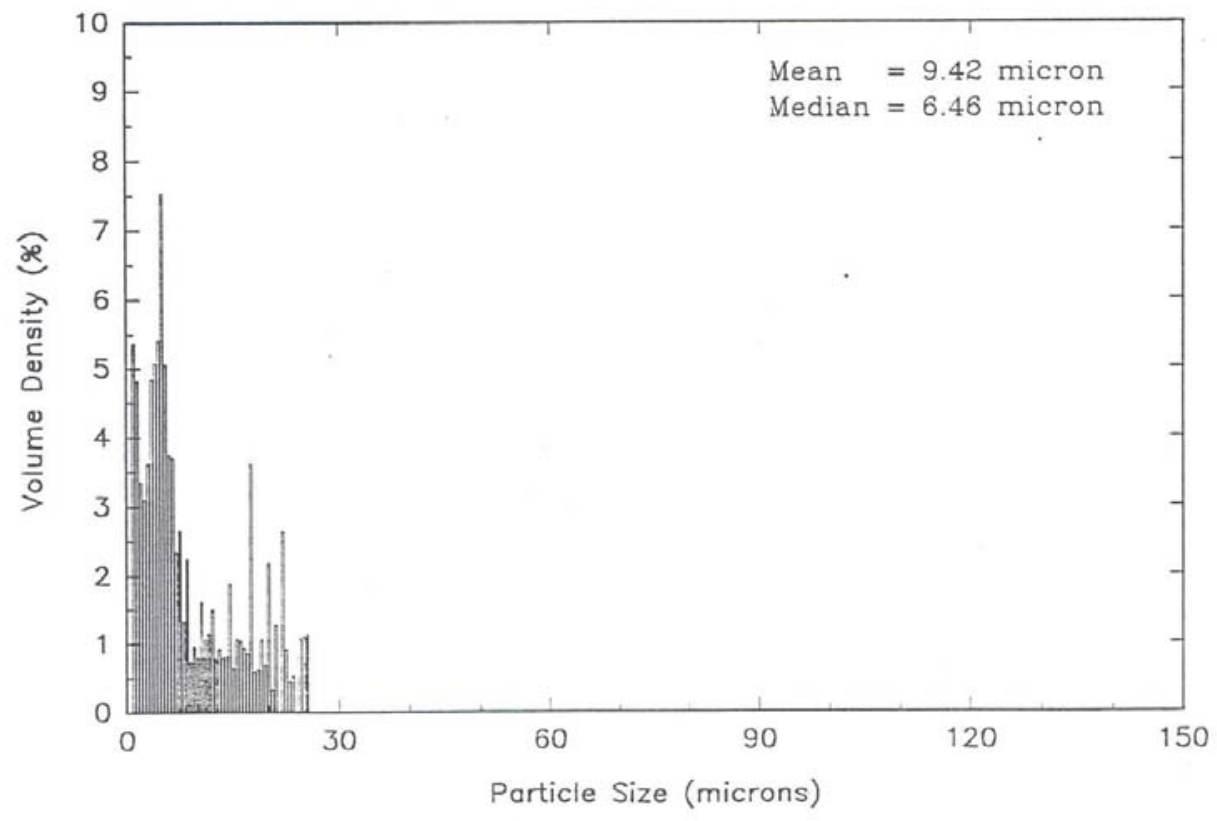

Figure 4.7. Particle Size Distribution in Core 27, Segment 5 of B-201 


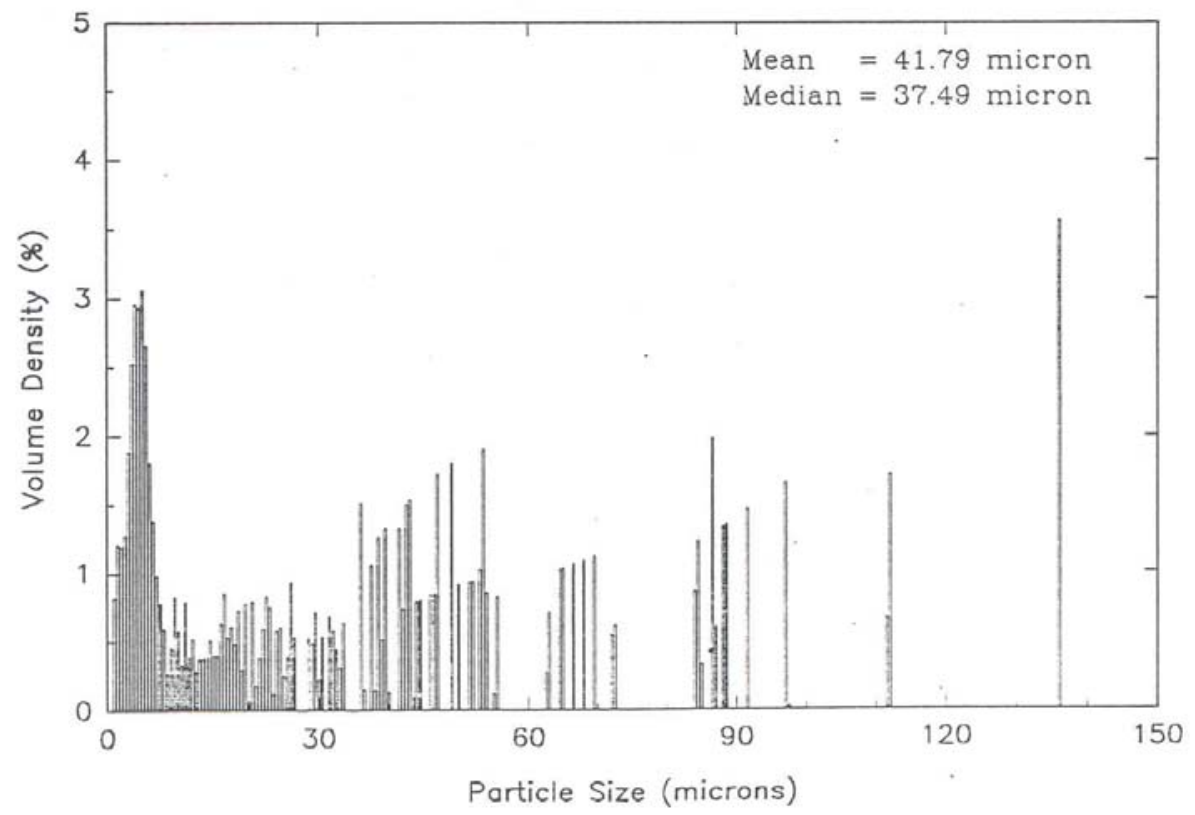

Figure 4.8. Particle Size Distribution in Core 27, Segment 6 of B-201

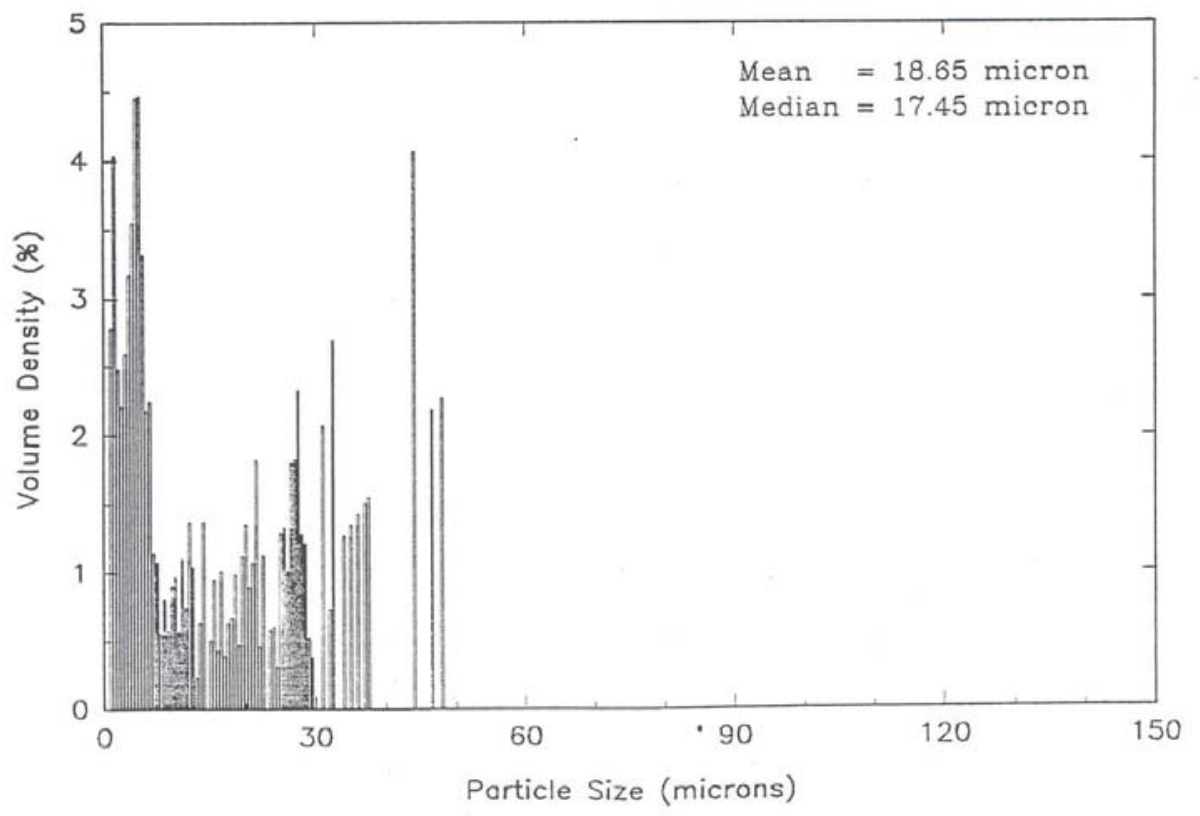

Figure 4.9. Particle Size Distribution in Core 27, Segment 7 of B-201 


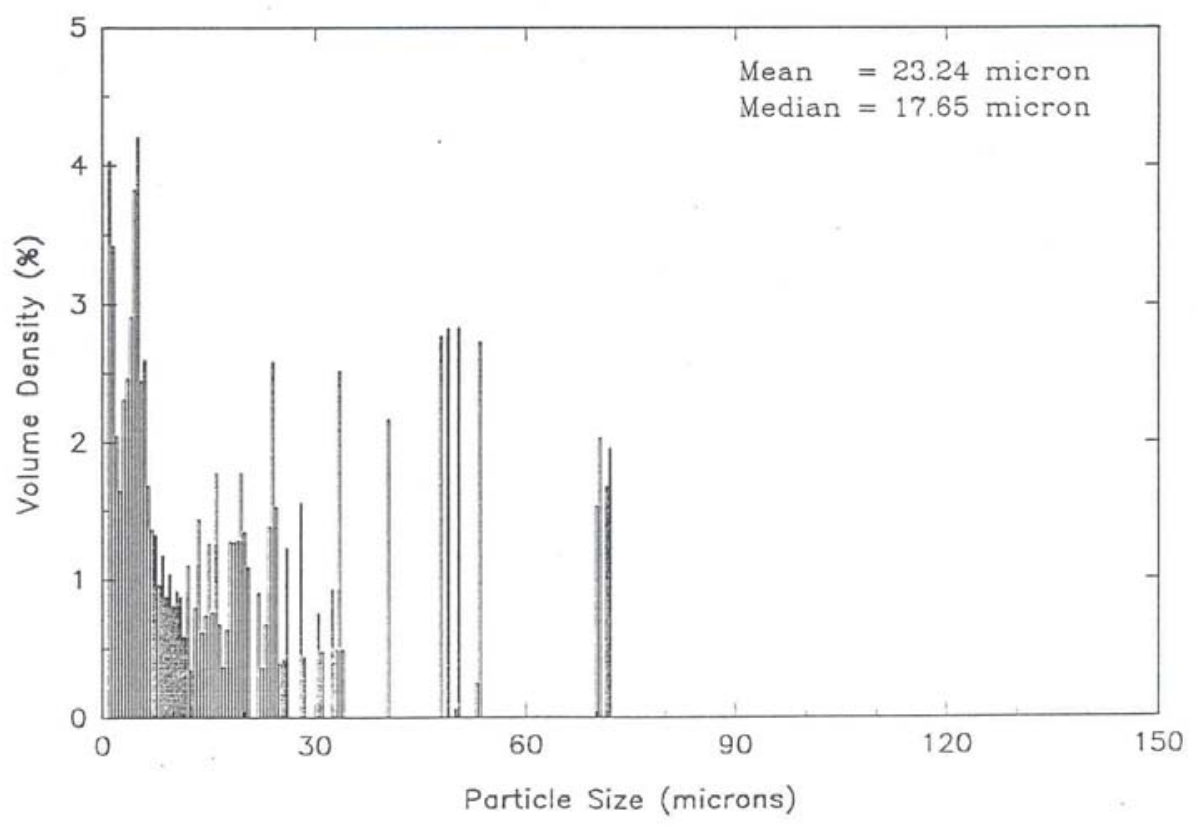

Figure 4.10. Particle Size Distribution in Core 27, Segment 8 of B-201

In one of the Tank B-201 composites from core 27, leaching studies suggested that the large particles $(>6 \mu \mathrm{m})$ were composed mainly of compounds removed by caustic leaching. These were mostly sodium salts, probably including sodium nitrate, phosphate, and oxalate (Lumetta and Rapko 1994). This suggests a distinction in composition between larger and smaller particles.

Another property of some significance is the abrasiveness of the waste. A general discussion of waste abrasiveness can be found in Duignan (2002), and the points of interest are summarized here. Abrasiveness is linearly proportional to the Vickers Hardness of the solids in the waste. It is linearly proportional to the particle size for particle diameters less than $100 \mu \mathrm{m}$ but does not vary with particle diameter above $100 \mu \mathrm{m}$. It is linearly proportional to the solids mass fraction for less than $5 \mathrm{wt} \%$ solids, still linearly proportional between 5 and $20 \mathrm{wt} \%$ but with a smaller proportionality constant, and increases only slightly for solids concentration above $20 \mathrm{wt} \%$.

Information about the compounds present in the tank solid phase is obviously important to estimating or matching the waste abrasiveness. Of the tanks whose waste is being considered for dry retrieval, the waste from Tanks B-202 and T-111 has undergone phase characterization by a combination of techniques, including powder X-ray diffraction (XRD), transmission electron microscopy/electron diffraction (TEM/ED), and scanning electron microscopy/electron dispersive X-ray (SEM/EDX). Rapko and Lumetta (2000) described details of the techniques. 
XRD did not identify any of the solid phases in the B-202 sample except for $\mathrm{NaNO}_{3}$ (sodium nitrate). TEM, SEM, and XRD techniques were used on the T-111 waste sample. They identified $\mathrm{Na}_{3} \mathrm{PO}_{4}, \mathrm{La}_{4}\left(\mathrm{P}_{2} \mathrm{O}_{7}\right)_{3}, \mathrm{Ca}_{5} \mathrm{OH}\left(\mathrm{PO}_{4}\right)_{3}$ (a form of apatite), $\mathrm{BiPO}_{4}, \mathrm{FePO}_{4}$, amorphous $\mathrm{Fe}(\mathrm{OH})_{3}, \mathrm{Mn}_{2} \mathrm{MnO}_{4}, \mathrm{Fe}_{2} \mathrm{MnO}_{4}$ (jacobsite), and $\mathrm{FeOOH}$ (goethite). The presence of other solid phases is not precluded by the fact that they were not identified, but they are less likely to be present in significant quantities. Of the phases that were identified, those with the greatest hardness were apatite ( 5 Mohs hardness) and goethite ( 5 to 5.5 Mohs). The manganesecontaining phases may also be hard, and any silicates that were present but not identified could be harder than goethite. 


\subsection{Relationship of Water Content, Bulk Density, and Shear Strength}

Evidence of waste compaction (dewatering) is shown by measurements of the water content and, to some extent, the bulk density of SST TRU waste samples. Additionally, waste shear strength variations in the tanks, as discussed in Section 3, suggest a degree of compaction. The data were examined for correlation between water content, bulk density, and shear strength; only slight indications of correlation were found.

\subsection{Water Content}

The bulk water content of core samples from the various TRU SSTs have been measured. ${ }^{\text {(a) }}$ ("Bulk" indicates that both solids and interstitial liquid are included.) All the water fraction data presented in this section were obtained by thermogravimetric analysis (TGA); in some cases, especially in the T-200 tanks, this method was supplemented by differential scanning calorimetry (DSC). The TGA method determines water content by measuring the weight loss resulting from progressive heating of the sample. In most of the samples, the water loss occurred below $130^{\circ} \mathrm{C}$; in this temperature range the water probably came from liquid. In some samples, a small amount of the water $\left(15 \%\right.$ or less) did not evaporate until temperatures between $130^{\circ} \mathrm{C}$ and $300^{\circ} \mathrm{C}$ were reached; this water probably represents chemically bound water of hydration in the solids. Thus the maximum overstatement of liquid water content that might result from including the water of hydration is about $15 \%$.

In a few cases, the water content of samples may have been underestimated because the sample-handling procedure allowed free liquid to drain from the sample. (The liquid was thereafter handled and analyzed separately.) However, the samples of the wastes discussed in this report produced little or no free liquid, so drainage was not a concern in data analysis.

Figure 5.1 provides information on the water content profiles in the tanks, hence on the longterm waste settling. The plots in the figure show the weight percent water as a function of the depth below the waste surface for all the TRU SSTs except B-201 and B-202, for which water content data were unreliable. A decrease in the water content with depth, suggestive of waste self-compaction, can be observed in most of these tanks, with T-201 and T-203 as possible exceptions.

(a) All data not otherwise referenced were taken from the Hanford Tank Waste Information Network System (TWINS) database, http://twins.pnl.gov:8001/twins.htm. 

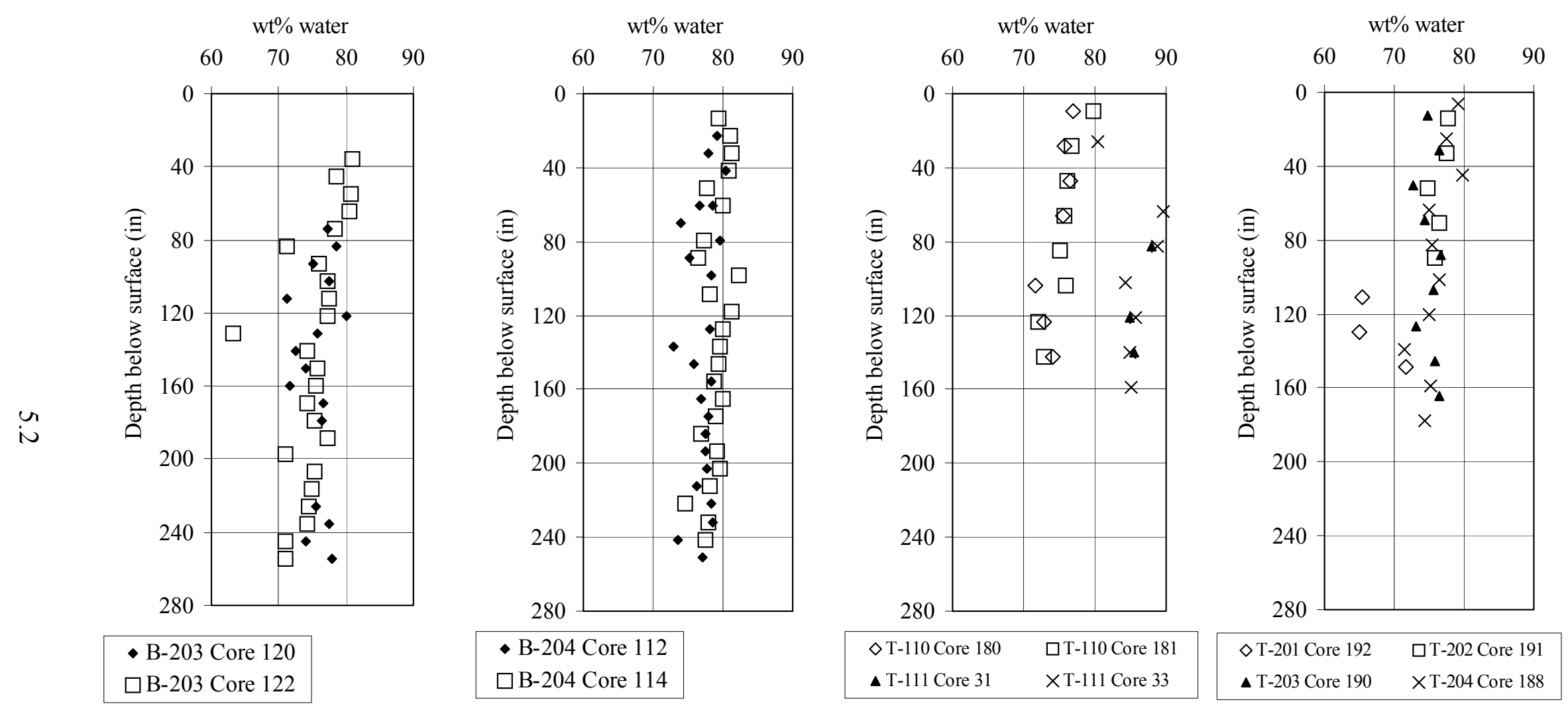

Figure 5.1. Waste Compaction, as Indicated by Variation in Water Content 


\subsection{Bulk Density}

The bulk density of the waste depends on the waste liquid fraction and the densities of the liquid and solid phases. This section compares the bulk density with the water fraction (which is nearly equal to the liquid fraction). Figure 5.2 shows the relationship of the sample bulk densities and water fractions (the latter are expressed as weight percent water) in the two B-200 series tanks for which reliable density and water data are available. (Some density and water data for Tanks B-201 and B-202 were also found, but these did not show good repeatability.) The data points in the upper-left corner of the plot are for tank liquid (typically containing inconsequential amounts of suspended solids). There is marked scatter in the data in Figure 5.2, but it appears that the density increases more rapidly with decreasing water content in B-204 waste than in B-203 waste.

Figures 5.3 and 5.4 show the density/water relationships for the T-200 series and T-110 and T-111 tanks. Considering the three data sets together (Figures 5.2 through 5.4), most of the data for bulk solids samples show bulk densities between 1.15 and $1.35 \mathrm{~g} / \mathrm{mL}$ and water content between 70 and $85 \mathrm{wt} \%$. Tanks B-203, T-201, and T-204 seem to have similar density/water relations. Tanks B-204, T-203, T-110, and T-111 show a greater amount of density change per decrease in water content than does the first group. Tank T-202 shows densities that vary even though the water contents of the various samples are about the same.

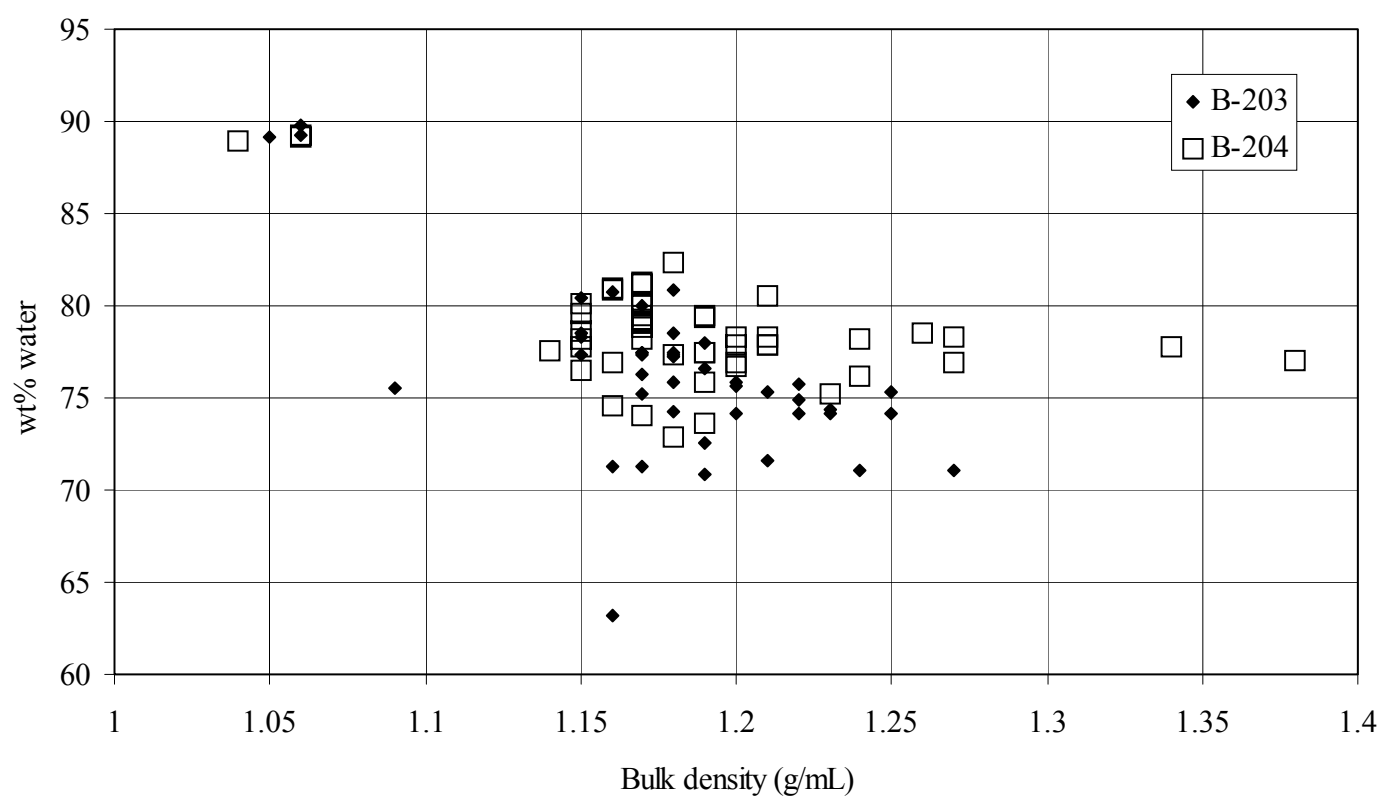

Figure 5.2. Bulk Density Versus Water Content in the B-200 Series Tanks 


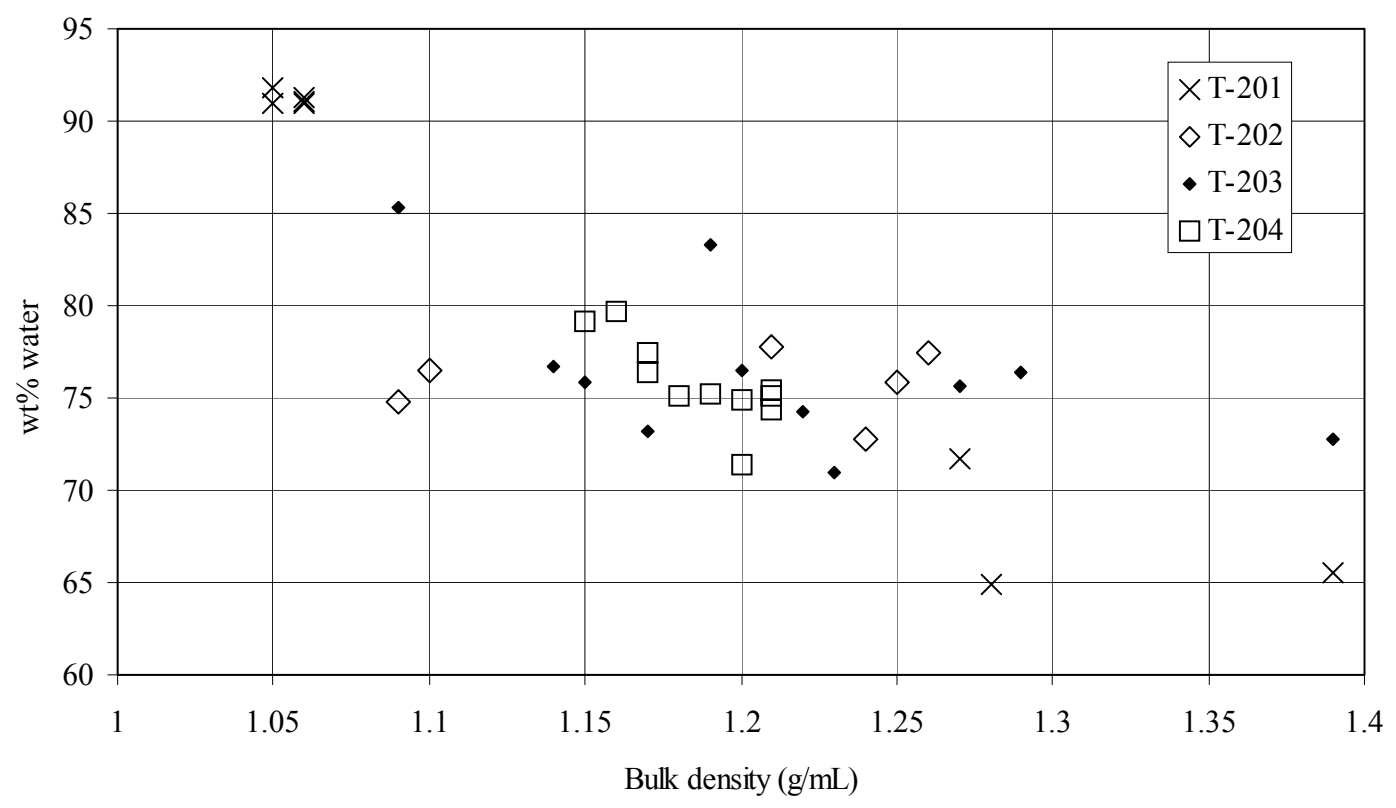

Figure 5.3. Bulk Density Versus Water Content in the T-200 Series Tanks

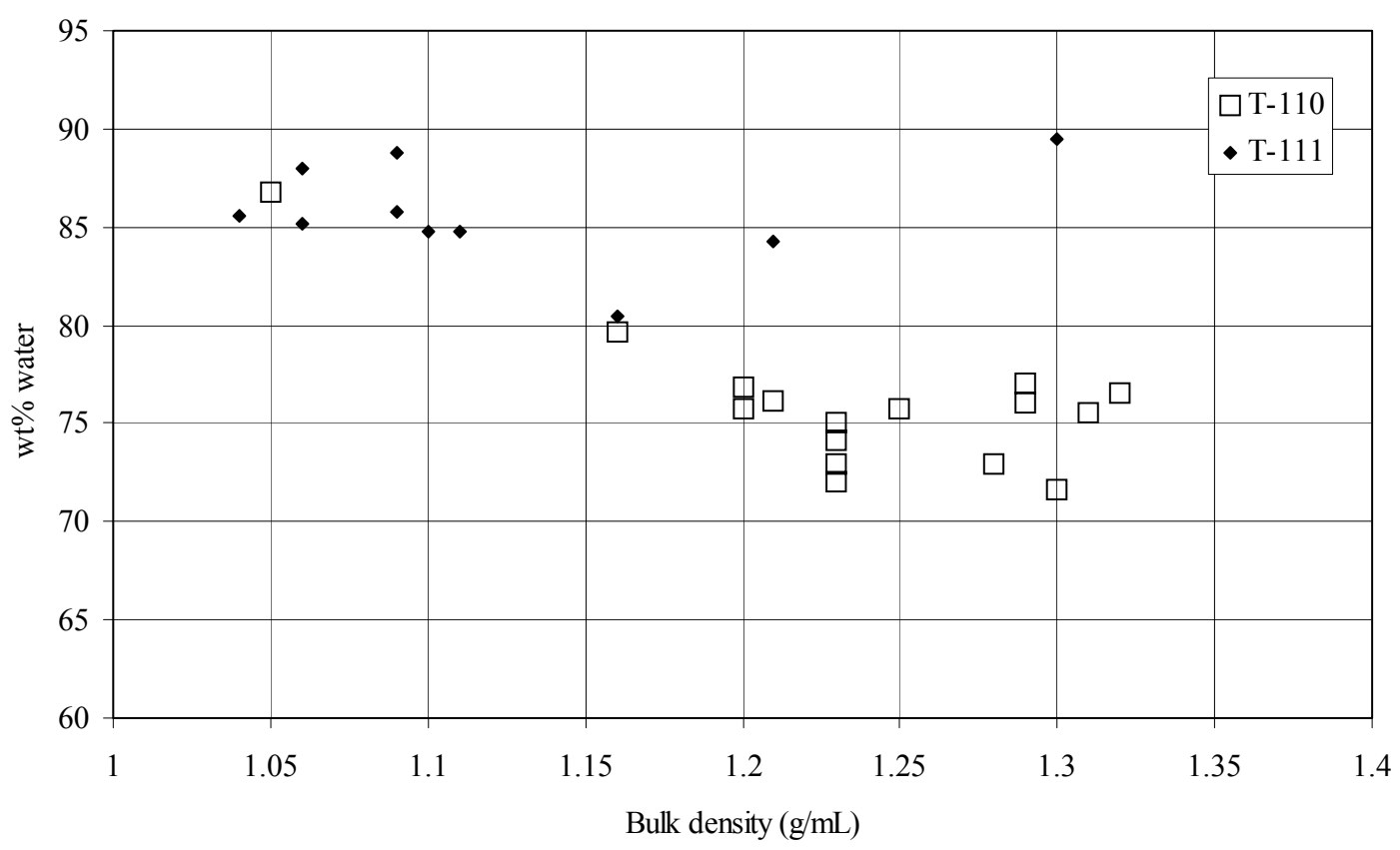

Figure 5.4. Bulk Density Versus Water Content in Tanks T-110 and T-111 


\subsection{Waste Shear Strength}

The best-estimate shear strength data from Section 3.2 are compared with water content and bulk density data for the same tank core segments, where overlapping data exist, to determine whether a meaningful correlation exists. Figures 5.5 and 5.6 show the best-estimate waste shear strength plotted with water content and density, respectively. The shear strength shows some tendency to decrease with increasing water, but the scatter in the data overwhelms the trend. There is an even less-evident relationship between the shear strength and the density.

One potential source of error in these comparisons results from the variation in strength within a given core segment. Whereas bulk density and water content are measured on a homogenized portion of a half-core segment, the shear strength estimates were obtained only for portions of the half-core segments with measurable extrusion failure lengths. In other words, the shear strength estimates are characteristic of the waste in the vicinity but do not represent averages over the core segment.

As noted in Section 3.2, the data suggest that the waste shear strength increases with depth in the tank in much the same way that water content and bulk density vary with depth. While water content may be a factor in waste shear strength (and bulk density), many other unspecified factors could have significant roles. For example, particle size, shape, and crystal structure are likely to impact shear strength.

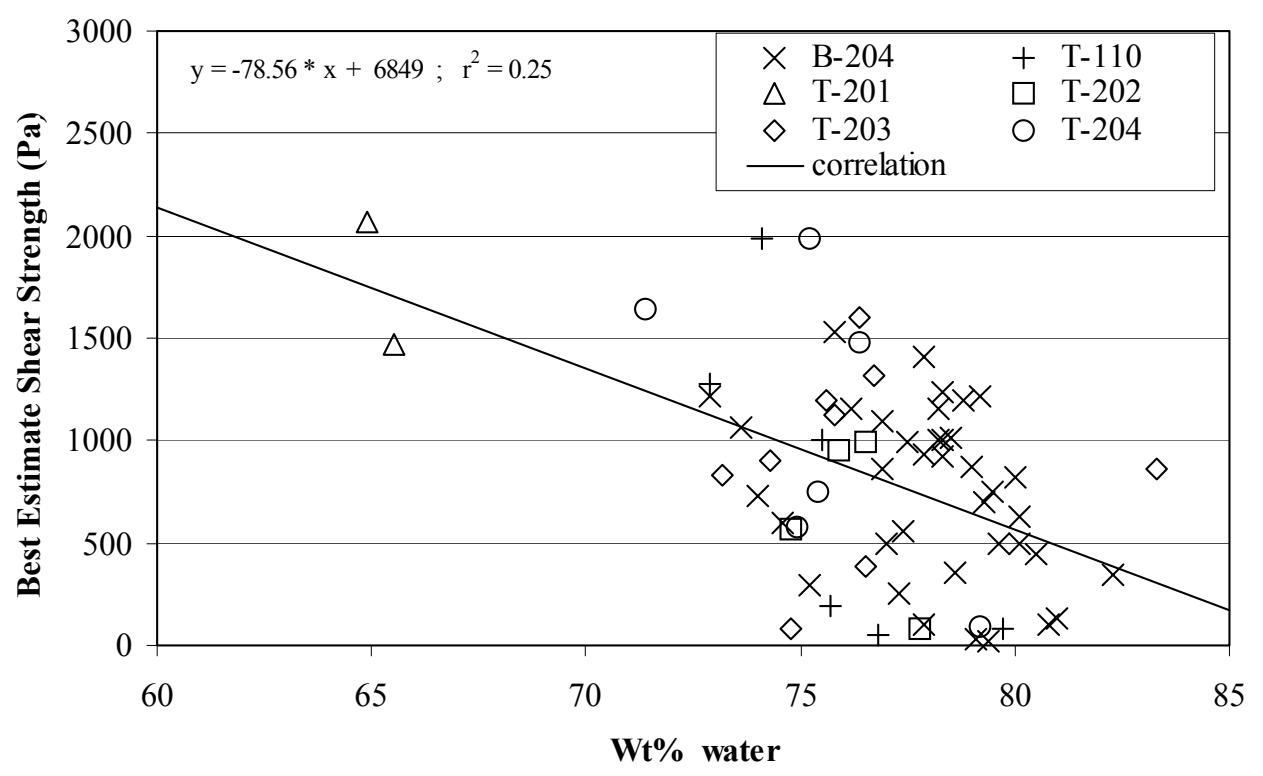

Figure 5.5. Relation of Estimated Waste Shear Strength and Water Content 


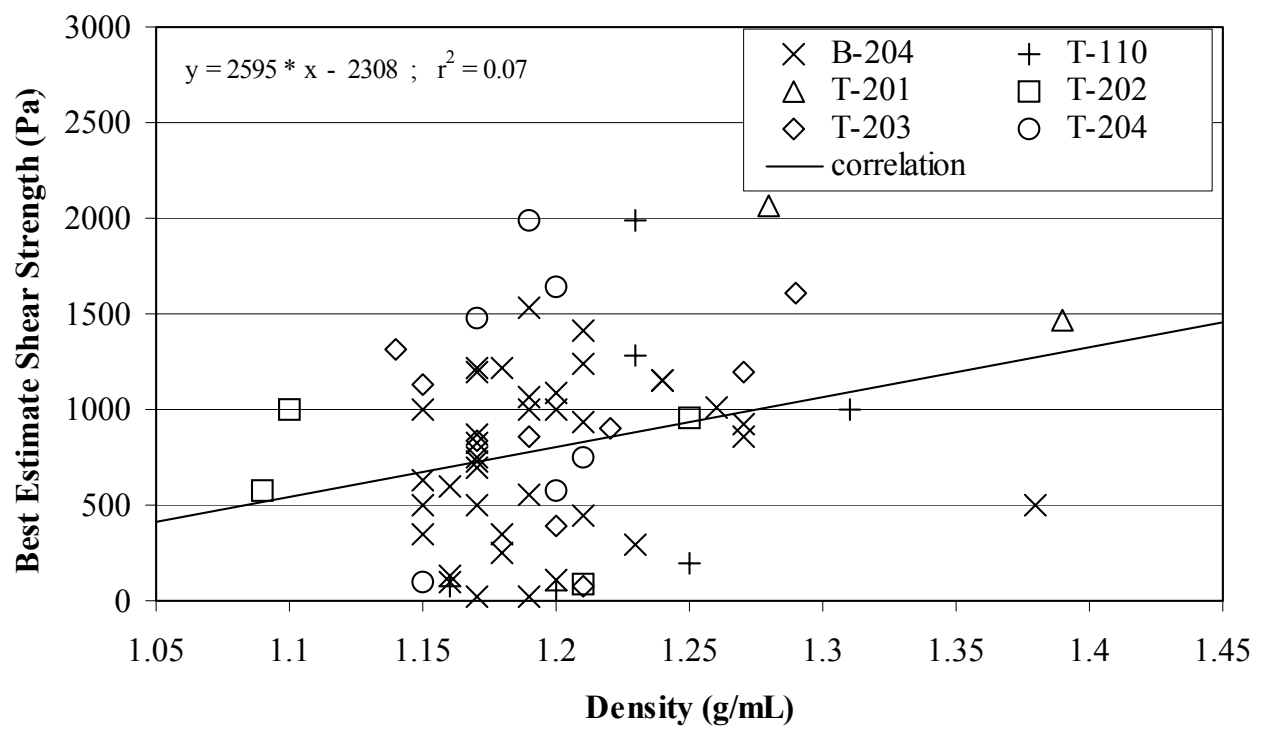

Figure 5.6. Relation of Estimated Waste Shear Strength and Bulk Density 


\subsection{Gas Retention}

As noted in the introduction, the process of dry TRU waste retrieval may result in the entrainment of air (or other retrieval process gas) in waste transferred to a hopper for subsequent loading to drums. Experience with a variety of Hanford tank wastes suggests that some of this gas is likely to be trapped or retained within a fluffed sludge and not readily released. This in turn might negatively impact waste mass loading in drums. This section summarizes some earlier studies of gas generation and gas retention in Hanford tank wastes and simulants, emphasizing the potential for gas retention in TRU sludge.

Historically, several of the 177 waste storage tanks at Hanford are known to generate and retain flammable gases, as summarized by Johnson et al. $(1997,2001)$. Typically, the flammable gas watch-list tanks contain high-level wastes and significant quantities of organic material from complexants and other sources. The gas generated within the waste volume by thermal and radiolytic mechanisms sometimes accumulates as bubbles or voids, causing the waste volume in the tank to increase. The ability of various Hanford waste types to retain gas and the mechanisms of gas retention and release have been the focus of several studies at Hanford (e.g., Gauglitz et al. 1995, 1996; Gauglitz and Terrones 2002; Bredt et al. 1995; Bredt and Tingey 1996; Stewart et al. 1996a; Meyer et al. 1997; Rassat et al. 1997, 1998, 1999). In general, it was found that gas retention would occur in any tank (or vessel) that had a settled layer of wet solids provided there was sufficient gas generation. The retention of bubbles is not surprising and is known to occur in a variety of materials, ranging from yield stress fluids and pastes (Chhabra 1993) to ocean sediments (Wheeler 1990).

While the TRU waste tanks identified in this report have not posed a significant concern for generating and retaining flammable gas in situ, studies of Hanford wastes clearly indicate that TRU sludge waste could retain gas to a significant extent if gas were generated or added within a bulk quantity of the sludge. For example, Gauglitz et al. (1996) observed and measured retained gas in samples of Hanford tank sludge (Tank S-102) and in sludge simulants (bentonite clay/ water mixtures). They determined that the maximum volume fraction of gas retained in the bulk waste or simulant before being (partially) released from the sludge-like material is a function of strength. In a series of experiments with bentonite clay simulants of varying initial shear strength, the maximum retained gas void fraction peaked near 0.4 for relatively weak to moderate strength material (30-100 $\mathrm{Pa}$ shear strength). The maximum gas fraction in stronger bentonite mixtures was lower but still significant $(\sim 0.3$ gas volume fraction at $\sim 1000 \mathrm{~Pa})$. Similar trends were observed in actual waste samples. The implication for TRU waste processing is that retrieved waste could retain significant volumes of gas (e.g., entrained air), depending on how the waste is handled and the strength of the material. 


\subsection{References}

Bredt PR and SM Tingey. 1996. The Effect of Dilution on the Gas Retention Behavior of Tank 241-SY-103 Waste. PNNL-10893, Pacific Northwest National Laboratory, Richland, WA.

Bredt PR, SM Tingey, and EH Shade. 1995. The Effect of Dilution on the Gas Retention Behavior of Tank 241-SY-101 Waste. PNL-10781, Pacific Northwest National Laboratory, Richland, WA.

Chhabra RP. 1993. Bubbles, Drops, and Particles in Non-Newtonian Fluids. CRC Press, Boca Raton, FL.

Duignan MR. 2002. RPP-WTP Slurry Wear Evaluation: Slurry Abrasivity. WSRC-TR-200200062 Rev. 0, Westinghouse Savannah River Company, Aiken, SC.

Field JG. 1997. Tank Characterization Report for Single-Shell Tank 241-T-111. HNF-SDWM-ER-540 Rev. 1, Lockheed Martin Hanford Corp., Richland, WA.

Gasper KA, KD Boomer, ME Johnson, GW Reddick Jr, AF Choho, and JS Garfield. 2002. Recommendation for Supplemental Technologies for Potential Mission Acceleration. RPP-11261 Rev. 0, CH2M HILL Hanford Group, Inc., Richland, WA.

Gauglitz PA and JT Aikin. 1997. Waste Behavior During Horizontal Extrusion: Effect of Waste Strength for Bentonite and Kaolin/Ludox Simulants and Strength Estimates for Wastes from Hanford Waste Tanks 241-SY-103, AW-101, AN-103, and S-102. PNNL-11706, Pacific Northwest National Laboratory, Richland, WA.

Gauglitz PA and G Terrones. 2002. Estimated Maximum Gas Retention from Uniformly Dispersed Bubbles in K Basin Sludge Stored in Large-Diameter Containers. PNNL-13893, Pacific Northwest National Laboratory, Richland, WA.

Gauglitz PA, SD Rassat, MR Powell, RR Shah, and LA Mahoney. 1995. Gas Bubble Retention and Its Effects on Waste Properties: Retention Mechanisms, Viscosity, and Tensile and Shear Strengths. PNL-10740, Pacific Northwest National Laboratory, Richland, WA.

Gauglitz PA, SD Rassat, PR Bredt, JH Konynenbelt, SM Tingey, and DP Mendoza. 1996. Mechanisms of Gas Bubble Retention and Release: Results for Hanford Waste Tanks 241-S-102 and 241-SY-103 and Single-Shell Tank Simulants. PNNL-11298, Pacific Northwest National Laboratory, Richland, WA. 
Hedengren DC, KM Hodgson, WB Barton, CW Stewart, JM Cuta, and BE Wells. 2000. Data Observations on Double-Shell Flammable Gas Watch List Tank Behavior. RPP-6655, CH2M HILL Hanford Group, Inc. Richland, WA.

Herting DL. 1999. Results of Dilution Studies with Waste from Tank 241-AW-101. HNF-4964 Rev. 0, Numatec Hanford Corporation, Richland, WA.

Johnson GD, WB Barton, JW Brothers, SA Bryan, PA Gauglitz, RC Hill, LR Pederson, CW Stewart, and LM Stock. 1997. Flammable Gas Project Topical Report. HNF-SP-1193 Rev. 2, Richland, WA.

Johnson GD, DC Hedengren, JM Grigsby, CW Stewart, JJ Zach, and LM Stock. 2001. Flammable Gas Safety Issue Resolution. RPP-7771 Rev. 0-A, LMSI, Richland, WA.

Lumetta GJ and BM Rapko. 1994. Washing and Alkaline Leaching of Hanford Tank Sludges: A Status Report. PNL-10078, Pacific Northwest National Laboratory, Richland, WA.

McKinley SG, LR Greenwood, EW Hoppe, JM Tingey, and MW Urie. 1992. Single Shell Tank Waste Characterization Project, Core 31/33 Data Report, Tank 241-T-111. WHC-SD-WM-DP024 Addendum 3, Rev 0-A, Pacific Northwest Laboratory, Richland, WA.

Meyer PA, ME Brewster, SA Bryan, G Chen, LR Pederson, CW Stewart, and G Terrones. 1997. Gas Retention and Release Behavior in Hanford Double-Shell Waste Tanks. PNNL-11536, Pacific Northwest National Laboratory, Richland, WA.

Onishi Y, BE Wells, SA Hartley, and SK Cooley. 2002. Pipeline Cross-Site Transfer Assessment for Tank 241-SY-101. PNNL-13650, Pacific Northwest National Laboratory, Richland, WA.

Onishi Y, BE Wells, ST Yokuda, and G Terrones. 2003a. Feasibility Study on Using a Single Mixer Pump for Tank 241-AN-101 Waste Retrieval. PNNL-14105, Pacific Northwest National Laboratory, Richland, WA.

Onishi Y, JM Tingey, BE Wells, J Lui, G Terrones, KP Recknagle, ST Yokuda, and M Quinn. 2003b. Retrieval and Pipeline Transfer Assessment of Hanford Tank 241-AN-105 Waste. PNNL-14144, Pacific Northwest National Laboratory, Richland, WA.

Pashias N, DV Boger, J Summers, and DJ Glenister. 1996. "A Fifty Cent Rheometer for Yield Stress Measurement." Journal of Rheology, 40(6):1179-1189.

Rapko BM and GJ Lumetta. 2000. Status Report on Phase Identification in Hanford Tank Sludges. PNNL-13394, Pacific Northwest National Laboratory, Richland, WA. 
Rassat SD, PA Gauglitz, PR Bredt, LA Mahoney, SV Forbes, and SM Tingey. 1997. Mechanisms of Gas Retention and Release: Experimental Results for Hanford Waste Tanks 241-AN103 and 241- $A W$-101. PNNL-11642, Pacific Northwest National Laboratory, Richland, WA.

Rassat SD, SM Caley, PR Bredt, PA Gauglitz, DE Rinehart, and SV Forbes. 1998. Mechanisms of Gas Retention and Release: Experimental Results for Hanford Single-Shell Waste Tanks 241-A-101, 241-S-106, and 241-U-103. PNNL-11981, Pacific Northwest National Laboratory, Richland, WA.

Rassat SD, PA Gauglitz, SM Caley, LA Mahoney, and DP Mendoza. 1999. A Discussion of SY-101 Crust Gas Retention and Release Mechanisms. PNNL-12092, Pacific Northwest National Laboratory, Richland, WA.

Rassat SD, CW Stewart, BE Wells, WL Kuhn, ZI Antoniak, JM Cuta, KP Recknagle, G Terrones, VV Viswanathan, JH Sukamto, and DP Mendoza. 2000. Dynamics of Crust Dissolution and Gas Release in Tank 241-SY-101. PNNL-13112, Pacific Northwest National Laboratory, Richland, WA.

Shaver RL. 1993a. PNL 325 Laboratories Single Shell Tank Waste Characterization, Tank B-201 Cores 26 and 27 Data Package. WHC-SD-WM-DP-037 and Addendum 1A Rev. 0, Westinghouse Hanford Company, Richland, WA.

Shaver RL. 1993b. PNL 325 Laboratories Single Shell Tank Waste Characterization, Tank B-202 Cores 24 and 25 Data Package. WHC-SD-WM-DP-034 and Addendum 5 Rev. 0, Westinghouse Hanford Company, Richland, WA.

Stewart CW, ME Brewster, PA Gauglitz, LA Mahoney, PA Meyer, KP Recknagle, and HC Reid. 1996a. Gas Retention and Release Behavior in Hanford Single-Shell Waste Tanks. PNNL11391, Pacific Northwest National Laboratory, Richland, WA.

Stewart CW, JM Alzheimer, ME Brewster, G Chen, RE Mendoza, HC Reid, GL Shepard, and G Terrones. 1996b. In Situ Rheology and Gas Volume in Hanford Double-Shell Waste Tanks. PNNL-11296, Pacific Northwest Laboratory, Richland, WA.

Swanson JL. 1991. Use of the TRUEX Process for the Pretreatment of Neutralized Cladding Removal Waste (NCRW) Sludge-Results of FY 1990 Studies. PNL-7780, Pacific Northwest National Laboratory, Richland, WA.

Wasp EJ, JP Kenny, and RL Gandhi. 1977. Solid-Liquid Flow Slurry Pipeline Transportation. Series on Bulk Materials Handling Vol. 1, No. 4, 1st Ed., Trans Tech Publications, Zurich. 
Wheeler SJ. 1990. "Movement of Large Gas Bubbles in Unsaturated Fine-Grained Sediments." Marine Geotechnology, Vol. 9, pp. 113-129. 


\section{Appendix}

\section{Development of Extrusion Length and Slump Methodologies}

to Estimate Yield Stress in Shear 


\section{Appendix}

\section{Development of Extrusion Length and Slump Methodologies to Estimate Yield Stress in Shear}

A methodology developed by Gauglitz and Aikin (1997) allows the rheological properties of waste sediment (solid, liquid, and gas matrix) to be estimated based on a visual comparison of horizontal extrusion behavior for simulants with known yield stress in shear and that of Hanford waste. In Section A.1, the simulant extrusion behavior from Gauglitz and Aikin is re-analyzed to provide a methodology to estimate yield stress in shear from core extrusion lengths. A "slump" method for estimating the yield stress in shear of weaker materials is also presented. The results of these methodologies are compared with data for select Hanford wastes in Section A.2.

\section{A.1 Horizontal Core Extrusion Yield Stress in Shear}

Alternative methodologies for estimating the yield stress in shear from horizontal waste core extrusions are developed and presented from data provided in Gauglitz and Aikin (1997) and "slump" measurements described by Pashias et al. (1996). Gauglitz and Aikin horizontally extruded bentonite/water and kaolin/Ludox/water simulants of known yield stress in shear and recorded the extrusion characteristics. Of particular interest is the behavior of the material during the initial part of the extrusion. The initially extruded sample can be considered to act as a cantilever beam.

The maximum tensile stress in a round cantilever beam at the proportional limit (tensile yield stress) may be determined from

$$
\sigma_{\max }=A \frac{\rho g L^{2}}{d}
$$

under the assumptions that

1. The beam (extruded waste or simulant sample) is of homogenous material that has the same modulus of elasticity in tension and compression.

2. The beam is essentially straight initially.

3. The cross section is uniform.

4. The beam has at least one longitudinal plane of symmetry.

5. All loads and reactions are perpendicular to a longitudinal plane of symmetry.

6. The beam is long in proportion to its depth.

7. The beam is not disproportionately wide.

8. The maximum stress does not exceed the proportional limit. 
In Eq. (A.1), $\mathrm{A}$ is a constant, $\rho$ is the density, $\mathrm{g}$ is the gravitational acceleration, $\mathrm{L}$ is the length of the beam supported at the proportional limit, and $\mathrm{d}$ is the diameter (for the basis of the equation, see Stevens 1979).

Gauglitz and Aikin modeled the initial horizontal extrusion of their simulants using an equation from Powell et al. (1995). The first term of their equation is equivalent to Eq. (A.1) (with $\mathrm{A}=4.0$ ) (Stevens 1979). A second term in the equation of Gauglitz and Aikin is an approximation of the maximum shear stress and accounts for approximately $4 \%$ (in the stronger simulants) to $30 \%$ (in the weaker simulants) of their calculated strength values.

The relationship of a material's yield stress in shear $\left(\tau_{y}\right)$ to its tensile yield stress is ambiguous. The relation is likely a function of the material microstructure (polycrystalline, polycrystalline face-centered cubic or body-centered cubic, etc.). The experimental results of Gauglitz et al. (1995) indicate that the gas content in a given material also affects this relationship. From their measured shear and tensile yield stresses in a bentonite clay simulant with the lowest gas content, $\sigma_{\max } / \tau_{\mathrm{y}}$ is approximately 2.0. They measured the yield stress in shear of the simulant using a shear vane, and the tensile yield stress was measured using a vertical extrusion technique. As the gas content was increased, the relationship of $\sigma_{\max } / \tau_{\mathrm{y}}$ was altered to the extent that, at gas concentrations of greater than approximately 10 to $15 \%$ by volume, the yield stress in shear was greater than the tensile yield stress. Gauglitz et al. noted that a "satisfying" explanation of the measured dependence of the tensile stress on the gas content has not been developed.

The shear and tensile yield stresses in a material are typically related through application of the von Mises $\left(\tau_{y}=\sigma_{\max } / 3^{0.5}\right)$ or Tresca $\left(\tau_{y}=\sigma_{\max } / 2\right)$ yield criterion. (Note the similarity of the lowest gas content results from Gauglitz et al. to the Tresca relation). The Taylor (or TaylorSchmid) factor $\left(\tau_{y}=\sigma_{\max } / 3.06\right)$ is also applied (Stroller and Zinkle 2000). By applying Eq. (A.1) with $\mathrm{A}=4.0$ to the horizontal extrusion results of Gauglitz and Aikin, $\sigma_{\max } / \tau_{\mathrm{y}}$ ranges from approximately 2 to 8 . The stress ratio for the kaolin/Ludox simulant is inversely correlated with the measured yield stress in shear. The stress ratio varies from $\sim 4$ to 7 in the bentonite simulant, and no correlation is evident with the measured yield stress in shear. Regardless, acknowledging possible issues such as the preceding simulant results and those raised by the data in Gauglitz et al., theory suggests that, with the appropriate factor, $\mathrm{f}$, the yield stress in shear of the horizontally extruded sample may be expressed from Eq. (A.1) as

$$
\tau_{y}=\frac{A}{f} \frac{\rho g L^{2}}{d}
$$

As is the norm in Hanford literature, the yield stress in shear is subsequently referred to in this section as the shear strength. As has been illustrated, uncertainty exists in the applicability and exact form of Eq. (A.1) as well as in the correct correlation of the tensile stress to the shear stress. However, Gauglitz and Aikin reported the shear strength and density of their simulants. 
They also reported the length at which the extrusion exhibited "failure." With these data we can correlate the shear strength of the material directly with the functional form of Eq. (A.2) from

$$
\tau_{\mathrm{y}}=\mathrm{K} \frac{\rho g L^{2}}{\mathrm{~d}}
$$

The proportionality coefficient $\mathrm{K}$ of Eq. (A.3) provides a means to compute the shear strength of a material given its density and the plastic failure length of a horizontal extrusion. Plastic failure occurs in the relatively ductile bentonite simulant as necking, while the brittle kaolin/Ludox simulant fractures. The correlation from the bentonite clay simulant data of Gauglitz and Aikin is shown is Figure A.1. A strong correlation is identified. As discussed above, we expect from theory that the shear strength and $\mathrm{ggL}^{2} / \mathrm{d}$ for a given material will be linearly correlated. Additionally, for low shear strength, $\rho \mathrm{gL}^{2} / \mathrm{d}$ should approach zero (i.e., $\mathrm{L}$ goes to zero as $\tau_{\mathrm{y}}$ goes to zero). An $\mathrm{R}^{2}$ value of 0.98 is achieved with the intercept set to zero, and the proportionality coefficient $(\mathrm{K})$ is 0.89 .

The results for the kaolin/Ludox simulant are presented in Figure A.2. Given that the correlation is most likely a function of the material microstructure, a different correlation for the bentonite and kaolin/Ludox simulants is possible. With an intercept of zero (expected behavior as $\tau_{\mathrm{y}}$ goes to zero), $\mathrm{R}^{2}$ is 0.58 and the $\mathrm{K}$ is 1.45 .

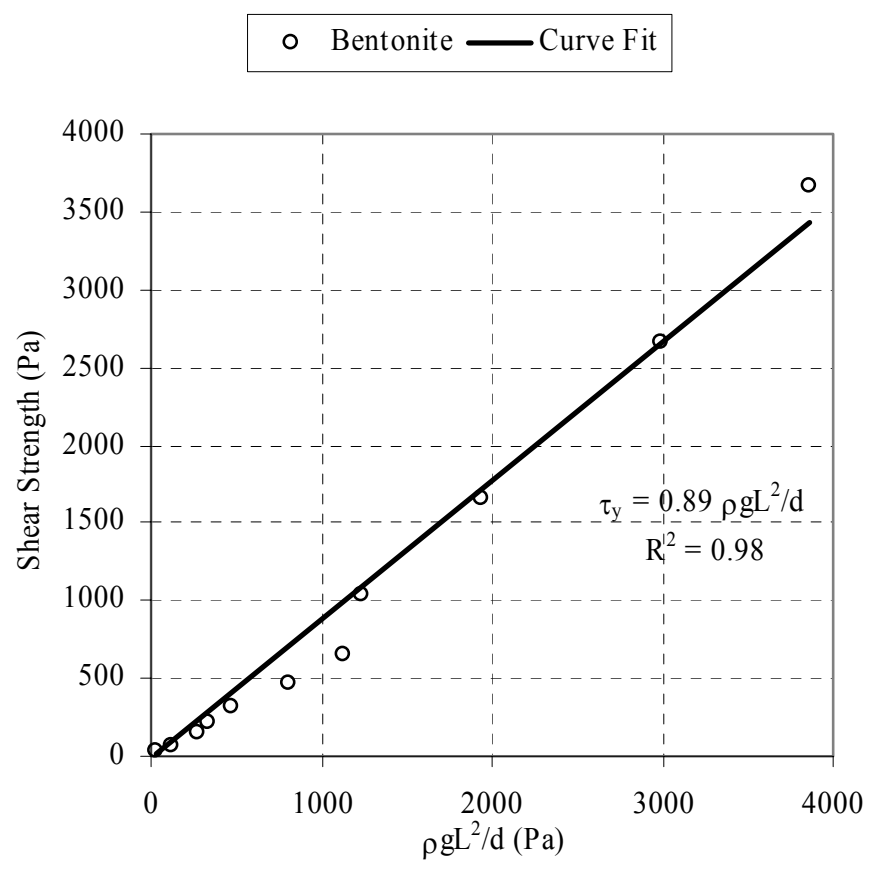

Figure A.1. Bentonite Simulant Correlation 


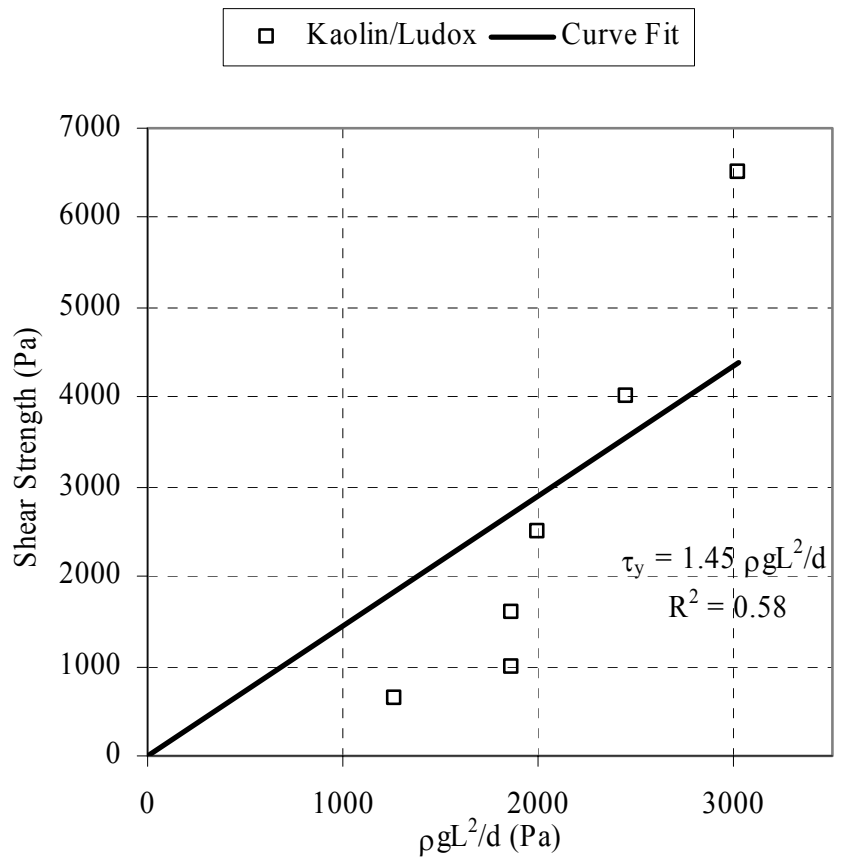

Figure A.2. Kaolin/Ludox Simulant Correlation

Based on this discussion, the shear strength of a material with a microstructure similar to the bentonite simulant is 0.89 times $\rho \mathrm{gL}^{2} / \mathrm{d}$. For materials with a microstructure similar to the kaolin/Ludox simulant, the shear strength is 1.45 times $\rho g L^{2} / \mathrm{d}$. As reported in Gauglitz and Aikin (1997), the two simulants were chosen to reflect the wide variety of mechanical behaviors typical of wastes from the Hanford tanks. If we assume that the simulants bound the mechanical behavior of Hanford waste, we can expect that the shear strength of the waste will be between 0.89 and 1.45 times $\rho g L^{2} / \mathrm{d}$. Recall, however, that a much better $\mathrm{R}^{2}$ (0.98 to 0.56$)$ was determined from the bentonite simulant data, so there is a higher level of confidence in the lower bound.

The methodology was back-applied to the simulant experiment horizontal extrusions. The K values of 0.89 and 1.45 are treated as bounding values and are subsequently referred to as the extrusion length bounds. The predicted shear strength calculated from the reported failure lengths (Gauglitz and Aiken 1997) and the measured shear strengths of the simulants are shown in Figure A.3. Because $\mathrm{K}$ values are applied indiscriminate of material type, it is of interest to consider the $\mathrm{K}$ that will provide the least error in predicted and actual yield stress in shear values for both simulants. From a least squares analysis applied to the entire group of simulants, the best fit is obtained with a $\mathrm{K}$ of 1.15. This fit is included in Figure A.3 as the "extrusion length best fit." 


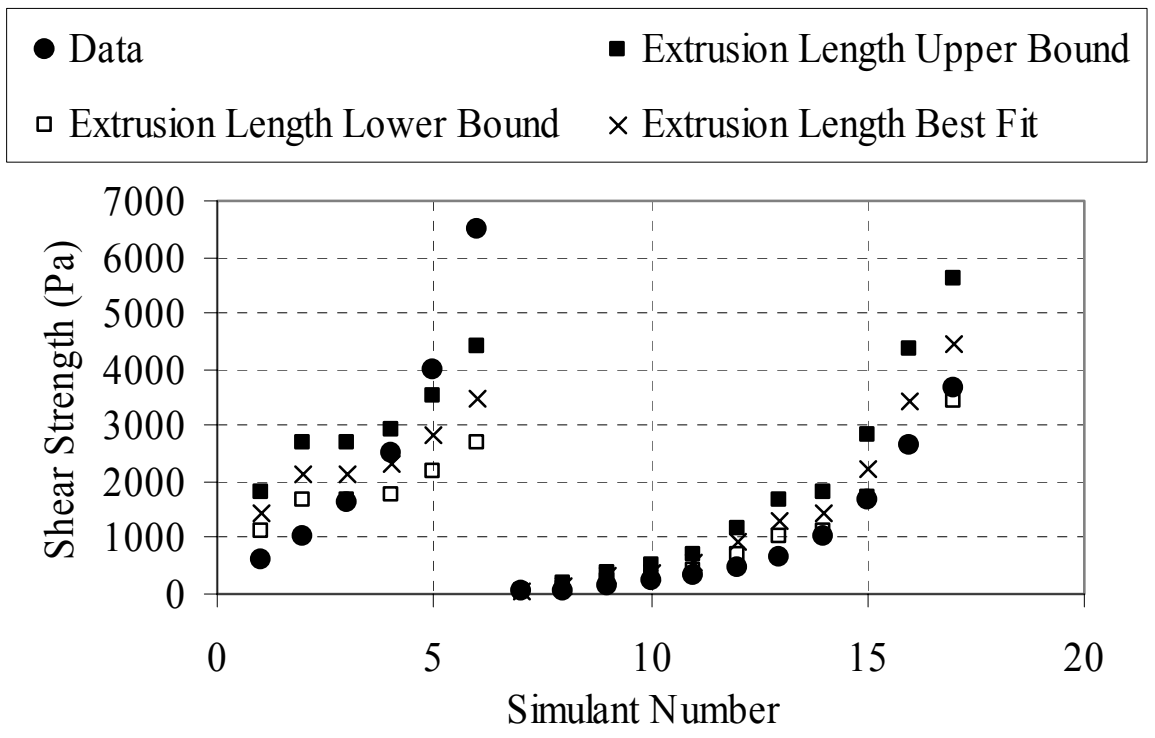

Figure A.3. Back-Application of Simulant Correlations to Simulants 1-6 Kaolin/Ludox; Simulants 7-17 Bentonite

If the extruded material is so weak that it "pours" out of the sampler instead of extending out, the yield stress in shear of the material may be determined by the amount of deformation, or slump, it undergoes. As depicted in Figure A.4, the slump is the change in the extrusion diameter. The slump is estimated from the core extrusions by comparing the diameter of the sampler with the height of the material after it has been extruded and is given by the slump length, s, divided by the extrusion diameter, $d$. The expression given by Pashias et al. (1996) for the yield stress as a function of slump in a vertical cylinder of sample was adapted to a horizontal cylinder. An expression for horizontal cylinders equivalent to the results of Pashias et al. for vertical cylinders was derived:

$$
\tau_{\mathrm{y}}=\frac{\rho g \mathrm{~d}}{2}\left\lfloor 1-\left(\frac{\mathrm{s}}{\mathrm{d}}\right)^{\frac{1}{2}}\right\rfloor
$$

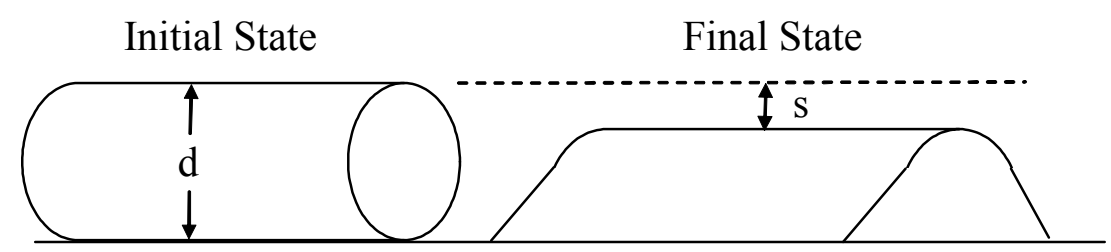

Figure A.4. Horizontal Cylinder Slump 
The slump methodology has been shown to be an effective means to determine yield stress in shear of viscoplastic materials (Pashias et al. 1996; Schowalter and Christensen 1998). Slumping behavior in TRU waste ( $\rho \approx 1.2 \mathrm{~g} / \mathrm{mL}$ ) may be expected (from Eq. A.4 at $1 \%$ slump) to occur at approximately $150 \mathrm{~Pa}$.

\section{A.2 Application of Yield Stress Methodologies to Select DSTs}

To investigate the applicability of these methodologies to tank waste, we compared the ball rheometer results (Stewart et al. 1996; Hedengren et al. 2000) with results achieved using the extrusion length and slump test in waste samples from double-shell tanks (DSTs) AN-103, AN-104, AW-101, and SY-103 for which extrusion videos were available and could be analyzed. The ball rheometer is deployed in situ, and the waste rheology is estimated directly from the drag force on the ball as it moves through the waste at various speeds. The ball rheometer results are typically accepted as being more representative of in situ waste conditions than laboratory rheological measurements (Hedengren et al.). Gauglitz and Aikin (1997) compared their visual results for AN-103, AW-101, and SY-103 extrusions to both the ball rheometer data and laboratory shear vane data. Their estimates generally agreed with the ball rheometer data within a factor of two.

Failure length measurements were taken from videos of the horizontal core extrusions from each waste. The recorded failure length was determined from the point at which plastic failure was judged to occur (i.e., the proportional limit was exceeded). The on-screen extrusion length is correlated to the actual length by measuring the on-screen extrusion diameter and correlating it to the actual extrusion diameter (1.125 in). This methodology forces a blind approach. Slump measurements, where appropriate, were determined by comparing the extrusion tube diameter with the extruded waste height. Given that the video footage was taken from outside a hot cell from various orientations, specific measurements may have significant uncertainty. In general, no shear strength estimates are reported for those samples where it would be difficult to discern the on-screen failure length to within approximately $10 \%$ of the measurement.

Data taken from the upper half of a core segment are ascribed to a level in the tank corresponding to 0.75 of the length of the segment plus the lower elevation of the segment. Similarly, data taken from the lower half of a core segment are assigned the segment elevation plus 0.25 of the segment length. Multiple measurements were available for individual segment halves in some instances, and each measurement is for reported for that elevation. Density values are taken from Hedengren et al. (2000).

The shear strength estimates for SY-103 using the extrusion length and slump methodologies are shown in Figure A.5. As presented in Section A.1, the extrusion length bounds are 0.89 and 1.45 times $\rho g L^{2} / \mathrm{d}$, and the extrusion length best fit is 1.15 times $\rho \mathrm{gL}^{2} / \mathrm{d}$. Using the ball rheometer results as the benchmark, we see that results agree to within better than a factor of 2 
for both slump and extrusion length estimates. In fact, the ball rheometer results are generally bounded by the extrusion length estimates.

Figure A.5 shows that the shear strength increases with depth in the SY-103 sediment layer. This phenomenon may be attributable to lithostatic loading and is therefore expected. The tank originally received concentrated complexant waste from B Plant via the 242-S evaporator. In late 1980, the tank was pumped down to a 46-in. "heel" and then received double-shell slurry and uranium sludge from ion exchange processing. Waste was also added from SX-104 (Stewart et al. 1996). The 46-in. heel is approximately equivalent to the height at which the ball rheometer was supported by the waste in both risers. When the ball is supported by the waste, the yield stress in shear is at least $900 \mathrm{~Pa}$ (Meyer et al. 1997).

As shown in the varied ball rheometer results for different risers, heterogeneities may be expected in the sediment layer. Any or all of the following may cause these heterogeneities: fill history, waste-disturbing activities (lancing, sampling, etc.), and/or spontaneous gas release. Thus, given a different riser or sampling time, the shear strength results are not necessarily expected to be in complete agreement.

The shear strength estimates for AW-101 are presented in Figure A.6. Again, results are generally within a factor of 2 or better of the ball rheometer measurements. The ball rheometer was supported at approximately $37 \mathrm{in}$. in riser 1C, almost twice the depth of the heel reached in 1986 (Stewart et al. 1996). The low slump estimate at approximately $20 \mathrm{in}$., though apparently

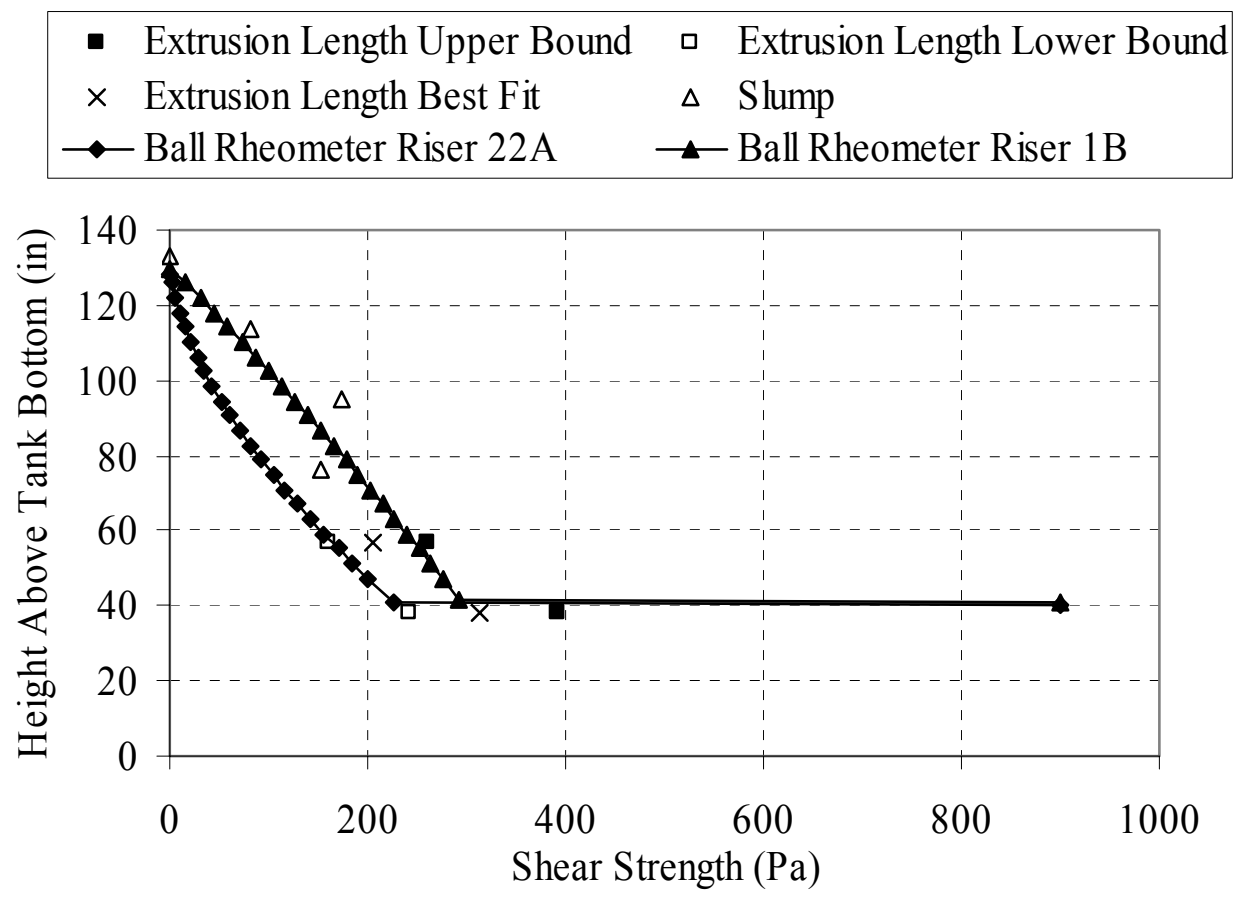

Figure A.5. Shear Strength as a Function of Height in SY-103 

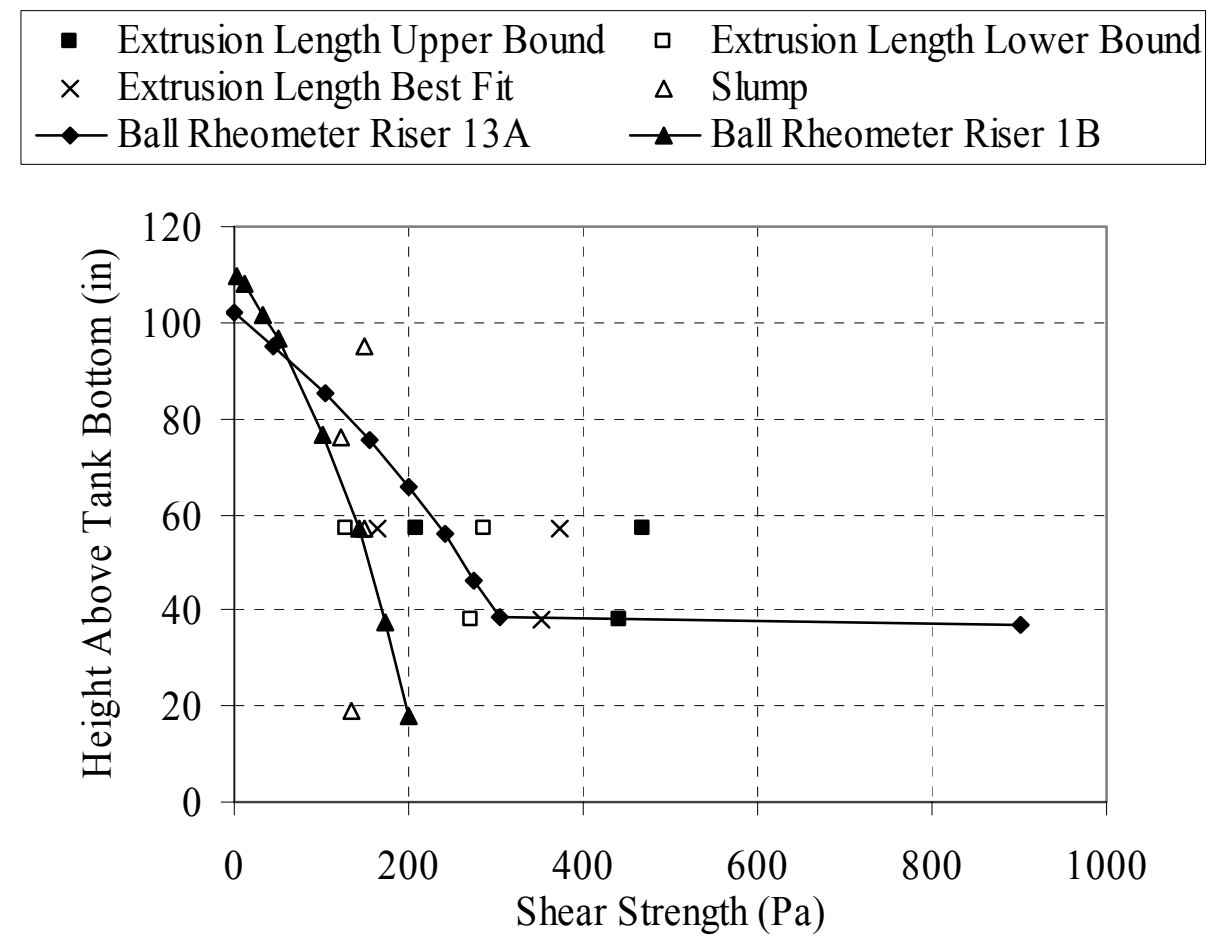

Figure A.6. Shear Strength as a Function of Height in AW-101

in agreement with the ball rheometer in riser $1 \mathrm{~B}$, results from significantly more fluid waste at the top of the sampler than that surrounding (above and below) it. It is hypothesized that this is a result of the sampling/handling process and is therefore not representative of in situ conditions.

Similar results are attained for AN-104 (Figure A.7) and AN-103 (Figure A.8). The 900-Pa values from the ball rheometer are reported where downward motion of the ball was prevented by the waste. Low slump values deep in the sediment are similar to AW-101 and are significantly more fluid than the surrounding waste.

The extrusion length and slump methodology results are similar in magnitude and reproduce the same trends as the ball rheometer results. In the absence of definitive in situ measurements, or in support of them, the methodologies applied here to horizontal waste core extrusion behavior are expected to produce representative results for the shear strength. 


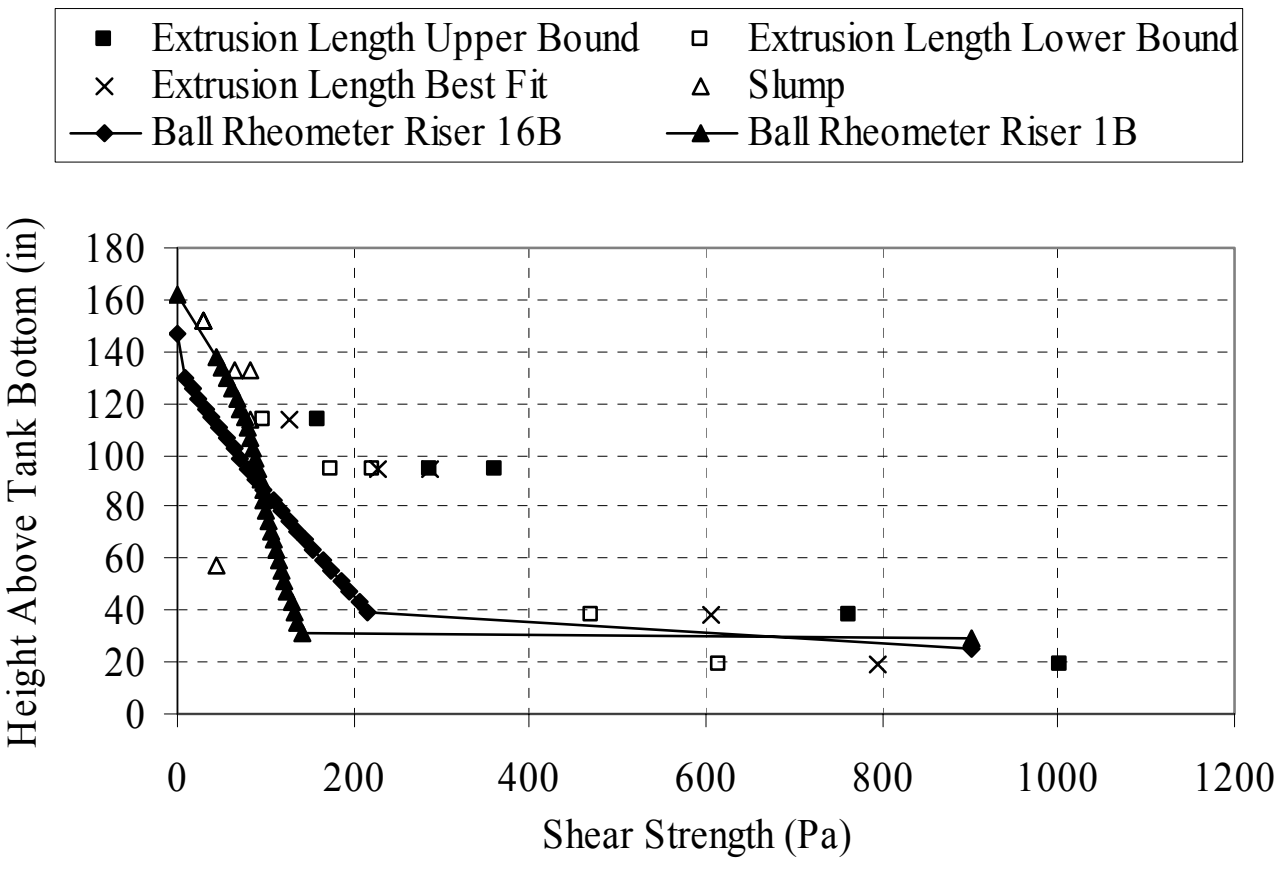

Figure A.7. Shear Strength in Shear as a Function of Height in AN-104

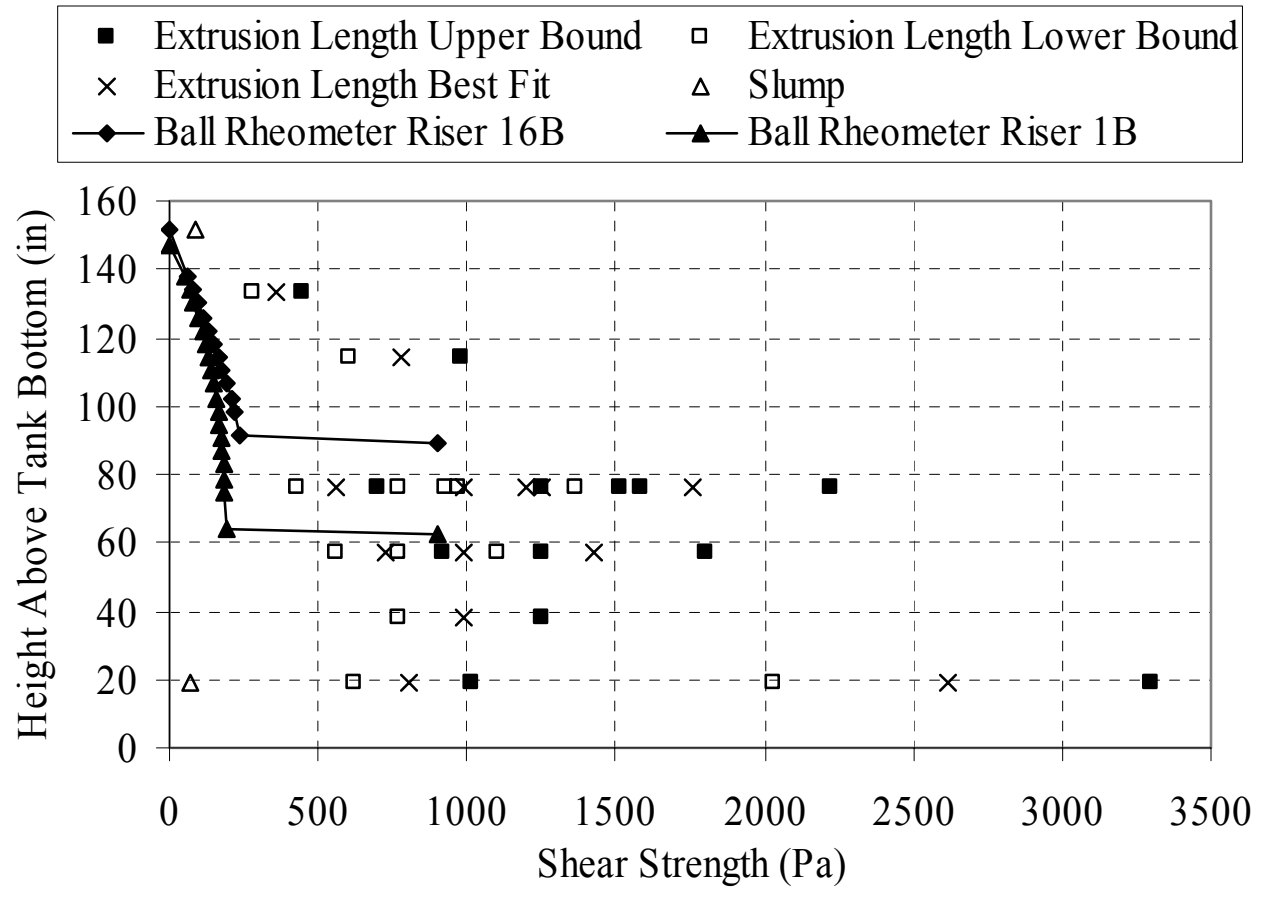

Figure A.8. Shear Strength as a Function of Height in AN-103 


\section{A.3 References}

Gauglitz PA, SD Rassat, MR Powell, RR Shah, and LA Mahoney. 1995. Gas Bubble Retention and Its Effects on Waste Properties: Retention Mechanisms, Viscosity, and Tensile and Shear Strengths. PNL-10740, Pacific Northwest National Laboratory, Richland, WA.

Gauglitz, PA and JT Aikin. 1997. Waste Behavior During Horizontal Extrusion: Effect of Waste Strength for Bentonite and Kaolin/Ludox Simulants and Strength Estimates for Wastes from Hanford Tanks 241-SY-103, AW-101, AN-103, and S-102. PNNL-11706, Pacific Northwest National Laboratory, Richland, WA.

Hedengren DC, KM Hodgson, WB Barton, CW Stewart, JM Cuta, and BE Wells. 2000. Data Observations on Double-Shell Flammable Gas Watch List Tank Behavior. RPP-6655, CH2M HILL Hanford Group, Inc. Richland, WA.

Meyer PA, ME Brewster, SA Bryan, G Chen, LR Pederson, CW Stewart, and G Terrones. 1997. Gas Retention and Release Behavior in Hanford Double-Shell Waste Tanks. PNNL-11536, Pacific Northwest National Laboratory, Richland, WA.

Pashias N, DV Boger, J Summers, and DJ Glenister. 1996. "A Fifty Cent Rheometer for Yield Stress Measurement." Journal of Rheology 40(6):1179-1189.

Powell MR, CM Gates, CR Hymas, MA Sprecher, and NJ Norter. 1995. Fiscal Year 1994 1/25Scale Sludge Mobilization Testing. PNL-10582, Pacific Northwest Laboratory, Richland, WA.

Schowalter WR and G Christensen. 1998. "Toward a Rationalization of the Slump Test for Fresh Concrete: Comparison of Calculations and Experiments.” Journal of Rheology 42(4):865-870.

Stevens KK. 1979. Statics and Strengths of Materials. Prentice-Hall, Inc., NJ.

Stewart CW, JM Alzheimer, ME Brewster, G Chen, RE Mendoza, HC Reid, GL Shepard, and G Terrones. 1996. In Situ Rheology and Gas Volume in Hanford Double-Shell Waste Tanks. PNNL-11296, Pacific Northwest Laboratory, Richland, WA.

Stroller RE and SJ Zinkle. 2000. "On the Relationship Between Uniaxial Yield Strength and Resolved Shear Stress in Polycrystalline Materials." Journal of Nuclear Materials, 283287(2000):349-352. 
PNNL-14221

\section{Distribution}

No. of

Copies

ONSITE

DOE Richland Operations Office

T. P. Pietrok

K8-50

DOE-Office of River Protection

B. M. Mauss

H6-60

16 CH2M HILL

K. D. Boomer

L4-07

D. W. Crass

L4-07

J. S. Garfield

D. W. Hamilton

M. E. Johnson

J. G. Kristofzski

M. W. Leonard

S. M. Mackay

R. W. Powell (5)

R. E. Raymond

G. W. Reddick, Jr.

R. D. Williamson

Fluor Hanford Inc.

R. Akita

T6-50

L4-07

H6-22
No. of

Copies

2 Numatec

C. M. Creze

S7-65

J. R. Jewett

R3-73

29 Pacific Northwest National Laboratory

L. M. Bagaasen

K6-28

S. Q. Bennett

K7-90

J. W. Brothers

K7-15

T. M. Brouns

K9-69

D. D. Caldwell

K6-28

C. H. Delegard

P7-25

P. A. Gauglitz (3)

K6-28

E. O. Jones

K6-24

G. B. Josephson

K6-69

G. J. Lumetta

P7-22

L. A. Mahoney

K7-15

D. P. Mendoza

K6-81

B. M. Rapko

P7-25

S. D. Rassat (10)

K6-28

J. M. Tingey

P7-25

B. E. Wells

K7-15

Information Release (2)

K1-06 